Transações Web: Um Estudo

Sobre Problemas e Soluções

Lorena Pereira da Ponte Pierre

\author{
Dissertação apresentada ao \\ INSTITUTO DE MATEMÁTICA E ESTATÍSTICA
}

da

UNIVERSIDADE DE SÃO PAULO

para obtenção do grau de mestre em Ciência da Computação

Área de Concentração: Banco de Dados

Orientador: Prof. Dr. Hernán Enrique Astudillo Rojjas

São Paulo, novembro de 2001 


\section{Transações Web: Um Estudo Sobre Problemas e Soluções}

Este exemplar corresponde à redação final da dissertação devidamente corrigida e defendida por

Lorena Pereira da Ponte Pierre e aprovada pela comissão julgadora.

São Paulo, novembro de 2001.

Banca Examinadora:

- Prof. Dr. Hernán Enrique Astudillo Rojas (Oriendador) - IME-USP

- Prof. Dr. Marcelo Finger - IME-USP

- Prof. Dr. Astério Tanaka - UNIRIO 
Se o teu sonho for maior que ti Alonga tuas asas Esgarça os teus medos Amplia o teu mundo

Dimensiona o infinito parte em busca da estrela ...

- Leda Selma -

Ао теи еsposo,

Guarany 


\section{Agradecimentos}

Ao Professor Hernán Astudillo, meu orientador, pelo apoio na definição do trabalho, orientação e confiança depositada no meu estudo e neste trabalho.

Aos demais professores do Departamento de Computação do IME-USP que colaboraram diretamente para minha formação acadêmica no mestrado.

Aos meus colegas e amigos do IME, Ana Paula, Clara, Euler, Franklin, Isabel, Leandro, Liliane, Luciano, Lucy, Marcelo, Marquinhos, Ricardo, Rogério, Said, Sílvio, Sirley, Uirá, Verinha que compartilharam comigo os momentos de estudo e descontração durante este período.

À minha amiga Maria do Carmo, pelo apoio, pelas palavras de incentivo em todos os momentos e pelo exemplo de vida dado por ela.

Aos meus pais e às minhas irmãs, que mesmo de longe, estiveram o tempo todo torcendo por mim.

Ao meu esposo Guarany, que soube suportar com paciência os momentos de ausência e pelo grande estímulo dado por ele.

À Deus pela força de superar os obstáculos e vencer os desafios.

À CAPES pelo apoio financeiro durante o mestrado. 


\section{Resumo}

Este trabalho estuda sobre transações de Banco de Dados em aplicações desenvolvidas para a Internet, e mais especificamente, para a Web.

Os conceitos básicos do ambiente de integração Web Banco de Dados são descritos. As transações Web são caracterizadas, abordando seus principais aspectos e ressaltando os problemas transacionais que surgiram em sistemas desenvolvidos para o ambiente Web Banco de Dados; considera-se os possíveis modelos de transações para o ambiente de integração, em substituição ao modelo convencional de transações planas, que se mostrou inadequado por não suportar transações de longa duração nem a capacidade de desfazer parte da transação.

Este estudo mostra também uma síntese das soluções existentes para resolver estes problemas e implementar transações de Banco de Dados no ambiente Web. Além de soluções mais simples como CGI, ASP e Servlets, estudo -se também os servidores de aplicação, que são softwares responsáveis pelo desenvolvimento e gerenciamento de aplicações Web mais robustas. Dentro deste contexto, os três principais modelos de componentes foram abordados: CORBA, COM+ e Enterprise JavaBeans.

Além dos modelos de componentes, foi feito um estudo sobre as principais tecnologias de processamento de transações, com o intuito de mostrar que as soluções para implementação de transações Web passam por uma das tecnologias abordadas. 


\begin{abstract}
This work studies on transactions of database in applications developed for the Internet, and more specifically, for the Web.

The basic concepts of the Web-database integration environment are described. Web transactions are characterized, approaching their main aspects and pointing out problems that have appeared in systems developed for the environment Web database. Possible models of transactions for the integration environment are considered to replace to the conventional model of flat transactions, which has been shown as inadequate for supporting transactions of long duration and for undoing part of the transaction.

This study also presents a synthesis of the existing solutions to solve these problems and to implement transactions of database in the Web platform. Beyond simpler solutions, such as CGI, ASP and Servlets, it also studies application servers, which are softwares responsible for the development and management of more robust Web applications. In of this context, the three main models of components were considered: CORBA, COM+ and Enterprise JavaBeans.

Besides the component models, the main transaction processing technologies were studied, to show that the approach to implementing Web transactions passes for such technologies.
\end{abstract}




\section{Sumário}

LISTAS DE FIGURAS, TABELAS, EXEMPLOS E QUADROS ............................3

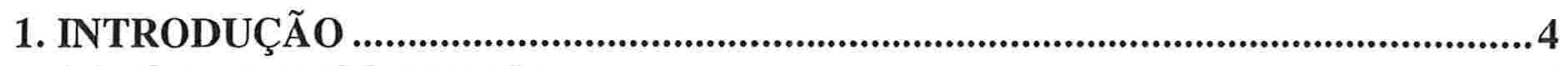

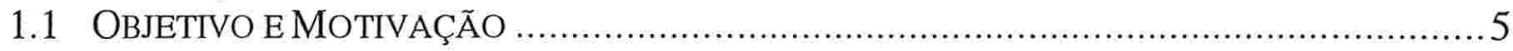

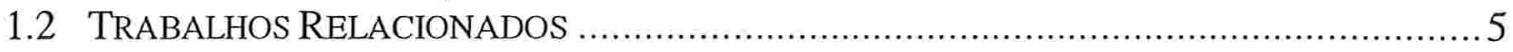

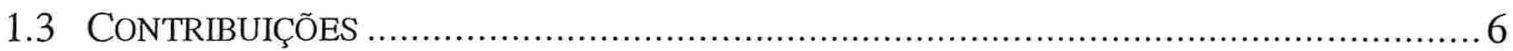

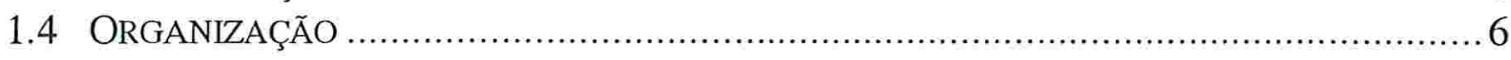

2. O AMBIENTE DE INTEGRAÇÃO WEB BANCO DE DADOS............................8

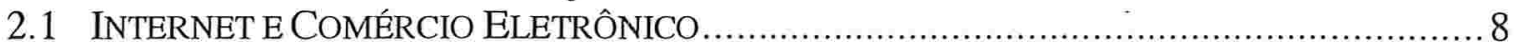

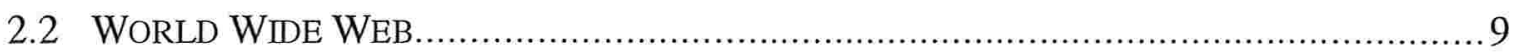

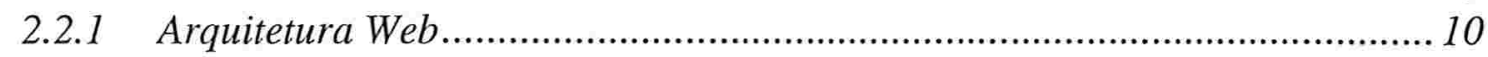

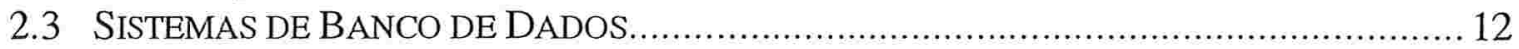

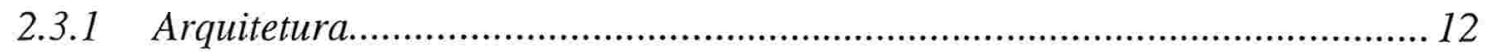

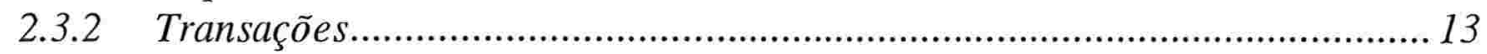

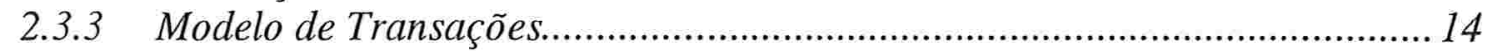

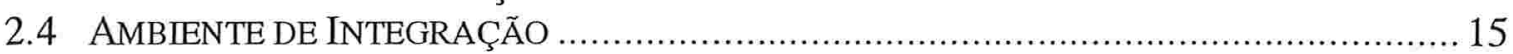

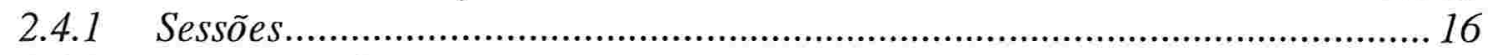

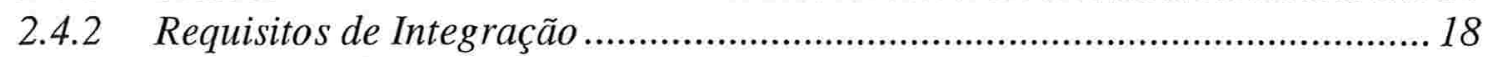

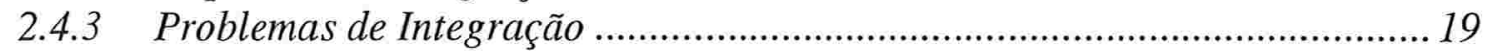

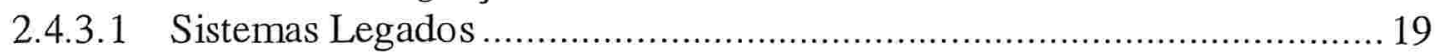

2.4.3.2 Problemas Transacionais ............................................................... 20

2.4.3.3 Desenvolvimento de Aplicações Web Banco de Dados............................ 22

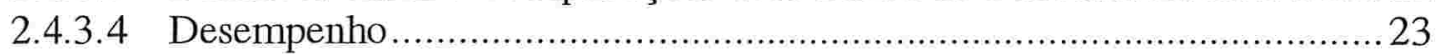

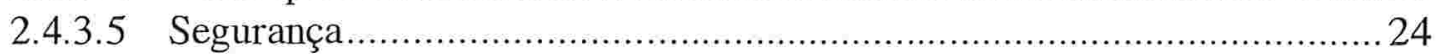

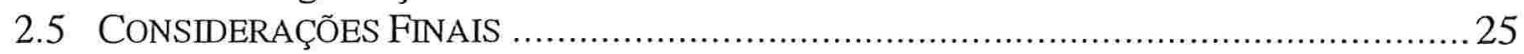

3. TRANSAÇÕES NO AMBIENTE WEB BANCO DE DADOS..............................22

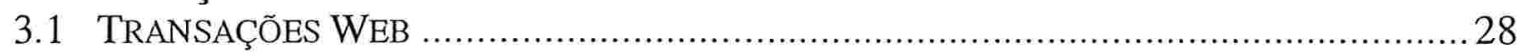

3.2 ESCOPO DE UMA TRANSAÇÃO WEB ….............................................................. 29

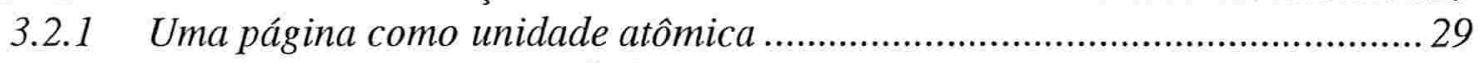

3.2.2 Várias páginas como unidade atômica ....................................................... 30

3.2.3 Páginas que não fazem parte de uma transação ......................................... 31

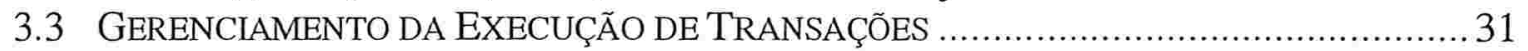

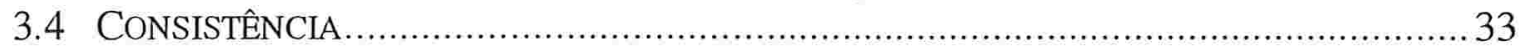

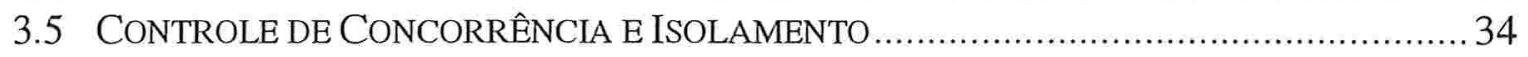

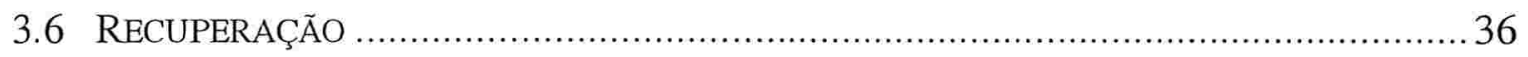

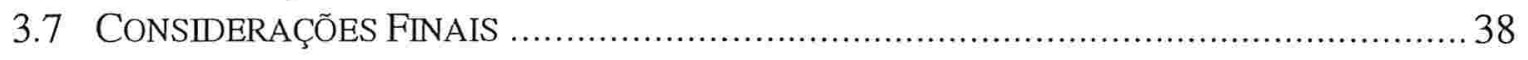

4. MODELOS DE TRANSAÇÕES PARA TRANSAÇÕES WEB ...............................39

4.1. LiMITAÇÕES DO MODELO DE TRANSAÇÕES PlanaS PARA TRANSAÇÕES WEB ….....40

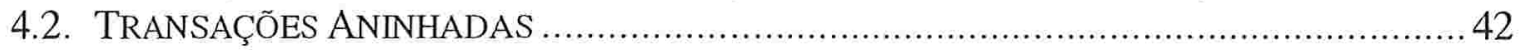

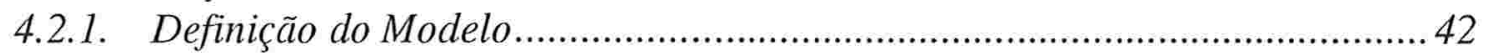

4.2.2. Analogia do Modelo de Transações Aninhadas com Transações Web ........... 44

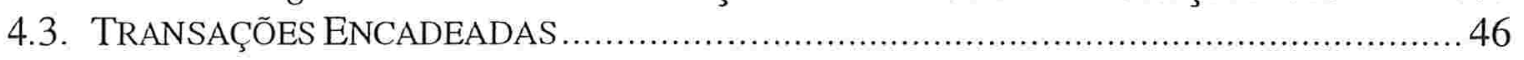




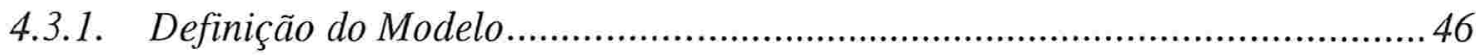

4.3.2. Analogia do Modelo de Transações Encadeadas com Transações Web ........ 49

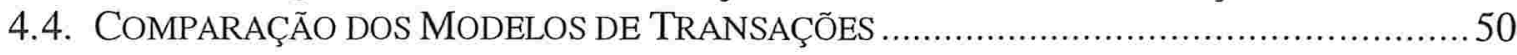

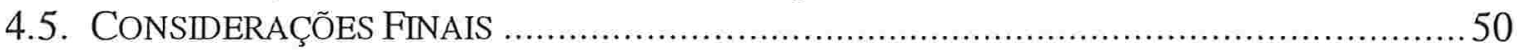

5. MODELOS DE SOLUÇÕES IMPLEMENTÁVEIS P/ TRANSAÇÕES WEB.......51

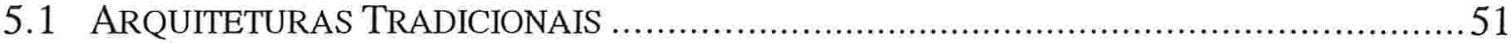

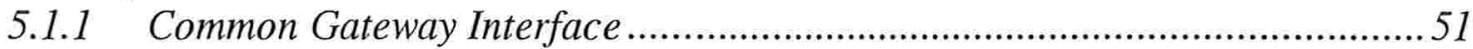

5.1.2 Hypertext Preprocessor - PHP …................................................................ 53

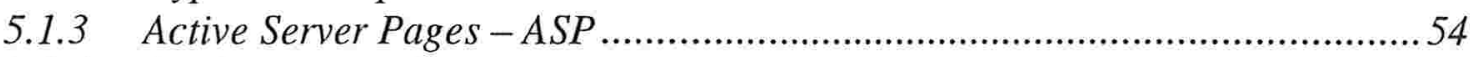

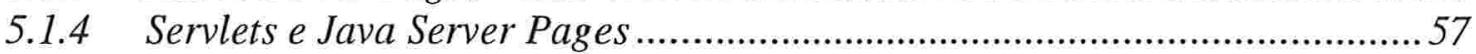

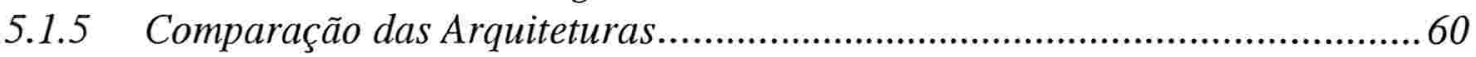

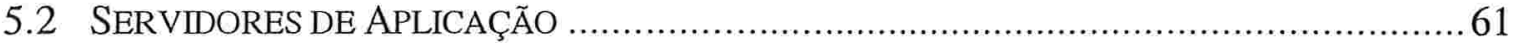

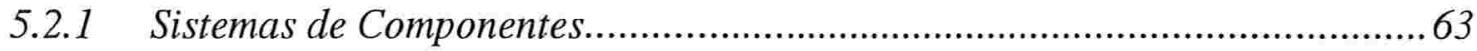

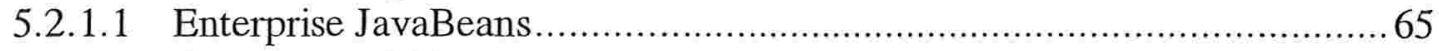

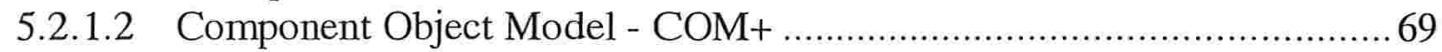

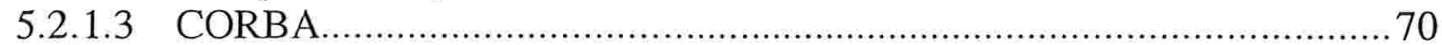

5.3 TECNOLOGIAS DE PROCESSAMENTO DE TRANSAÇÃO............................................ 73

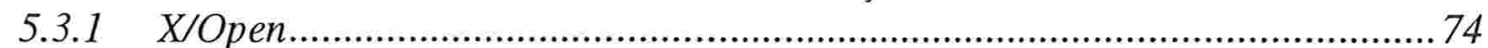

5.3.2 Java Transaction Service e Java Transaction API...................................... 75

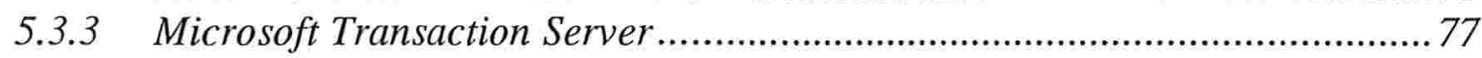

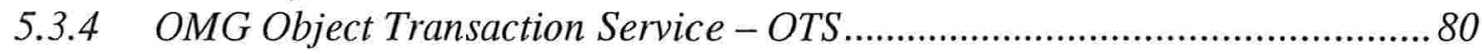

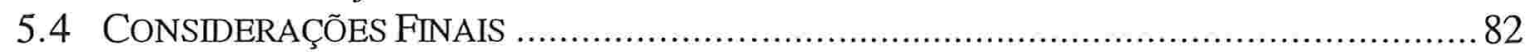

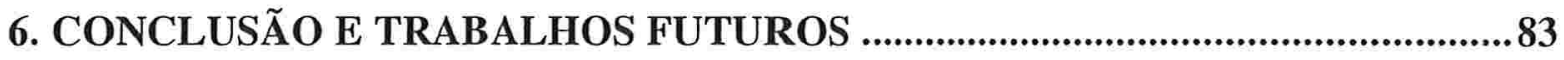

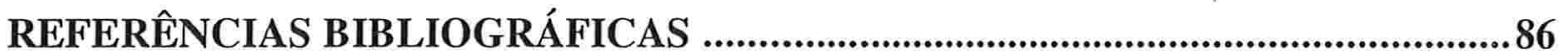




\section{Lista de Figuras, Tabelas e Exemplos e Quadros}

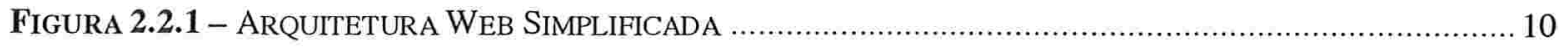

Figura 2.3.1 - ARQUITETURA DUAS CAMADAS CLIENTE/SERVIDOR DE BANCO DE DADOS............................ 13

FIGURA 2.3.3.A - REPRESENT AÇÃO DO MODELO DE ESTRUTURA PLANA ..................................................... 14

FigURA 2.3.3.B - REPRESENTAÇÃO DO MODELO DE ESTRUTURA DE SUBTRANSAÇÕES ……………............... 15

Figura 2.4 - AMBIENTE DE INTEGRAÇÃo WEB BANCO DE DADOS ............................................................ 16

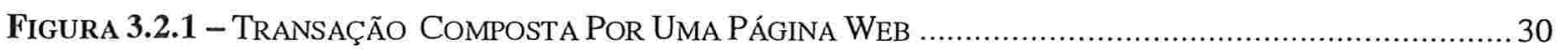

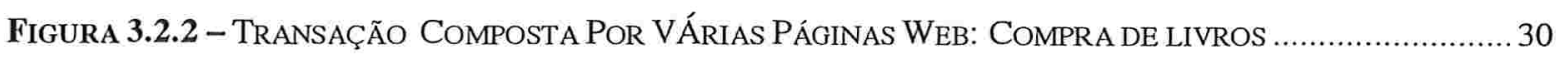

Figura 3.2.3 - Transação Composta Por Páginas Transacionais e Não transacionais .................... 31

Figura 3.7 - Pontos de Possíveis Falhas no Ambiente Web Banco de Dados ……............................. 37

Figura 4.1.A - EXEMPLOS DE UMA TRANSAÇÃo CoM VÁRIAS PÁGINAS DE INTERAÇão.................................. 41

FIGURA 4.1.B - AdEQUAÇÃO DO MODELO DE TRANSAÇÕES PLANAS NO CASO DE UMA TRANSAÇÃO

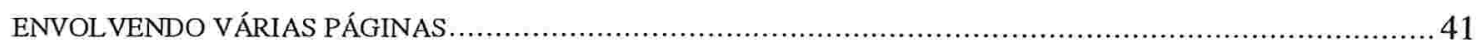

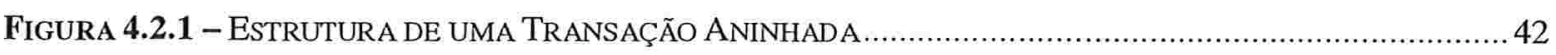

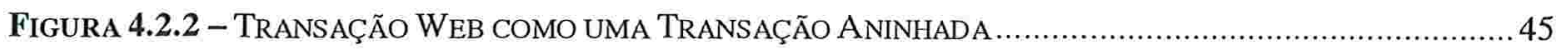

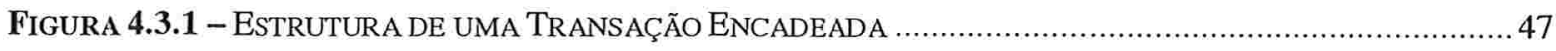

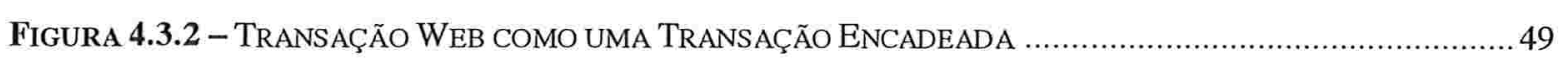

QUADRO 4.4 - QuADRO COMPARATIVO DOS MODELOS DE TRANSAÇÕES .....................................................50

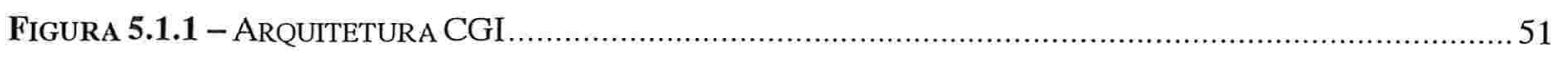

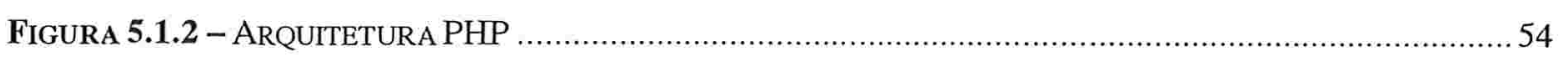

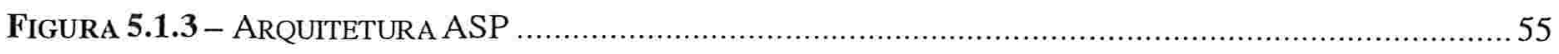

TABELA 5.1.3 - AtributoS DE UMA TRANSAÇÃo EM ASP .................................................................... 56

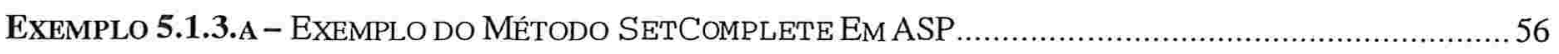

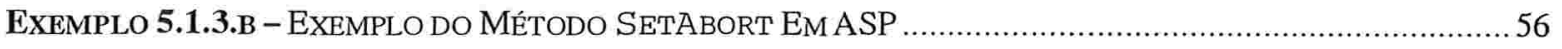

EXEMPLO 5.1.3.C - EXEMPLO dOS EVENTOS ONTRANSACTIONCOMMIT E ONTRANSACTIONABORT …….............57

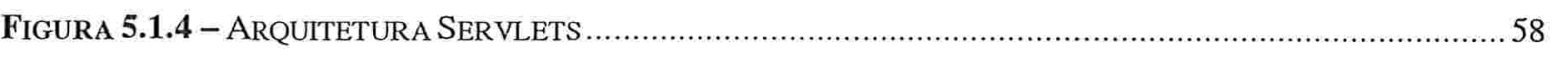

EXEMPLO 5.1.4 - TRANSAÇÃO JTA USANDO SERVLET ............................................................................. 59

QUADRO 5.1.5 - QUADRO COMPARATIVO DAS ARQUITETURAS TRADICIONAIS ............................................ 60

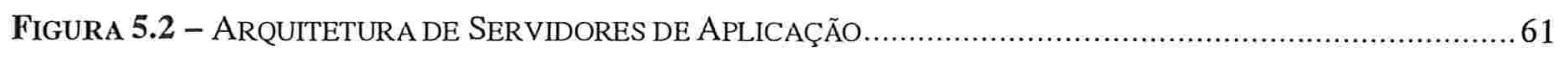

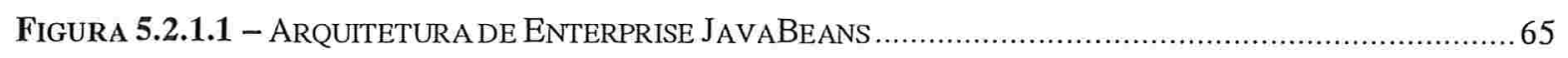

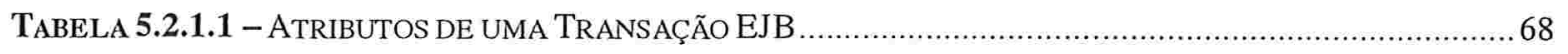

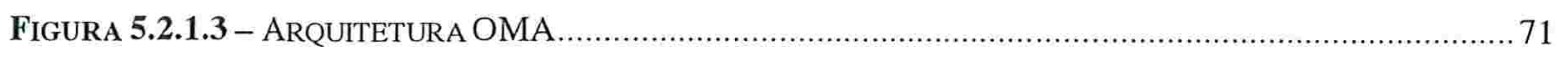

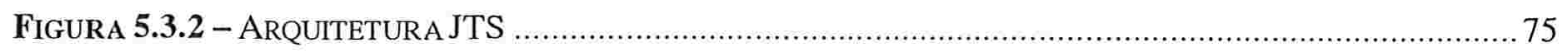

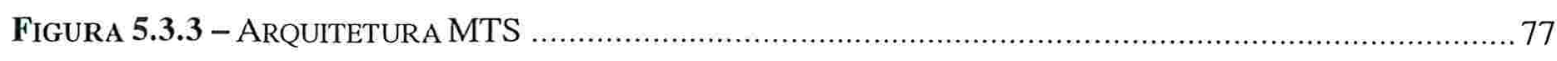

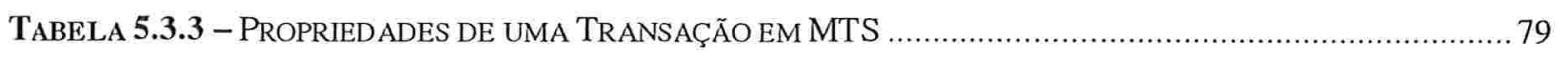

EXEMPLO 5.3.3 - EXEMPLO DE UMA TRANSAÇÃO MTS NUM ARQUIVO ASP .............................................. 80

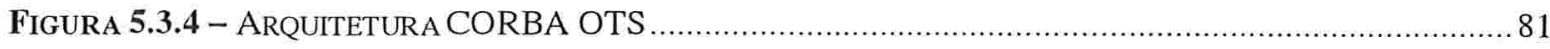




\section{Capítulo 1}

\section{Introdução}

Nos últimos anos a Internet e, em particular, a World Wide Web (WWW) ou simplesmente Web, tem se tornado o canal mais utilizado para transmissão e distribuição de informações, acesso a dados e comunicação pessoal.

Porém, desde a sua criação até os dias atuais, a Web tem sofrido sucessivas alterações, passando rapidamente da condição de plataforma para a troca irrestrita de documentos, conforme projetado inicialmente, para tornar-se uma plataforma de desenvolvimento de inúmeras aplicações distribuídas e multiplataforma, como comércio eletrônico, bibliotecas digitais, educação a distância e sistemas hipermídia.

Seguindo esta tendência, a integração da Web com os Sistemas de Gerenciamento de Banco de Dados (SGBDs) foi inevitável, já que estes são componentes imprescindíveis para o gerenciamento dos dados das aplicações. No entanto, esta junção de tecnologias não se dá de forma trivial, já que os SGBDs surgiram e evoluíram para atender requerimentos característicos de seu ambiente, sem a preocupação com uma futura e eventual integração com outros ambientes, como por exemplo, a Web.

Diante destes fatos, surgiu um novo componente de software, o gateway Banco de Dados, que funciona como um elo entre o ambiente Web e o Banco de Dados, com a função de fazer o mapeamento entre as requisições do cliente Web (navegador Web) e do SGBD.

Apesar de já existirem gateways bastante eficientes, o desenvolvimento de aplicações Web Banco de Dados ainda possui alguns problemas funcionais cujas soluções não são triviais [Lim97]. Dentre eles está a garantia da corretude das transações. Isto é, as propriedades ACID (Atomicidade, Consistência, Isolamento, Durabilidade) das transações devem ser garantidas sem restrições no ambiente de integração. Já existem gateways que garantem em grande parte esta corretude, porém é possível determinar diversos elementos que apontam o modelo de transações planas dos atuais SGBDs como um dos fatores restritivos para a solução dos problemas transacionais. Portanto, é necessário observarmos 
as particularidades das aplicações deste novo ambiente a fim de identificarmos as características de um modelo de transações satisfatório.

Esta nova área de pesquisa, denominada Web Banco de Dados (Web Database), vem crescendo muito na medida em que se verifica a enorme potencialidade desta integração para o desenvolvimento de várias aplicações Web baseadas em SGBDs. O volume de informações disponível na Web vem aumentando consideravelmente e a tecnologia de Banco de Dados representa uma parte crítica deste crescimento, não só como fonte para armazenamento e gerenciamento de objetos Web como também para o desenvolvimento de novas aplicações sob sistemas de Banco de Dados na Web.

\subsection{Objetivo e Motivação}

O objetivo principal desta dissertação é apresentar uma visão global dos aspectos transacionais no ambiente de integração Web Banco de Dados, destacando suas características, problemas e soluções.

A principal motivação veio do fato de não existir, ou de não se ter encontrado no levantamento bibliográfico - mesmo tendo sido este minucioso - um trabalho que possua este enfoque, ou seja, um estudo aprofundado das transações no ambiente Web Banco de Dados. A grande parte da literatura disponível trata de artigos em revistas "comerciais" e de artigos produzidos por desenvolvedores de soluções sem nenhum compromisso acadêmico.

\subsection{Trabalhos Relacionados}

As pesquisas na área Web Banco de Dados são recentes e vêm abrangendo vários tópicos distintos. Em linhas gerais, três pontos principais de pesquisa têm se destacado: a visão da Web como um enorme Banco de Dados distribuído e multiplataforma, o acesso a Bancos de Dados através da Web e o desenvolvimento de técnicas e ferramentas para desenvolvimento de aplicações Web integradas a SGBDs. Este trabalho está enfocado basicamente na segunda área.

Os trabalhos relacionados com o acesso a Bancos de Dados através da Web incluem, entre outros, implementação de arquiteturas de integração das tecnologias [HM97], estudo das arquiteturas existentes [Per95, Kim96], análise de desempenho de arquiteturas [HM97] e processamento de transações [LSCI97, LEK98].

Os estudos acerca dos aspectos transacionais no ambiente Web Banco de Dados são recentes e, por isso, poucos trabalhos foram publicados sobre o assunto [Bi198, LEK98, 
EB97]. Tais trabalhos não se preocupam com os aspectos navegacionais impostos pelo ambiente e nem com o modelo de transações usado no Banco de Dados. Porém, deve-se ressaltar que existem referências [Lim97] que destacam a importância de um estudo mais detalhado do assunto desta dissertação.

[EN00] cita alguns problemas em aberto na área Web Banco de Dados. Segundo ele, alguns dos desafios a serem superados são: a tecnologia Web precisa ser integrada com a tecnologia de objetos, a funcionalidade do HTML é muito restrita para suportar aplicações complexas, o conteúdo das páginas Web deve ser feito de maneira mais dinâmica adicionando mais "individualidade" a ele como um objeto e o suporte a um grande número de clientes com tempo de resposta razoável.

\subsection{Contribuiç̧̃es}

Como contribuições deste trabalho, espera-se:

- Mostrar os principais conceitos envolvendo o ambiente de integração Web Banco de dados;

- Definir uma transação Web;

- Apresentar modelos de transações que podem ser utilizados na implementação de uma transação Web;

- Analisar os aspectos transacionais, seus problemas e soluções, deste novo modelo de transações;

- Fazer um estudo sobre as principais tecnologias de componentes que são bastante úteis em aplicações Web;

- Fazer um levantamento das principais tecnologias de processamento de transações distribuídas, para dessa forma conhecer melhor os mecanismos para se implementar transações Web;

- Acrescentar à literatura em português um estudo sobre transações Web;

- Apresentar um extenso material bibliográfico sobre o do ambiente Web Banco de Dados.

\subsection{Organização}

O restante da dissertação é organizado nos seguintes capítulos: 
- O Capítulo 2 apresenta uma visão geral da Web, dos Sistemas de Banco de Dados e do ambiente de integração Web Banco de Dados, destacando a arquitetura e conceitos básicos necessários ao entendimento dos demais capítulos.

- O Capítulo 3 define o conceito de transação Web e analisa características e problemas deste modelo no ambiente de integração Web Banco de Dados.

- O Capítulo 4 apresenta dois possíveis modelos conceituais de transações para representar uma transação Web.

- O Capítulo 5 aborda os diversos tipos de tecnologias das soluções para implementar transações Web.

- O Capítulo 6 contém um resumo do trabalho apresentado nos capítulos anteriores e propõe trabalhos futuros. 


\section{Capítullo 2}

\section{O Ambiente de Integração Web Banco de Dados}

Este capítulo descreve as principais características do ambiente de integração Web e SGBDs. A seção 2.1 fala da Internet e suas aplicações, e de modo particular, do comércio eletrônico. Na seção 2.2 são apresentados os conceitos básicos envolvidos no ambiente Web que serão utilizados ao longo deste trabalho. A seção 2.3 focaliza os conceitos essenciais pertencentes ao ambiente de Banco de Dados. A seção 2.4 procura detalhar aspectos do ambiente de integração, destacando os principais problemas e a forma como algumas funcionalidades dos SGBDs são afetadas pelo ambiente Web.

\subsection{Internet e Comércio Eletrônico}

A Internet é composta por um conjunto de redes de computadores que se comunicam e cooperam entre si. Estas redes utilizam diversos tipos de tecnologia, protocolos, meios de transmissão e computadores. Ela surgiu no final dos anos 60 e vem apresentando um grande crescimento desde a sua concepção, quando era essencialmente acadêmica. Os principais serviços oferecidos pela Internet são: World Wide Web (WWW) ou simplesmente Web, correio eletrônico, transferência de arquivos e acesso remoto.

Dentre as aplicações desenvolvidas para a Web, a que mais tem se destacado é o comércio eletrônico. Ele pode ser definido como a execução de transações comerciais envolvendo meios eletrônicos, e mais especificamente, a Internet.

O sucesso do comércio eletrônico pode ser explicado por três aspectos [MMR00]. O primeiro diz respeito à facilidade de disseminação de informação na Internet, devido à rapidez, ao alcance e ao baixo custo de distribuição e obtenção de informação. O segundo aspecto é o baixo custo das transações via Internet comparadas a transações feitas por telefone, fax, pessoalmente ou através de outros meios. Esta redução de custos estimula a atividade econômica por este canal. O terceiro aspecto se refere à competição pelos clientes. Devido à facilidade de se obter informação, é possível ter acesso rápido a grande 
quantidade de informações sobre produtos e preços, o que beneficia diretamente o consumidor.

Atualmente são identificadas quatro classes de aplicações de comércio eletrônico: comércio entre consumidores ou $\mathrm{C} 2 \mathrm{C}$ (consumer-to-consumer), como por exemplo os leilões virtuais; comércio no varejo ou B2C (business-to-consumer), no qual a empresa atende a um cliente especificamente; comércio entre empresas ou B2B (business-tobusiness), que permite a compra e venda de bens de serviços entre empresas; e, comércio intra-organizacional, que se refere ao gerenciamento de todas as atividades comerciais das empresas de uma mesma organização. Todas essas classes de aplicação são desenvolvidas para a Internet.

Portanto, a cada operação de compra e venda de produtos ou serviços ou uma simples consulta a um Banco de Dados sobre a Internet, tem-se uma transação de Banco de Dados. Como o ambiente é a Web, chamamos tal transação de transação Web, que será mais profundamente analisada no capítulo 3. Com o crescente aumento da utilização comercial na Internet, percebe-se a importância da existência de modelos de transações bem definidos e ferramentas de gerenciamento específicas para este novo tipo de transação.

\subsection{World Wide Web}

A World Wide Web, ou simplesmente Web, é um sistema de informação hipermídia em escala global acessível em tempo real baseado na Internet. Um documento hipermídia pode ser definido como a reunião de hipertexto e multimídia numa única página Web. Hipertexto é a combinação de textos não lineares, de forma a poder saltar de um texto para outro dinamicamente por meios de vínculos (links). Multimídia é a combinação de textos e outras mídias como imagens estáticas ou em movimento, sons, vídeos, gráficos, entre outros.

Desde seu desenvolvimento, esta tecnologia tem crescido rapidamente e agora está sendo exaustivamente empregada em aplicações comerciais e acadêmicas, usando um formato que seja acessível de forma semelhante em diversos ambientes computacionais.

A seguir, é mostrada a arquitetura Web. 


\subsubsection{Arquitetura Web}

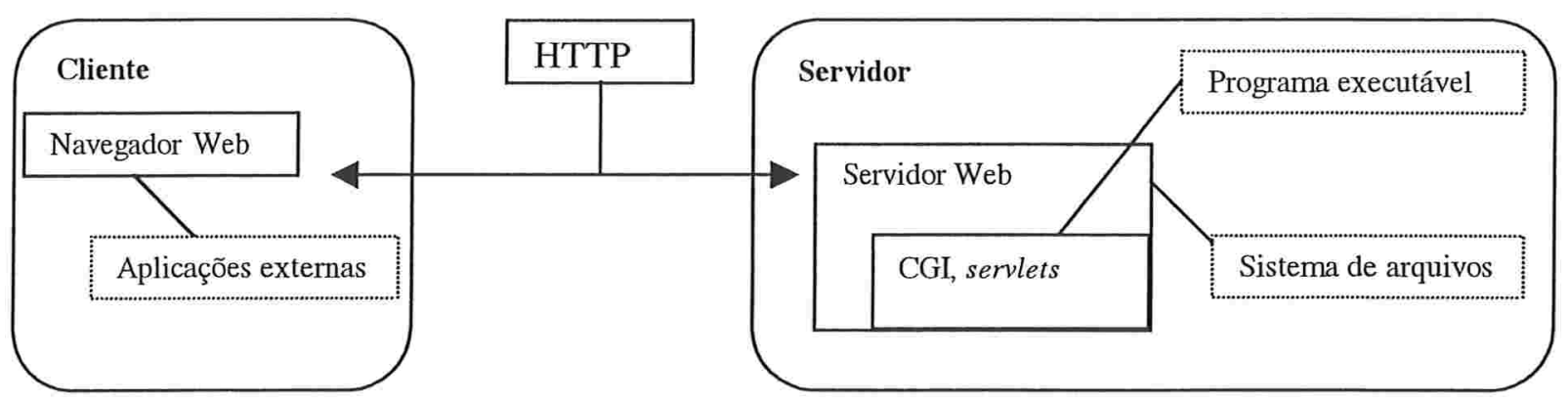

Figura 2.2.1 - ARQUitetura Web Simplificada

A figura 2.2.1 mostra a arquitetura simplificada da Web. Como se pode notar, é uma arquitetura típica cliente/servidor. De um lado fica o cliente, que é composto pelos navegadores, os chamados browsers Web, que são capazes de exibir e solicitar documentos sob a rede. Os navegadores podem acoplar aplicações externas, permitindo a visualização de alguns tipos de dados que não podem ser interpretados por eles, como sons ou imagens em movimento. Atualmente, os navegadores estão sendo estendidos para permitir a execução de lógica de programação, como por exemplo, a inserção da Máquina Virtual Java.

Do outro lado da arquitetura Web fica o servidor, composto pelo servidor Web, cuja principal função é atender os pedidos dos clientes Web por documentos armazenados no sistema de arquivos da plataforma onde se encontra instalado. Dependendo do pedido do cliente, o servidor Web pode disparar uma aplicação externa como, por exemplo, a execução de um programa via interface padrão CGI (Common Gateway Interface). Esta tecnologia será apresentada no Capítulo 5. Os servidores Web também estão sendo estendidos para suportar a execução de lógica de programação, como por exemplo, a inserção da Máquina Virtual Java no servidor, no caso da tecnologia de servlets [Ser01], visto também com mais detalhes no Capítulo5.

Uma característica importante é que a Web foi projetada para suportar vários protocolos Internet incluindo FTP (File Transfer Protocol), TELNET, entre outros. Assim é eliminada a necessidade de usar um programa separado para cada serviço Internet diferente, unificando-os num único serviço, no caso a Web. 
A base dessa arquitetura compreende três padrões abertos que permitem transferir a informação, descrever a formatação da informação e localizar a informação distribuída pela rede. São eles:

- HTTP (HyperText Transfer Protocol) - é um protocolo do nível de aplicação do padrão OSI/ISO, adequado para reconhecer e transferir dados em sistemas hipermídia distribuídos [MMR00]. É um protocolo "sem estado" (stateless), o que significa que nenhum tipo de informação é armazenado sobre requisições anteriores, não definindo, portanto, o conceito de estado da informação. Este é um dos principais problemas quando se trabalha com transações na Web. Isto será melhor explicado no próximo capítulo.

- HTML (HyperText Markup Language) - é a linguagem padrão para a apresentação e formatação de documentos Web. Ela é baseada no padrão SGML (Standard Generalized Markup Language) e, como tal, independe da plataforma em que é exibida, cabendo ao cliente Web interpretá-la de acordo com sua configuração. Outra importante característica da linguagem HTML é a possibilidade de geração de formulários (forms) contendo ícones e campos para preenchimento de dados pelos usuários. Os formulários proporcionam um maior dinamismo, pois permitem que as páginas Web funcionem como a "porta de entrada" para aplicações que necessitem de uma interação com o usuário.

- URL (Universal Resource Locator) - é um protocolo para identificar e localizar documentos Web distribuídos.

A comunicação entre cliente e servidor Web é feita na forma de pares requisição/resposta e é sempre iniciada pelo cliente. Inicialmente, o cliente envia uma mensagem para o servidor solicitando abertura de conexão. O servidor responde aceitando ou não este pedido. Se aceitar, a conexão é estabelecida. Uma recusa pode indicar que o servidor está sobrecarregado e não consegue tratar novos pedidos de conexão que chegam. Normalmente, existe um número máximo de pedidos pendentes. Um pedido de conexão pode ser recusado se este limite tiver sido atingido.

Uma vez estabelecida a conexão, o cliente envia uma mensagem com a requisição feita pelo usuário, representada por uma URL. Esta mensagem é enviada através da rede para o servidor, que busca a informação no disco local ou dispara a execução de uma 
aplicação externa. Após o processamento do pedido, uma mensagem de resposta é enviada ao cliente que, ao recebê-la, retorna um pedido de fechamento de conexão.

Quando o cliente recebe a informação solicitada, é necessário verificar se os dados são válidos, através de informações contidas em campos do cabeçalho da mensagem. Somente após esta verificação o navegador pode mostrar o documento para o usuário. Para tanto, ele precisa saber qual o tipo e o formato do arquivo. Esta informação também é obtida no cabeçalho da mensagem. Todo este processamento impõe um atraso no cliente, que é refletido no tempo de resposta observado pelo usuário.

Os programas utilizados pelo servidor Web em resposta a um pedido de um cliente são chamados scripts Web. Pode ser um código compilado como $\mathrm{C}$ ou $\mathrm{C}++$ ou um código interpretado como Perl ou PHP [BS01]. Um script pode chamar outros programas ou contactar outros servidores. Seu objetivo principal é gerar informação dinâmica (em tempo de execução) para o cliente Web que o solicitou. Por exemplo, um script pode usar os campos de entrada de um formulário HTML para gerar e enviar uma consulta a um servidor de Banco de Dados. Cabe ao script retornar os dados num formato que o cliente consiga interpretar, como por exemplo, no formato HTML.

\subsection{Sistemas de Banco de Dados}

Um sistema de Banco de Dados é um ambiente de hardware e de software, composto por dados armazenados em Banco de Dados (BD), o software de gerenciamento do Banco de Dados (SGBD) e os programas de aplicação [MST97].

A tecnologia de Banco de Dados tem causado um grande impacto no desenvolvimento das aplicações. Pode-se dizer que os Banco de Dados têm um papel fundamental em quase todas as áreas onde os computadores são utilizados.

\subsubsection{Arquitetura}

Atualmente, as aplicações de Banco de Dados são, em geral, baseadas no ambiente cliente/servidor. As aplicações cliente/servidor de Banco de Dados, consistem de três componentes de software. O primeiro é o módulo de gerenciamento de dados (SGBD), responsável pelo armazenamento e a recuperação dos dados. Este pode ser subdividido em dois submódulos: um para o processamento de consultas e o outro para o acesso aos dados. O segundo componente é o módulo que implementa a lógica da aplicação utilizando a 
interface do módulo de gerenciamento de dados. O último é o módulo de apresentação usado na interação com os usuários.

Existem algumas variações de sistemas cliente/servidor de Banco de Dados. A mais comum hoje é a arquitetura de duas camadas, como ilustra a figura 2.3.1.

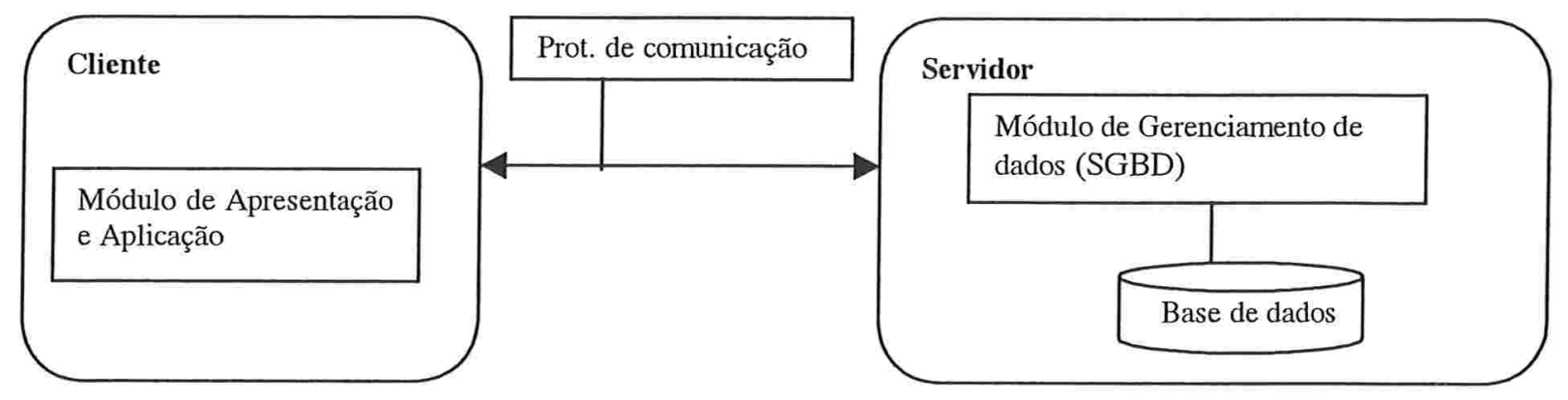

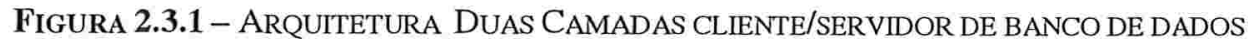

Na arquitetura de duas camadas, os módulos de aplicação e apresentação são implementados como um único módulo.

Existe ainda a arquitetura de três camadas. Nela, o módulo de aplicação é separado do módulo de apresentação, ficando o primeiro num servidor, chamado servidor de aplicação, de onde é compartilhado entre os vários clientes. A principal vantagem deste modelo é a maior flexibilidade e escalabilidade para sistemas de grande porte. No capítulo 5 , vamos falar sobre os servidores de aplicação, que são utilizados para desenvolver aplicações de grande porte para a Web e que estão baseados nesta arquitetura.

\subsubsection{Transações}

Transações são as unidades básicas de trabalho dos SGBDs. Uma transação é vista como uma unidade atômica de processamento consistente e confiável, composta de uma sequiência de operações elementares sobre os dados. Como produto de sua execução, uma transação pode mudar o estado do Banco de Dados ou não produzir qualquer alteração, dependendo dos efeitos de sua execução serem confirmados ou abortados.

As quatro propriedades fundamentais sobre as transações de Banco de Dados são representadas pela sigla $\mathrm{ACID}$ :

- $\quad$ Atomicidade - uma transação é uma unidade atômica de processamento. Isto significa que todos ou nenhum dos seus efeitos são considerados.

- $\quad$ Consistência - a execução correta de uma transação deve levar o Banco de Dados de um estado consistente a outro. 
- $\quad$ Isolamento - implica que toda transação deve ver um estado consistente do Banco de Dados sempre que for executada. Isto requer que os resultados intermediários de uma transação não confirmada não sejam vistos por outras transações e/ou usuários.

- $\quad$ Durabilidade - significa que os efeitos de uma transação, uma vez completada, são tornados permanentes no Banco de Dados.

Uma transação pode ser finalizada de duas maneiras: com sucesso/confirmada (commit) ou cancelada (abort). Quando uma transação é finalizada com sucesso, todas as mudanças feitas por ela tornam-se duráveis no Banco de Dados. Quando uma transação é cancelada, todas as mudanças feitas por ela são desfeitas (rollback).

\subsubsection{Modelo de Transações}

Um modelo de transações define quando uma transação começa, quando ela finaliza e quais ações são tomadas no caso de falha. Ele possui a característica de ser abstrato com relação às operações realizadas por estas transações, ou seja, ignora o código da transação. O modelo de transações cuida somente das operações realmente executadas sobre os itens de dados. Todos os outros detalhes da execução do programa são ignorados. Desta forma, o modelo consegue ser genérico e independente da linguagem em que as transações foram escritas.

As transações executadas pela maioria dos SGBDs seguem o modelo de transações planas, assim chamado porque existe uma única camada de controle na aplicação [GR93]. A impossibilidade de fazer referência a resultados intermediários e confirmar ou cancelar somente parte das ações são as principais restrições com relação às transações planas.

A figura 2.3.3.a ilustra este modelo.

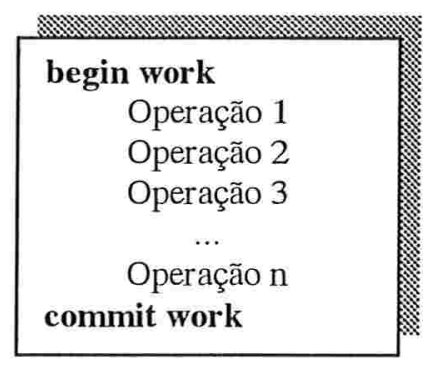

FigURA 2.3.3.A - REPRESENTAÇÃO DO MODELO DE ESTRUTURA PLANA

Este modelo é adequado para transações de curta duração. Porém, como as aplicações vêm se tornando cada vez mais complexas, têm surgido extensões do modelo de transações 
planas para atender às necessidades dos novos ambientes (distribuídos, cooperativos e heterogêneos).

Um outro modelo de transações utiliza uma estrutura de subtransações em oposição ao modelo de transações planas. Neste modelo, uma transação é constituída de um conjunto de outras transações, chamadas subtransações. Este grupo pode ainda ser subdividido segundo o relacionamento entre as subtransações e a forma como se interligam. Como exemplo, pode-se mencionar transações estruturadas na forma de árvore, que são denominadas transações hierárquicas. A figura 2.3.3.b ilustra este modelo.

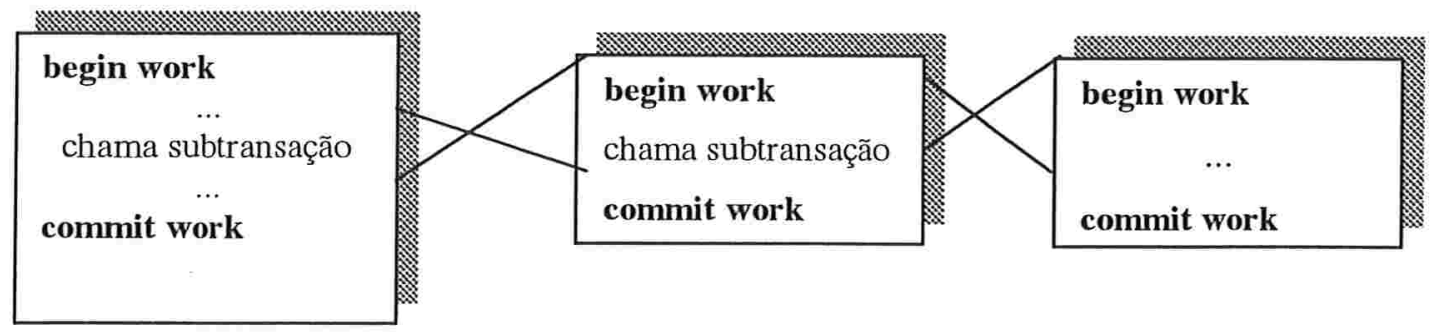

FiguRa 2.3.3.B - REPRESENTAÇÃo DO MODELO DE ESTRUTURA DE SUBTRANSAÇÕES

No capítulo 4 serão apresentados os modelos de transações aninhadas e encadeadas, que utilizam o modelo de subtransações e que podem servir como referencial para implementar transações Web.

\subsection{Ambiente de Integração}

Desde a sua criação até os dias atuais, a Web tem sofrido contínuas alterações. Ela vem passando rapidamente da condição de troca irrestrita de documentos, conforme projetada inicialmente, para tornar-se uma plataforma de desenvolvimento de inúmeras aplicações. Seguindo esta tendência, a integração da Web com os Sistemas Gerenciadores de Banco de Dados (SGBDs) foi inevitável, já que estes são componentes indispensáveis para o gerenciamento dos dados das aplicações.

A união destas duas tecnologias ocasionou o surgimento de um novo ambiente computacional. Ele é ilustrado pela figura 2.4 a seguir. 


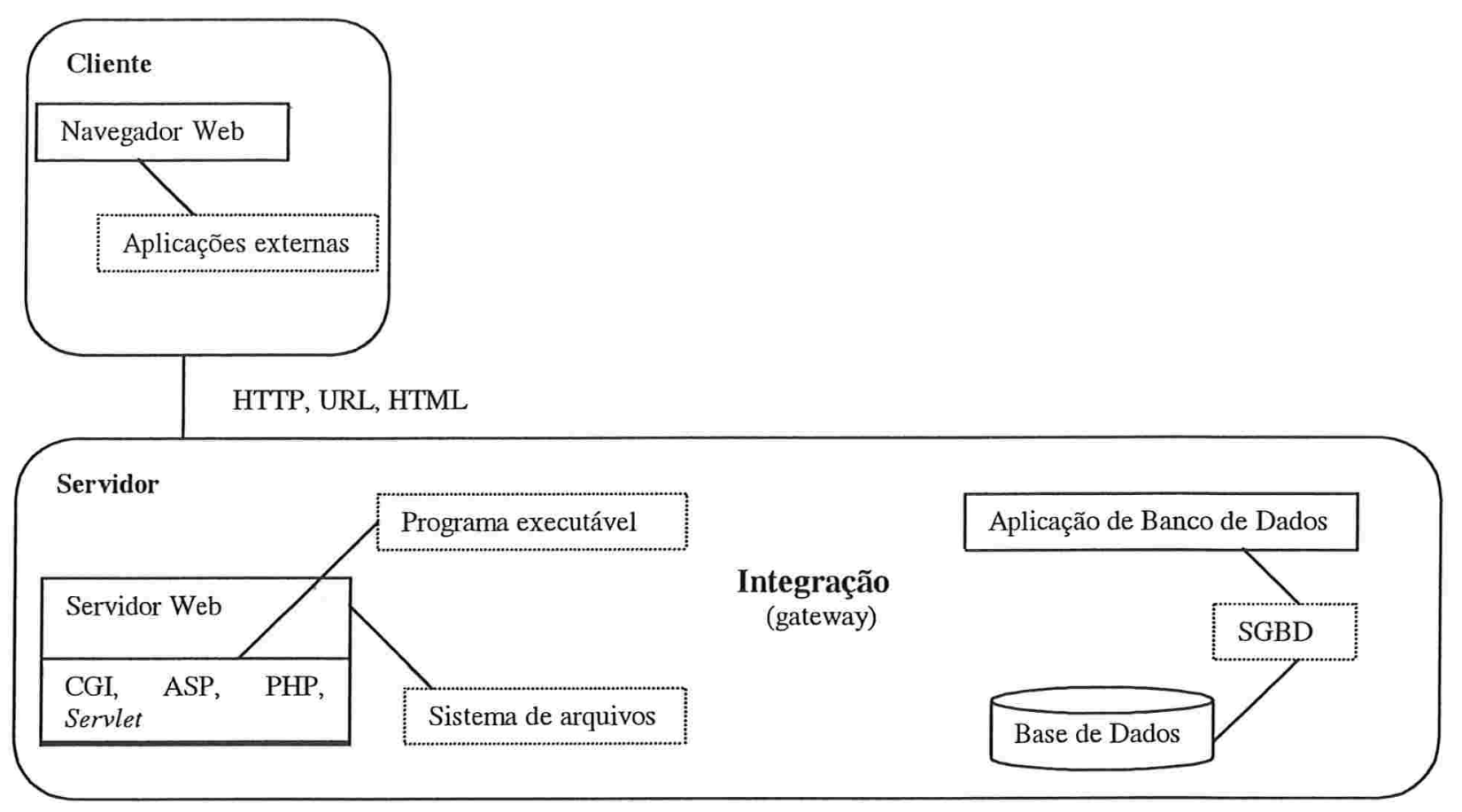

Figura 2.4 - AMBIENTE DE INTEGRAÇÃo WEB BANCO DE DADOS

Os softwares responsáveis pelo gerenciamento da comunicação e por proporcionar serviços de aplicação entre o servidor Web e o servidor de Banco de Dados são chamados gateways. Eles residem no servidor Web e são compostos por um ou mais programas scripts. Entre suas principais funções podemos citar [Str96]:

- Receber informações do cliente Web, utilizando o protocolo HTTP;

- Executar acessos aos servidores de Banco de Dados, fazendo com que o servidor Web atue como cliente do Banco de Dados;

- Gerar documentos HTML dinamicamente com as informações provenientes da base de dados.

Neste ambiente, o usuário utiliza o cliente Web para fazer suas requisições e visualizar os resultados. O SGBD é encarregado do armazenamento e manipulação dos dados e o gateway de Banco de dados faz o mapeamento entre os pedidos do cliente e o SGBD.

\subsubsection{Sessões}

Uma sessão é uma associação entre um cliente (usuário) e um servidor. Assim, quando um usuário começa a navegar pelo site através dos links fornecidos, é iniciada uma sessão entre o usuário e a aplicação. O tempo de vida de uma sessão é determinado pelo 
período em que o cliente está interagindo com o sistema, que pode ser curto ou longo. Uma sessão é formada por várias interações do usuário com a aplicação.

Um outro conceito que está interligado ao conceito de sessão é o de estado da informação. Ele consiste de um conjunto de informações sobre o status das interações em andamento com seus usuários que é mantido pelo sistema, permitindo identificar os pedidos sucessivos de cada usuário no servidor Web.

O estado da informação inclui, entre outros, a situação de todas as variáveis e seus valores. Sistemas que não mantêm qualquer estado da informação são chamados sistemas stateless ou "sem estado".

A Web é um sistema tipicamente "sem estado", já que é baseado no protocolo HTTP. Em particular, o servidor Web não armazena nenhuma informação do cliente ou da solicitação deste. Cada mensagem que chega do cliente Web solicitando algum novo recurso é tratada independentemente da mensagem solicitada anteriormente.

Em contrapartida, sistemas stateful ou "contínuos" são os que mantêm o estado da informação sobre as ações do usuário enquanto durar a sessão do mesmo com o sistema. No ambiente de trabalho dos SGBDs, as sessões são contínuas, ou seja, o usuário fica conectado ao SGBD enquanto durar sua sessão [GR93].

É necessário manter as informações do estado e da sessão do usuário para que as informações sobre as transações Web sejam mantidas. Como o ambiente Web não fornece esta funcionalidade, é preciso que ela seja implementada. As formas básicas de fazer esta implementação são [Lim97]:

- A utilização de cookies - um cookie é um item de dado que é armazenado em um arquivo texto no cliente Web. Quando o navegador ativa uma página de uma determinada aplicação, esta página pode conter comandos cookies para armazenar dados no sistema de arquivos da máquina onde o navegador é executado. Estes dados podem ser, por exemplo, uma informação fornecida pelo usuário em um formulário HTML. Mais tarde, uma outra página poderá recuperar esta informação a partir do navegador do usuário quando, por exemplo, o gateway enviar um comando com o item de dado a ser recuperado. O navegador recupera o cookie especificado e o retorna para o gateway.

- Uso de campos ocultos nas páginas Web - a solução mais simples para a manutenção do estado é inserir o estado da informação nas próprias páginas 
que estão sendo submetidas pelo usuário. Existem duas formas para implementar esta técnica:

- Passar a informação em campos ocultos na página HTML. Estes campos não são visualizados pelo usuário quando o conteúdo da página the é exibido. A linguagem HTML disponibiliza a tag $<$ hidden> que pode ser usada com esta finalidade.

- Pode-se colocar as informações na URL como parâmetros, de acordo com a especificação CGI.

Estas informações são enviadas para o gateway na próxima ação solicitada pelo usuário. O gateway, então, vai tratá-las e novamente incluí-las, se necessário, na próxima página de interação do usuário.

Para aplicações mais simples que precisem reter poucas informações durante a execução da aplicação, como por exemplo, qual o usuário da aplicação, esta solução é bastante eficaz. No entanto, para aplicações mais complexas trata-se de uma solução não muito adequada, visto que a informação tem que fluir de página em página da aplicação para não ser perdida. Além disso, esta solução implica em um esforço adicional no desenvolvimento da aplicação que deve ser muito bem modelada e implementada, visto que o desenvolvedor deve prever quais informações escondidas devem ser transportadas entre as páginas da aplicação durante sua execução.

\subsubsection{Requisitos de Integração}

Assim como em todas as áreas que envolvem a integração de duas ou mais tecnologias, é importante definirmos quais os requisitos necessários à integração da Web com os SGBDs. Na maioria das vezes, o critério de escolha está relacionado com a questão de não limitar ou alterar a natureza do ambiente Web e do Banco de Dados.

A satisfação ou não de um requisito depende do tipo de aplicação a ser desenvolvida. Por exemplo, um simples site de informações não requer nenhum controle transacional. Já numa loja virtual, este controle é de grande importância.

Os requisitos adotados neste trabalho foram extraídos da união dos propostos em [Lim97] e [EKR97], já que eles apresentam critérios de alto nível e são bastante abrangentes. São eles:

- $\quad$ Interface do usuário integrável - a interface do usuário deve permitir a junção de diferentes mídias. Por exemplo, o resultado de uma consulta ao Banco de 
Dados pode apresentar tanto texto como imagens. Esta propriedade está relacionada com a característica multimídia da Web.

- $\quad$ Modelo interativo - a interatividade das páginas Web refere-se à possibilidade de mudar de contexto de acordo com a reação do usuário, ou seja, cada usuário pode percorrer as páginas da maneira que melhor lhe convier. Esta característica corresponde à capacidade navegacional da Web (hipertexto).

- $\quad$ Consistência e integridade - refere-se à condição de que os dados visualizados no navegador devem corresponder aos dados armazenados no Banco de Dados. Tal requisito está intimamente relacionado ao suporte das características transacionais neste ambiente.

- Desempenho - refere-se ao tempo necessário para fornecer a resposta de um pedido do cliente ao Banco de Dados. Este tempo deve ser o menor possível.

- $\quad$ Escalabilidade - pode ser avaliada pelo número de usuários capazes de fazer acesso simultâneo ao Banco de Dados. Um sistema escalável deve estar apto a crescer de acordo com as necessidades, sem causar transtornos ou prejuízos. Está relacionado com o desempenho.

- $\quad$ Segurança - corresponde à inviolabilidade dos dados.

- Desenvolvimento - permitir a criação de aplicações Web Banco de Dados de forma mais rápida e transparente.

\subsubsection{Problemas de Integração}

Apesar das inúmeras vantagens proporcionadas pela integração SGBD e Web, o desenvolvimento de aplicações nesse ambiente ainda possui problemas técnicos cujas soluções não são triviais. Esta seção pretende discutir alguns desses problemas, tendo como referência os requisitos especificados anteriormente, e apresentar algumas das soluções propostas na literatura.

\subsubsection{Sistemas Legados}

O problema de sistemas legados é inerente a qualquer tecnologia nova como a Web. Sistemas legados são sistemas úteis que resistem a modificação e evolução. Os SGBDs representam, no contexto atual do ambiente Web, um importante subconjunto de sistemas legados. 
Até o momento, a maioria dos SGBDs comerciais foram projetados e implementados sem levar em consideração as necessidades especiais do ambiente Web. Além disso, muito já foi investido em SGBDs e em ferramentas de desenvolvimento. Portanto, a integração com o ambiente Web envolve a consideração dos mecanismos já desenvolvidos pelos fabricantes de SGBDs.

\subsubsection{Problemas Transacionais}

A capacidade transacional é uma das principais características que diferencia um SGBD de outros sistemas de armazenamento de dados. Portanto, qualquer tecnologia que se integre a Bancos de Dados deve ser capaz de suportá-la.

O protocolo de comunicação entre o servidor e o cliente Web é o HTTP. Como tratase de um protocolo de natureza "sem estado", surge um dos principais problemas na integração da Web com Banco de Dados: como unir um ambiente baseado em sessões "sem estado" (Web) a outro baseado em sessões contínuas (SGBDs)?

Os atuais SGBDs foram projetados para atender pedidos de usuários que se conectam ao Banco de Dados em sessões contínuas, ou seja, o usuário fica conectado ao SGBD enquanto durar sua sessão [GR93]. A orientação à sessão contínua do usuário é a base para o suporte das propriedades transacionais, pois permite ao SGBD, entre outras tarefas, gerenciar eficientemente o processamento das transações, controlar a concorrência aos dados, fazer otimização de consultas, garantir a integridade transacional, manter os mecanismos de autenticação e autorização de acesso aos objetos do Banco de Dados.

Assim, trabalhar neste ambiente unido a outro baseado em sessões "sem estado", como a Web, requer alguns questionamentos relacionados aos aspectos transacionais, como por exemplo: como manter o contexto transacional? Qual modelo de transação melhor se adapta ao ambiente de integração?

O problema da manutenção do contexto transacional é devido à característica "sem estado" da Web. Esta característica torna inviáveis alguns dos mecanismos existentes nos SGBDs, tais como:

- $\quad$ Autenticação de usuário - nos SGBDs, o usuário inicia uma conexão onde é feita uma prévia verificação para acesso ao Banco de Dados solicitando-se um login e uma senha, e em todas as transações que se seguem o usuário não mais precisa se identificar junto ao SGBD até o fim de sua sessão. Na Web, como a 
cada novo requerimento é perdido o contexto, torna-se necessário que o usuário se identifique ao SGBD a cada nova requisição de um pedido.

- Otimização de consultas - refere-se a mecanismos dos atuais SGBDs que permitem um melhor gerenciamento do acesso aos dados armazenados, entre eles, a manutenção de um cache em memória e armazenamento dos planos de consultas compilados e otimizados da conexão corrente. Desta forma, consultas repetidas são executadas simplesmente interpretando a estratégia estabelecida anteriormente, sem nenhum overhead de re-computação, re-otimização e acesso ao disco. Devido à característica "sem estado" do ambiente Web, a cada novo pedido do usuário é necessário criar um novo contexto e, portanto, os dados armazenados na memória principal e os planos de consulta pré-compilados, que formam a base para o mecanismo de otimização, são perdidos, não podendo ser utilizados nos próximos pedidos.

- Uso de cursores - a maioria dos Bancos de Dados relacionais dispõe de um mecanismo que preserva a posição de um cursor na tabela para a recuperação posterior dos demais registros sem que seja necessária nova execução da consulta. $\mathrm{Na}$ Web, como as informações dos pedidos anteriores são perdidos, é necessário criar um novo cursor a cada requerimento, ocasionando a perda da posição da tupla apontada anteriormente.

Outro problema transacional que ocorre diz respeito à capacidade de executar transações distribuídas na Web, ou seja, permitir que a execução de uma transação envolva a execução de outras transações em diferentes SGBDs. Alguns trabalhos estão relacionados a esta discussão, como:

- $\quad$ A especificação do protocolo TIP (Transaction Internet Protocol) [LEK98], padrão desenvolvido pela IETF (Internet Engineering Task Force) para a execução de transações distribuídas na Internet. O TIP é baseado no protocolo de confirmação bifásica (2PC, do inglês two-phase commit [BHG87]), que permite a comunicação entre os gerenciadores de transação para a execução de transações distribuídas. O ponto chave deste protocolo é que a comunicação entre os gerenciadores de transação pode ser feita com qualquer protocolo de comunicação da Internet. 
- O O modelo de transações proposto por [Bi198], chamado "I-transaction". Ele é baseado em ações atômicas, com mecanismos de tolerância a falhas e segurança. Esta solução é destinada à execução de transações distribuídas, que operam sob Banco de Dados heterogêneos, não conhecidos a priori, situados na Internet, acessados através da interface Web. Este modelo pode ser implementado sobre o TIP.

\subsubsection{Desenvolvimento de Aplicações Web Banco de Dados}

Com relação ao ambiente de desenvolvimento de aplicações Web baseadas em Banco de Dados, vários problemas podem ser destacados.

Um deles está relacionado com a dificuldade de escolher a tecnologia ideal para o desenvolvimento da aplicação, pois existe uma grande variedade de tecnologias para este fim, como por exemplo, CGI, ASP, PHP, Servlets. Todas essas tecnologias serão descritas no capítulo 5. Como cada uma delas possui suas próprias características e objetivos, é necessário, portanto, que o projetista da aplicação tenha um amplo conhecimento e uma contínua aprendizagem para escolher e utilizar a melhor tecnologia para a aplicação que está desenvolvendo. Além disso, a escolha de uma determinada solução pode ocasionar sérios problemas de portabilidade, pois estas soluções são, na maioria, proprietárias ou específicas a um determinado servidor Web, cliente ou SGBD.

A reutilização é outro problema, visto que a interoperabilidade entre as ferramentas é geralmente uma tarefa muito onerosa. Assim, se um desenvolvedor decidir mudar de tecnologia, é bem possível que ele tenha que escrever tudo novamente.

A falta de metodologias para o desenvolvimento destas aplicações é outro sério problema, pois a grande maioria das ferramentas é desenvolvida para ser utilizadas apenas na fase de implementação, não dispondo de um modelo lógico através do qual o projetista possa abstrair-se dos detalhes de implementação.

Mesmo com todos esses obstáculos, estão surgindo algumas ferramentas que facilitam o desenvolvimento dessas aplicações. [Fra98] faz um estudo detalhado destas ferramentas, organizando-as segundo uma classificação baseada em critério da Engenharia de Software, arquitetura e qualidade da expectativa do usuário. Ele considera o desenvolvimento de uma aplicação Web sob três perspectivas:

- $\quad$ Estrutural - quais objetos constituem a aplicação.

- $\quad$ Navegacional - como ir de um objeto a outro. 
- $\quad$ Apresentação - como os objetos são visualizados.

\subsubsection{Desempenho}

O conceito de desempenho relacionado ao ambiente Web Banco de Dados refere-se ao tempo de resposta a uma requisição do usuário ao SGBD. A grande parte dos problemas de desempenho neste ambiente surge porque a Web foi projetada apenas para visualizar documentos e não para ser uma plataforma de desenvolvimento de aplicações.

Para calcular o desempenho neste ambiente, é necessário que se leve em conta três componentes: o desempenho do cliente Web, o tráfego na rede e o desempenho do servidor Web.

O desempenho no cliente Web refere-se à capacidade de exibir os dados enviados pelo servidor Web, considerando-se os diversos tipos de mídias possíveis, o gerenciamento do cache local e a execução de códigos associados aos dados enviados, como por exemplo, applets Java, códigos JavaScript e a ativação de plug-ins.

O tráfego na rede refere-se ao tempo necessário para prover acesso remoto, escolha da melhor rota para conexão com o servidor Web e transmissão dos dados na rede. Este é um problema crucial do ambiente Web principalmente se a aplicação for executada em horários de intenso tráfego na rede.

O servidor Web é um dos componentes determinantes no tempo de resposta de uma operação do cliente, já que ele é afetado pela carga de pedidos, pela plataforma de hardware e pelo ambiente de software (sistema operacional, gerenciador de arquivos e execução de programas CGI, ASP, PHP, entre outros).

Além destes fatores, pode-se identificar outros dois que afetam particularmente o desempenho de aplicações Web Banco de Dados, como por exemplo:

- $\quad$ Número de usuários - nas aplicações Web é muito difícil quantificar o número exato de usuários simultâneos, podendo este número ser bastante grande, o que pode degradar o desempenho do servidor Web, do gateway ou até mesmo do próprio SGBD. Isto requer arquiteturas com alto desempenho que sejam bastante escaláveis e onde exista a possibilidade de processamento paralelo.

- Balanceamento da carga de trabalho - é imprevisível a carga de processamento que pode ser encontrada em aplicações Web Banco de Dados e seu gerenciamento envolve um grande número de fatores, entre os quais a habilidade da aplicação em lidar com consultas complexas sobre Bancos de Dados 
volumosos. Os mecanismos mais sofisticados devem usar arquiteturas de processamento distribuído que podem dividir os pedidos de usuários entre as várias máquinas físicas disponíveis.

Assim, conclui-se que o desempenho do ambiente de integração Web Banco de Dados envolve muitos aspectos, e o não cumprimento de um deles pode levar ao desenvolvimento de aplicações inviáveis de ser utilizadas.

\subsubsection{Segurança}

Mesmo com a crescente utilização da Web como plataforma para aplicações comerciais, existem ainda vários problemas que dificultam a implantação de sistemas de comércio eletrônico neste ambiente. Entre eles podemos citar a questão de segurança, visto que em muitas aplicações Web, como é o caso das que envolvem o pagamento de bens e serviços eletronicamente, é necessário que as entidades comunicantes, cliente (navegador) e servidor Web, se autentiquem mutuamente e que seja garantida a privacidade das transações.

As técnicas mais utilizadas para resolver problemas de segurança em redes de computadores são as técnicas de criptografia, que podem ser divididas em: algoritmos de criptografia de chave secreta, algoritmos de criptografia de chave pública, funções de hash seguras e assinaturas digitais.

Os protocolos que implementam segurança sobre o protocolo de transporte da Internet, o TCP (Transport Control Protocol), são o SSL e o HTTPS.

A especificação do SSL (Secure Sockets Layer) define os conceitos de sessão e conexão. A sessão é uma associação entre um cliente e um servidor. A criação de uma sessão, feita pelo próprio SSL, define um conjunto de parâmetros de segurança que podem ser compartilhados por muitas conexões e inclui uma troca de mensagem entre cliente e servidor para autenticação mútua e negociação do processo de codificação e das chaves criptográficas a serem usadas. O objetivo do estabelecimento de sessões é evitar a negociação dos parâmetros de segurança a cada conexão estabelecida. Cada conexão, portanto, é associada a uma sessão e seu objetivo é prover o serviço requisitado. Os dados contidos na requisição são criptografados. A maioria dos navegadores e servidores Web implementa o SSL.

O HTTPS (Secure HTTP) é um protocolo que executa sobre o SSL e criptografa todo o tráfego. O desempenho do HTTPS é inferior ao desempenho do HTTP devido 
principalmente ao processo de codificação e decodificação de cada byte transmitido. A troca de certificados no início da conexão segura também gera latência.

Com relação à questão de segurança no ambiente de integração Web Banco de Dados, além de levarmos em conta os mecanismos de segurança da Web, devemos considerar as questões relacionadas à segurança e ao acesso ao Banco de Dados.

O mecanismo de segurança mais utilizado pelos SGBDs é baseado na segurança discriminatória, onde são concedidos privilégios aos usuários, podendo estes executar determinadas operações sobre o Banco de Dados [EN94]. Neste caso, o usuário faz acesso ao Banco de Dados através de um login e senha. O acesso aos objetos de Banco de dados é feito através de privilégios (grants) que são concedidos ao usuário.

Caso o contexto da aplicação seja uma Intranet, pressupõe-se que o número de usuários seja limitado. Assim, os mecanismos tradicionais de segurança e acesso aos dados são satisfatórios. Entretanto, quando o contexto da aplicação envolve a Internet, os mecanismos tradicionais são ineficientes, pois pode ser inviável controlar o acesso ao Banco de Dados e aos seus objetos individualmente, devido à perda de desempenho dos mecanismos tradicionais gerada pelo grande número de usuários simultâneos.

Para reduzir este problema, pode-se adotar a estratégia de classificar os usuários segundo grupos com as mesmas características de acesso aos dados e seus objetos, e dar acesso a eles (usuários) segundo o grupo que estão inseridos [Lim97]. Perde-se, entretanto, as características de acesso individual de cada usuário, sem que se saiba exatamente quem executou quais operações.

Por fim, ressalta-se os estudos referentes à execução de transações seguras [Bi198], onde se pretende estender as propriedades ACID a PLACID (Privacidade, Lealdade, Atomicidade, Consistência, Integridade, Durabilidade), permitindo assim que a execução de uma transação seja confidencial (privacidade) e que haja a autenticação entre os participantes e o não-repudiamento das mensagens trocadas.

\subsection{Considerações Finais}

Este capítulo apresentou os principais conceitos do ambiente Web, de Banco de Dados e, principalmente, do ambiente de integração dessas duas tecnologias que são de extrema importância para o bom entendimento deste trabalho. 
Foram discutidos também os principais problemas inerentes ao ambiente de integração Web Banco de Dados com o intuito de se ter uma visão geral do contexto em que este trabalho está situado.

O próximo capítulo é inteiramente voltado ao estudo das transações Web, destacando suas principais características e problemas encontrados neste novo paradigma de transações. 


\section{Capítulo 3}

\section{Transações no Ambiente Web Banco de Dados}

Uma das grandes dificuldades para integrar os ambientes Web e Banco de Dados é a natureza "sem estado" do protocolo HTTP usado na comunicação do cliente Web com servidor, pois isso implica na existência de transações Web da mesma natureza.

Quando um servidor Web responde a uma solicitação do cliente, ele o faz retornando uma página HTML ou disparando uma aplicação externa via interface CGI ou ainda utilizando tecnologias como PHP, ASP e Servlets. Segundo o protocolo HTTP, uma vez que o pedido é atendido, a operação é completada e a conexão se encerra. O servidor Web não armazena nenhuma informação sobre o pedido e/ou sobre o usuário que o solicitou.

Esta estratégia é boa para distribuir documentos, pois se alivia o servidor Web para atendimento dos demais pedidos dos clientes, porém este método causa vários problemas nos projetos de aplicação Web sobre Banco de Dados. Isso acontece porque os atuais SGBDs foram projetados para atender pedidos de usuários que se conectam ao Banco de Dados em sessões contínuas.

A mudança para um ambiente baseado em um protocolo "sem estado", como o da Web, implica em vários questionamentos, como, por exemplo, uma definição formal de uma transação Web, o gerenciamento da execução de transações neste ambiente de integração e a necessidade de se verificar se o modelo de transações usado nos atuais SGBDs é adequado ao ambiente Web Banco de Dados.

Este capítulo descreve as principais características das transações Web. A seção 3.1 mostra a definição de transação Web. Na seção 3.2 são descritos os possíveis escopos de uma transação Web. A seção 3.3 fala sobre o gerenciamento da execução destas transações. As seções seguintes 3.4, 3.5 e 3.6 abordam, respectivamente, consistência, controle de concorrência e recuperação das transações Web. 


\subsection{Transações Web}

Uma definição para uma transação Web pode ser dada por: baseia-se no modelo navegacional hipertexto, composta por uma ou mais páginas Web, com uma possível interação de longa duração com o usuário e que irá resultar num acesso a um Banco de Dados. Pode-se destacar ainda as seguintes particularidades dessas transações:

- As transações Web se iniciam no cliente Web, passando pelo servidor Web, sob o protocolo HTTP "sem estado" e pelo servidor de Banco de Dados. Ou seja, se usarmos os padrões estabelecidos para o ambiente Web, haverá necessariamente uma descontinuidade na sessão do usuário entre o cliente Web e o servidor de Banco de Dados.

- São formuladas por meio da interação com o usuário, podendo ter tempo "infinito" se comparadas com a duração do tempo das transações dos SGBDs tradicionais. Na Web, um usuário pode, por exemplo, abandonar a navegação sem notificar ao servidor Web ou ao SGBD. Uma outra possibilidade é o usuário navegar por outras páginas que a princípio não fazem parte do contexto transacional, podendo retornar mais tarde à transação que estava em andamento.

- São baseadas em páginas Web, ou seja, mesmo que uma página de origem contenha vários comandos para serem realizados no Banco de Dados, seria desejável que todos eles fossem considerados como uma unidade atômica de processamento.

- Podem ser resultado de várias páginas de interação com o usuário. Isto indica que uma transação na Web é formada por um grafo de navegação por páginas Web, geradas dinamicamente ou não.

- São baseadas no modelo navegacional da Web, sendo que não existe a priori como impor um rígido controle na ordem das transações. O usuário pode, por exemplo, submeter uma transação e logo em seguida retornar à mesma transação por meio da opção "voltar" do navegador e resubmetê-la.

- Podem ter um caráter distribuído, ou seja, permitir a execução de transações em diferentes SGBDs.

Diante destas particularidades, o conceito de uma transação Web se diferencia do conceito tradicional de transação de Banco de Dados como uma unidade básica de trabalho 
no SGBD. Porém, é importante um estudo focado nas transações Web devido ao aumento constante das aplicações sobre a Web que utilizam Banco de Dados e de modo especial, as aplicações de comércio eletrônico.

Embora a Teoria de Banco de Dados Distribuídos defina transações distribuídas [CP85], ainda assim este modelo não pode ser completamente utilizado na Web, já que este ambiente possui características que impedem o seu uso, como por exemplo, a natureza "sem estado" do protocolo HTTP utilizado na comunicação entre o cliente e o servidor Web. Além disso, as transações neste ambiente possuem particularidades que as distinguem do modelo tradicional de transações, como mostrado anteriormente. Ainda que os gateways resolvam o problema da natureza "sem estado" do ambiente, isso não resolve o problema das transações Web, sendo necessário um modelo que realmente as represente.

\subsection{Escopo de uma Transação Web}

As transações gerenciadas pela maioria dos SGBDs existentes seguem o modelo de transações planas. O modelo é assim chamado porque existe uma única camada de controle pela aplicação: todas as operações entre os delimitadores de início (begin transaction) e término (end transaction) estão no mesmo nível, e são aceitas ou rejeitadas em bloco (atomicidade). A expansão deste modelo para o ambiente de integração deve levar em consideração o escopo ou abrangência de uma transação Web. Como as páginas Web são as unidades básicas de interação com o usuário, então deve existir uma relação entre essas unidades e o conceito de transação no ambiente de integração. Esta relação deve ser discutida tendo em vista o escopo das transações Web.

\subsubsection{Uma página como unidade atômica}

A estrutura mais trivial de uma transação Web é aquela onde uma página é composta por uma ou mais operações sob o SGBD. Uma vez que uma página Web é considerada como uma unidade básica de operação, se a página contiver um conjunto de operações sob o SGBD, é desejável que estas operações sejam consideradas como uma unidade atômica: ou todas as operações serão executadas ou nenhuma delas será.

A figura 3.2.1 mostra uma página Web composta por várias operações a ser efetivadas pelo SGBD. Neste caso, as operações contidas na página Web são consideradas como uma unidade atômica de processamento para o SGBD. 


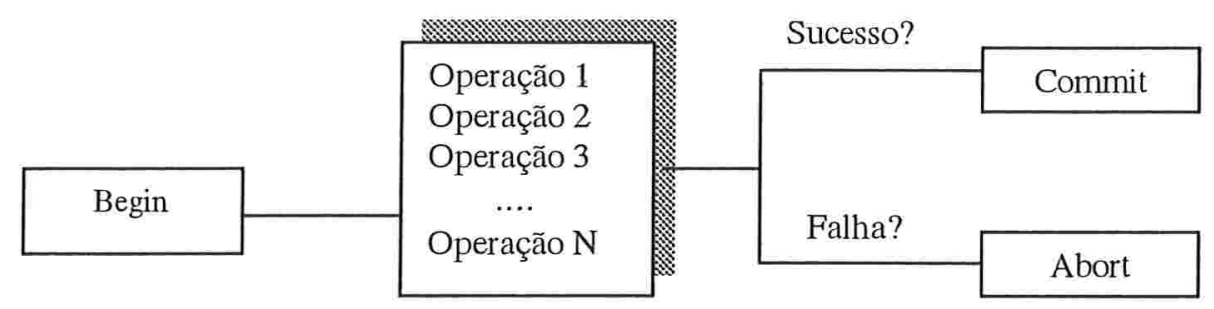

Figura 3.2.1 - Transação Composta Por UMa PÁgina Web

\subsubsection{Várias páginas como unidade atômica}

A limitação do escopo de uma transação Web a uma única página Web é desejável para efeitos de desempenho, podendo assim minimizar o tempo de duração de bloqueio aos dados no SGBD, favorecendo a concorrência. No entanto, desenvolvedores de aplicações freqüentemente precisam que várias interações com o usuário sejam realizadas como se fossem uma única transação atômica.

Considerando que cada interação origina uma página no ambiente Web, é desejável então que várias páginas façam parte de uma transação global atômica. Portanto, deve-se expandir o escopo de uma transação Web de forma a aceitar várias páginas Web como uma unidade atômica no SGBD.

A figura 3.2.2 apresenta uma seqüência de páginas Web que devem ser manipuladas no contexto de uma transação atômica. Primeiramente o usuário seleciona os produtos desejados navegando por diversas páginas Web. Em seguida preenche os dados para efetuar a compra, confirma o pedido e recebe uma ordem de pagamento com o total a ser pago.

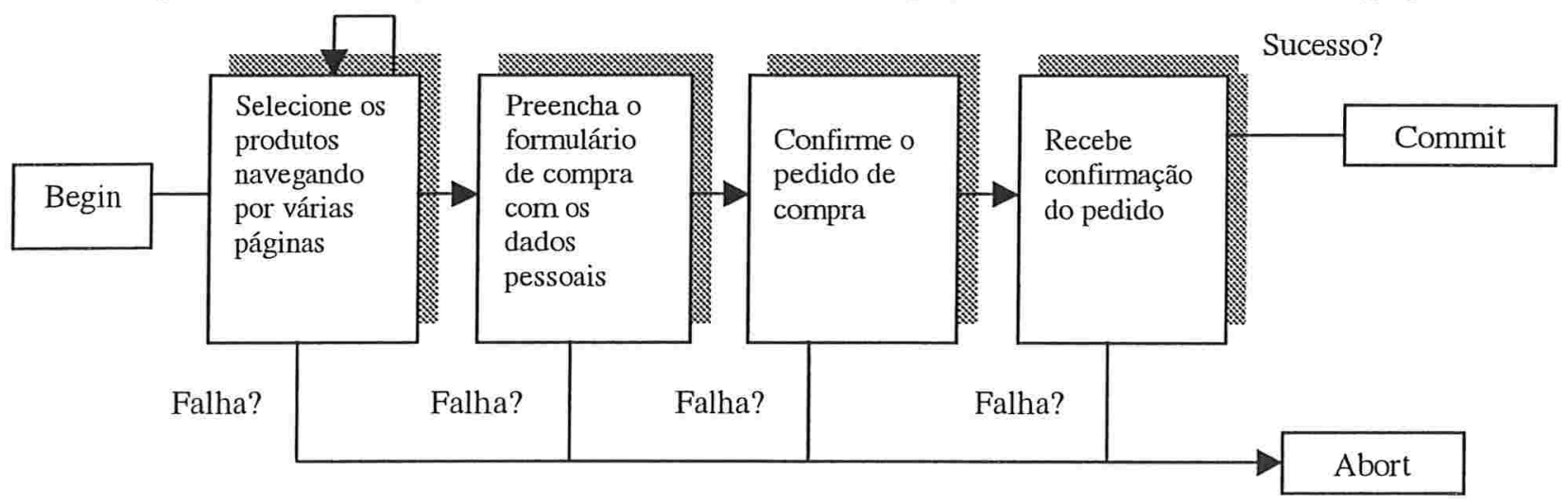

Figura 3.2.2 - TransaÇÃo Composta Por VÁrias PÁginas Web: Compra de livros 


\subsubsection{Páginas que não fazem parte de uma transação}

A possibilidade de delimitar um conjunto de páginas para formar uma transação atômica é útil para resolver o problema de transações que exijam várias interações com o usuário, mas pode ser muito restritiva no ambiente Web.

De fato, podem existir situações em que a navegação hipertexto possibilite, durante a execução de uma transação, composta por várias páginas Web, que o usuário saia do escopo transacional que deveria ser seguido, para realizar, por exemplo, consultas contidas em páginas que, a princípio, não fazem parte do contexto da transação sendo submetida. Veja na figura 3.2.3 um exemplo de uma transação com estas características.

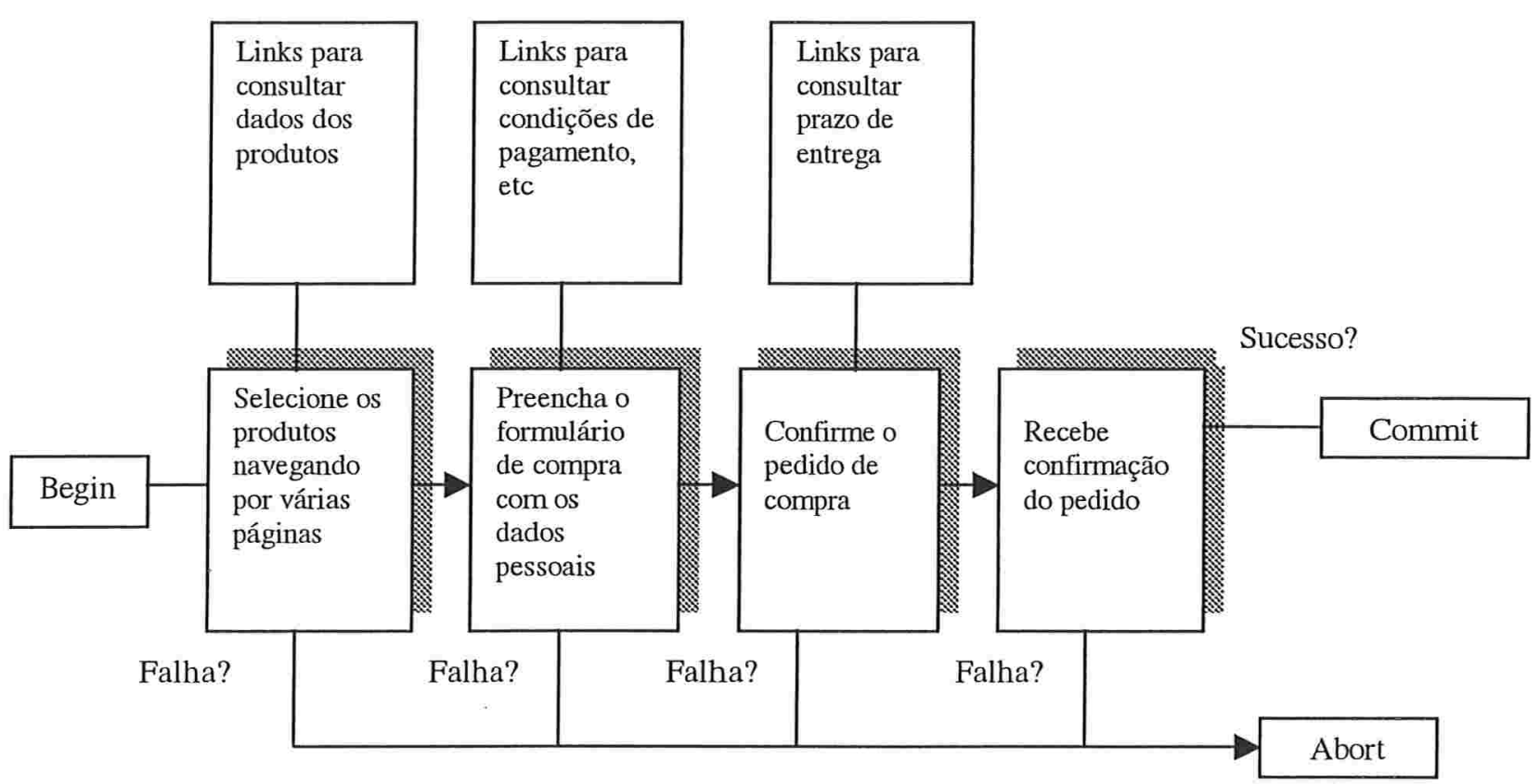

Figura 3.2.3 - Transação Composta Por Páginas Transacionais e Não transacionais

Neste exemplo, além das páginas que fazem parte da transação, existem páginas que não fazem parte diretamente do contexto transacional sendo submetido pelo usuário, podendo, inclusive, ser páginas estáticas armazenadas no sistema de arquivos na plataforma do servidor Web.

\subsection{Gerenciamento da Execução de Transações}

As transações de Banco de Dados devem ser executadas concorrentemente, de forma transparente e confiável para a aplicação, reforçando a propriedade de isolamento. A transparência refere-se à capacidade da manter o Banco de Dados em um estado 
consistente, mesmo na presença de várias transações executadas simultaneamente. A confiabilidade refere-se à capacidade do sistema de Banco de Dados em resistir aos diversos tipos de falhas que podem ocorrer no ambiente durante a execução de uma transação.

A avaliação da correção da execução concorrente de transações é feita com um critério que indica se o resultado final é ou não aceitável. O critério tradicionalmente empregado é o de seriabilidade do escalonamento das ações das transações, isto é, verificase se o resultado final é equivalente ao de uma execução serial dessas ações. Para isso podem ser usados diferentes mecanismos, sendo que o método mais difundido é o baseado em bloqueios aos dados compartilhados pelas transações concorrentes [EN94].

Uma avaliação cuidadosa de transações Web indica que os mecanismos tradicionalmente empregados para verificação da execução serial das transações em SGBDs tradicionais podem não ser apropriados ao ambiente Web Banco de Dados. De fato, os critérios de correção e seriabilidade de uma transação Web devem suportar os seguintes aspectos:

- Ser orientado a páginas Web, onde possivelmente uma página pode conter uma única ou várias operações no Banco de Dados.

- Ser baseado num controle de concorrência para interação com transações de longa duração. Isto é decorrente do fato de que os mecanismos atuais, como bloqueios, podem diminuir a concorrência e até mesmo eliminá-la dependendo da granularidade do bloqueio (no nível de registro, página de dados, tabelas ou Banco de Dados inteiro), em virtude do tempo "infinito" que uma transação Web pode levar.

- Ser flexível o suficiente de forma a englobar combinação de várias páginas Web para execução de uma única transação.

- Possuir mecanismos para recuperação por falhas na comunicação entre o cliente, o servidor Web e o servidor de Banco de Dados para garantir a integridade das transações Web.

Os critérios de correção e seriabilidade adotados atualmente pelos gateways Web Banco de Dados são baseados no critério usado pelo SGBD que se está utilizando, ou seja, geralmente são baseados nos mecanismos tradicionais, como bloqueios. 


\subsection{Consistência}

Como vimos no capítulo anterior, consistência de uma transação é simplesmente sua validação, ou seja, uma transação é um programa que faz o mapeamento de um estado consistente do Banco de Dados para outro também consistente após a sua correta execução [BHG87]. Os mecanismos presentes nos SGBDs garantem o estado consistente do Banco de Dados ao final da transação de acordo com a modelagem do Banco de Dados previamente definida.

Entretanto, a orientação a páginas de dados do ambiente Web, ao contrário da orientação a conjunto de tuplas dos SGBDs, pode originar sérios problemas de consistência das transações Web [Lim97]. Isto se deve principalmente às características de navegação da Web. A maioria dos navegadores disponibiliza opções que permitem o usuário voltar ou avançar (backfforward) pelas páginas de interação da aplicação em execução, baseado no cache local.

A seguir são apresentados alguns exemplos que ilustram o problema e suas implicações na questão da consistência das transações:

- Inserção de tupla - um exemplo típico ocorre quando um usuário utiliza a opção "voltar" do navegador após inserir uma tupla e re-submete a mesma operação de inclusão com os mesmos dados. Se a chave primária da tupla for gerada automaticamente pela aplicação, pode acarretar um estado indesejado no Banco de Dados com duas informações iguais armazenadas, embora com identificadores distintos.

- Exclusão de tupla - considere o caso em que o usuário exclui uma tupla por meio de uma interação. Em seguida, ele utiliza a opção "voltar" do navegador e tenta novamente excluir o mesmo registro. Como este não existe mais, um erro de falha da transação vai ser retornado pelo SGBD, o que é indesejável.

- Atualização de tupla - o problema da atualização é o mais crítico, pois podem existir situações onde são atualizadas várias tuplas que podem causar danos difíceis de serem revertidos futuramente. Um exemplo é o caso de aplicações que envolvam atualizações monetárias de produtos sob um percentual definido pelo usuário da aplicação. Se o usuário submeter a aplicação e retornar a operação via opção "voltar" do navegador, e submetê-la novamente, os produtos serão reajustados duas vezes sob o mesmo percentual. 
- Páginas inconsistentes - este problema é causado porque o cliente Web possui um cache local para um melhor desempenho do sistema. Entretanto, este mecanismo de cache cria um problema potencial para aplicações cujas páginas de dados são geradas dinamicamente, como é o caso das aplicações Web Banco de Dados. Assim, podem existir situações em que o cache local está inconsistente em relação à informação de fato disponível no Banco de Dados. É o caso, por exemplo, de consultas submetidas a Bancos de Dados atualizados com muita freqüência.

A primeira tentativa para solução do problema seria desabilitar as opções "voltar" e "avançar" do navegador. Isto, de fato, é possível em alguns deles, mas para isso seria necessário retirar todas as opções presentes nos navegadores impedindo a navegação hipertexto normal e a maioria das outras funcionalidades destes softwares. Além disso, nem todos eles permitem desabilitar seus botões de navegação.

Outro problema de consistência de transações Web decorrente da navegação hipertexto, diz respeito à possibilidade de se cancelar uma operação solicitada ao servidor Web ainda em andamento, através da opção "parar" presente nos navegadores. Esta opção permite uma semântica de cancelamento de transações por parte dos usuários que é difícil de ser implementada no ambiente de integração. De fato, uma vez submetida uma transação Web não será possível cancelá-la através de uma ação explícita do usuário neste sentido, via opção "parar" do navegador, já que estão envolvidos dois servidores na transação: o servidor Web e o servidor de Banco de Dados. A transação sempre será realizada se não houver nenhuma falha durante sua execução. Caso o usuário selecione a opção "parar" dos navegadores durante a execução da transação, o máximo que pode ocorrer é que ele não receberá a resposta da transação enviada pelo servidor Web, embora a transação tenha sido completada pelo servidor de Banco de Dados. Dessa forma, o fato dos navegadores Web permitirem cancelar uma solicitação por meio da opção "parar" não é adequado, sob o ponto de vista de transações Web.

\subsection{Controle de Concorrência e Isolamento}

Como já mencionado, o isolamento de uma transação requer que cada transação veja um estado consistente do Banco de Dados sempre que for executada concorrentemente, ou seja, a execução de uma transação não pode interferir no resultado de outras transações concorrentes antes que estas validem. Para garantir esta propriedade os SGBDs são dotados de técnicas que garantem a seriabilidade das transações concorrentes, questão já 
amplamente discutida na literatura [GR93, EN94]. Um dos principais mecanismos para garantir a seriabilidade de execução de transações concorrentes é baseado em bloqueios, onde se impede que várias transações acessem um mesmo item de dado simultaneamente.

A primeira questão a se discutir é relativa ao escopo de uma transação, como descrito na seção 3.3. Quando a transação que estiver sendo executada for composta por apenas uma página atômica, a técnica de bloqueio aos dados implementada pelos SGBDs é válida, pois como não existe o problema da perda de conexão, que resultaria na perda de bloqueios, e, devido ao fato de esta ser uma transação de curta duração, então estas características assemelham-se ao modelo atual implementado nos SGBDs, não precisando de qualquer alteração.

O problema aparece quando várias páginas originam uma transação atômica. Considere este fato e também a situação onde não há uma sessão contínua do usuário com o SGBD. Os mecanismos do SGBD irão garantir concorrência aos dados somente para cada interação sob o Banco de Dados. Se a transação for composta por um conjunto de interações, o SGBD considerará cada interação como uma unidade atômica e não será garantida a propriedade de isolamento de transações compostas por várias páginas. Isto pode ocorrer, por exemplo, numa aplicação de comércio eletrônico. Considere que um usuário seleciona produtos e os coloca na sua cesta de compras. Estes itens ficam bloqueados enquanto durar essa sessão. Considere que este usuário encerra esta sessão e retorna depois de um tempo indeterminado e tenta efetuar a compra. Aqueles itens que ele já tinha escolhido podem não estar mais disponíveis, caso outro usuário os tenha selecionado e a empresa não os tenha mais em estoque. A perda de isolamento das transações concorrentes pode ser inadequada para uma grande parte de aplicações Web Banco de Dados, principalmente se for possível realizar atualizações via Web.

As técnicas atuais para controle de concorrência dos SGBDs baseadas em bloqueio aos itens de dados podem se tornar inadequadas nesse ambiente de integração. Por exemplo, se uma operação solicitou bloqueio exclusivo aos dados (para atualização) numa página Web de interação e se o usuário demorar em submeter as próximas páginas da transação para a finalização da mesma, o mecanismo de timeout do SGBD que garante bloqueio aos dados somente por um tempo determinado vai ser acionado, e a transação em andamento vai ser desfeita para que se libere os dados para outras transações concorrentes. Não só o usuário pode ter um tempo de resposta grande mas o tráfego na rede ou uma 
sobrecarga no servidor Web pode ser um fator determinante no tempo final da transação. $O$ SGBD poderá decidir por abortar a transação tornando a operação inviável.

Os seguintes aspectos também devem ser levados em consideração a respeito desse problema:

- A granularidade [EN94] dos itens de dados no SGBD para técnicas de concorrência baseadas em bloqueio deve ser muito bem configurada. Níveis de granularidade para tabelas inteiras ou mesmo para páginas de dados podem ser inadmissíveis no ambiente de integração. A granularidade de bloqueio no nível de tuplas é a mais adequada na maioria das vezes, apesar de poder gerar sobrecarga no gerenciador de bloqueios do SGBD.

- A configuração do valor do timeout que o SGBD deve esperar para liberar os bloqueios de uma transação no ambiente de integração deve ser um valor que leve em consideração a aplicação (Internet/Intranet), o tráfego na rede e a sobrecarga no servidor Web.

- O uso, sempre que possível, de cursores, que podem ser úteis para aumentar a concorrência aos dados.

Além disso, deve-se também garantir que a navegação via opções "voltar" e "avançar" dos navegadores não gerem situações indesejáveis do ponto de vista do controle de concorrência. Por exemplo, situações em que um usuário submete uma página que solicite um bloqueio a um item de dado e, logo em seguida, o usuário re-submete a mesma página via opção "voltar" do navegador.

\subsection{Recuperação}

Uma transação entra num estado de falha depois de ser determinado que ela não pode mais prosseguir com sua execução normal. A recuperação garante que, mesmo havendo falhas durante a execução das transações, o Banco de Dados sempre será restaurado para um estado consistente.

Uma transação pode falhar devido a vários erros, entre eles [EN94]:

- Erros de hardware;

- Erros do sistema ou da transação, como por exemplo uma divisão por zero;

- Erros locais (dado não encontrado);

- Erros na comunicação dos componentes do sistema. 
Para impedir que estes erros produzam um estado inconsistente no Banco de Dados, são ativados mecanismos de recuperação do sistema. Nos atuais SGBDs, este é um problema já bem estudado e resolvido.

Sob o ponto de vista da recuperação decorrente de falhas no ambiente de integração Web Banco de Dados, deve-se considerar a existência de uma sessão contínua com o usuário. Do contrário, os mecanismos do SGBD garantem a recuperação somente para as transações compostas por uma página Web. Se a transação for composta por um conjunto dessas páginas, o SGBD considerará cada interação como uma unidade atômica e portanto, caso haja uma falha em algum ponto da transação não será possível desfazer (rollback) a transação como um todo pois o SGBD já poderá ter emitido um commit para as interações anteriores, dependendo da estrutura do modelo de transações empregado para a implementação das transações Web, como será mostrado no próximo capítulo.

Além das falhas do SGBD, surgem vários outros pontos de falha. [Lim97] ressalta alguns deles:

1. Falha no cliente Web;

2. Falha na rede entre o cliente Web e o servidor Web;

3. Falha no servidor Web;

4. Falha na conexão entre o servidor Web e os gateways;

5. Falha no gateway;

6. Falha na conexão entre o gateway e o SGBD;

7. Falha no SGBD.

A figura 3.7 ilustra estes pontos de falha.

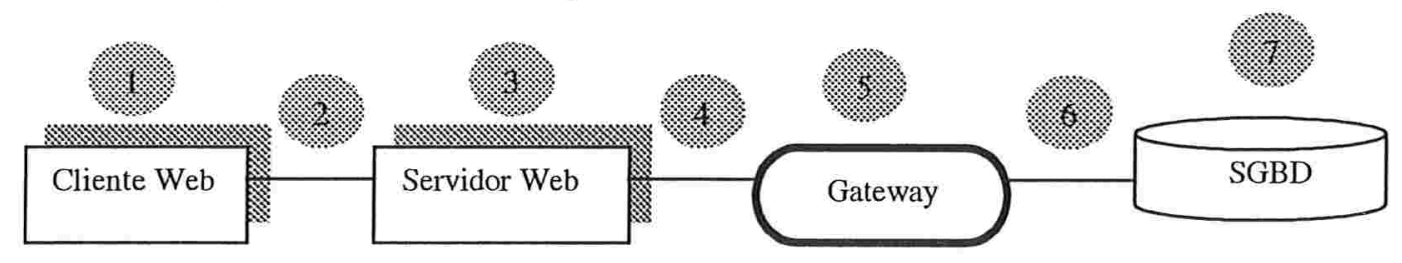

Figura 3.7 - Pontos de PossÍveis FalHas No Ambiente Web Banco de Dados

Além desses sete pontos de falhas, deve ser levado em consideração para implementação do processo de recuperação da transação, a semântica dos estados da transação.

Desde o momento que se inicia uma transação no cliente até seu fim, uma transação Web pode estar em três possíveis estados. São eles: 
1. Transação iniciada mas não confirmada: o usuário solicitou o início de uma transação e nenhuma resposta de confirmação foi recebida. Neste caso um erro pode ter ocorrido em qualquer dos sete pontos.

2. Transação em processo: o usuário recebeu a confirmação de que uma transação se iniciou e está em execução e portanto, uma sessão para ele será mantida pelo gateway junto ao SGBD. Nenhuma confirmação de fim de transação (commit/abort) foi solicitada.

3. Transação finalizada mas não confirmada: o usuário decidiu confirmar o fim da transação, mas nenhuma resposta de confirmação foi recebida. Neste caso, o usuário fica, em princípio, sem saber se sua transação foi ou não efetivada no Banco de Dados.

Como atualmente os clientes e servidores Web não estão habilitados a tratar de falhas que possam ocorrer no ambiente Web, então, para que a capacidade de recuperação seja efetiva no ambiente de integração, é necessário que ela seja tratada no gateway responsável pela integração das duas tecnologias, sem desconsiderar, no entanto, os mecanismos de recuperação presentes nos atuais SGBDs.

\subsection{Considerações Finais}

Neste capítulo, foi feita uma definição de transações Web e foram abordados os pontos mais importantes tais como o escopo, o gerenciamento da execução, a consistência, o isolamento e recuperação de tais transações.

A partir de uma definição e avaliação de transações Web, conclui-se que os mecanismos tradicionais empregados para a execução das transações nos SGBDs podem não ser apropriados para a execução de transações Web, e, de uma forma geral, todos os problemas referentes à integração do ambiente Web com Banco de Dados levantados neste capítulo devem ser solucionados pelo gateway integrador utilizado em cada aplicação.

No próximo capítulo serão apresentados dois modelos de transações: aninhadas e encadeadas, como alternativas para modelar transações Web. 


\section{Capítulo 4}

\section{Modelos de Transações para Transações Web}

Como mostrado nos capítulos anteriores, a integração do ambiente Web com Banco de Dados não se dá de forma natural.

Por vários anos, as pesquisas nesta área restringiram-se basicamente ao problema de como fazer o mapeamento entre as operações "sem estado" da Web e operações contínuas dos SGBDs. Entretanto, à medida que foram surgindo soluções mais eficientes para este mapeamento, observou-se que a simples resolução deste problema não garantiria a ampla integração deste ambiente, pois ainda existiam algumas propriedades que precisavam de uma solução mais específica.

Uma dessas propriedades está relacionada com o suporte das características transacionais neste ambiente. Como abordamos no capítulo anterior, muitas dessas novas características não são suportadas pelo modelo de transações implementado nos SGBDs.

As transações executadas pela maioria dos SGBDs seguem o modelo de transações planas. Uma transação neste modelo é caracterizada por apresentar uma estrutura simples, pela impossibilidade de fazer referência a resultados intermediários e confirmar ou cancelar somente parte das ações. Além disso, o tempo de execução dessas transações é geralmente curto.

Durante anos, este modelo tem sido a base para o desenvolvimento de aplicações. No entanto, à medida que novas tecnologias e novos requisitos foram surgindo, as aplicações passaram a requisitar das transações novas características, como por exemplo, a interatividade com o usuário e a existência de transações de longa duração.

Novos modelos de transações começaram a surgir motivados pelo intuito de adicionar novas características às transações, tendo como finalidade básica dar suporte às necessidades de determinados tipos de aplicações. 
No entanto, pode surgir a seguinte pergunta: qual a diferença entre o modelo tradicional e esses novos modelos apresentados, se as transações que realmente acessam o Banco de Dados não mudam de um modelo para o outro?

A diferença está na maneira em que estas transações são estruturadas. Elas são modeladas de forma que possam dividir seus trabalhos em subtransações, o que é conveniente em transações de longa duração. Assim, a falha de uma subtransação leva ao desfazer de um menor número de operações e todo o trabalho já completado por subtransações confirmadas não precisa ser refeito ao se reiniciar uma transação não finalizada com sucesso [FF00].

Neste contexto, serão apresentados dois modelos de transações para a implementação de transações Web. A seção 4.2 fala sobre transações aninhadas e a 4.3 mostra as transações encadeadas. Antes, porém, a seção 4.1 descreve algumas limitações do modelo tradicional de transações e porque ele não é adequado às transações Web.

\subsection{Limitações do Modelo de Transações Planas para Transações Web}

O problema da utilização da estrutura plana para transações Web é decorrente da natureza do escopo das operações, como mencionado no capítulo 3.

No modelo tradicional, que utiliza a estrutura plana, todas as operações de uma transação estão no mesmo escopo, delimitadas pelos operadores begin_transaction e commit_transaction ou abort_transaction. Já numa transação Web, onde a unidade de consistência é uma página Web, o escopo das operações deve variar segundo a página onde se encontram [Lim97]. Assim, todas as operações que pertencem a uma página devem ser tratadas como uma transação atômica, isto é, ou todas as operações ou nenhuma são executadas.

Considere a situação onde uma transação compreende várias páginas Web (várias páginas como uma unidade atômica), como ilustra a figura 4.1.a. 


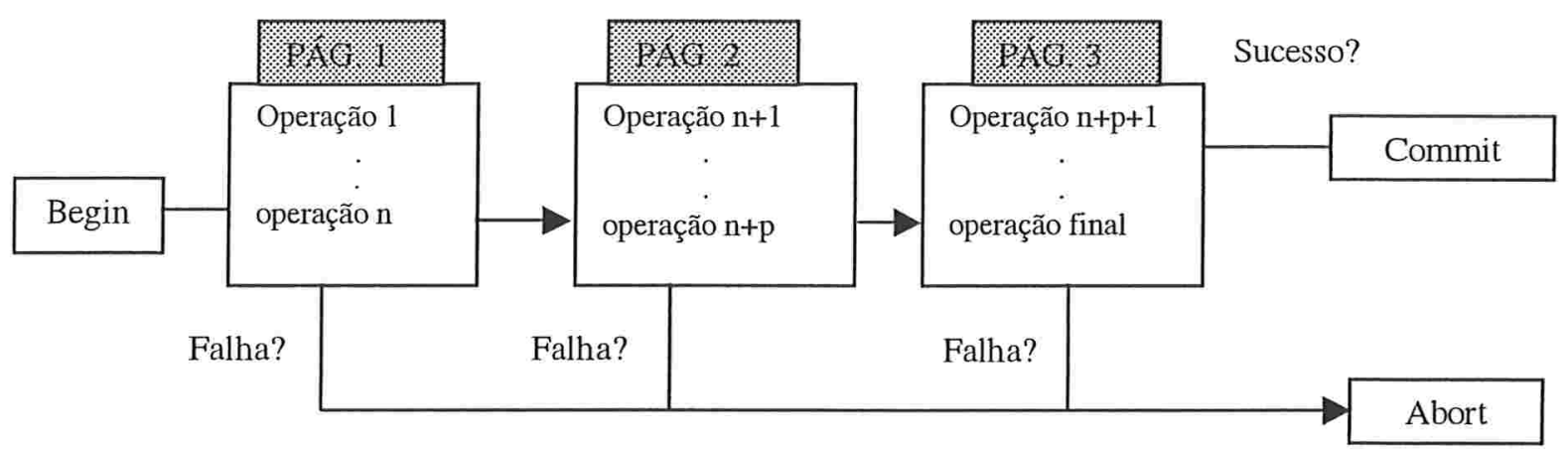

Figura 4.1.A - EXEMPLos de UMA TRANSAÇÃo Com VÁRIAS PÁGinaS DE INTERAÇÃo

Para implementar esta situação usando o modelo tradicional, indica-se antes da primeira operação da página 1, o início da transação (begin_transaction) e depois da última operação da página 3, o fim da transação (commit_transaction ou abort_transaction). Assim, todas as operações que ocorrem entre estes demarcadores serão consideradas como parte de uma única transação atômica global. A figura abaixo ilustra este fato.

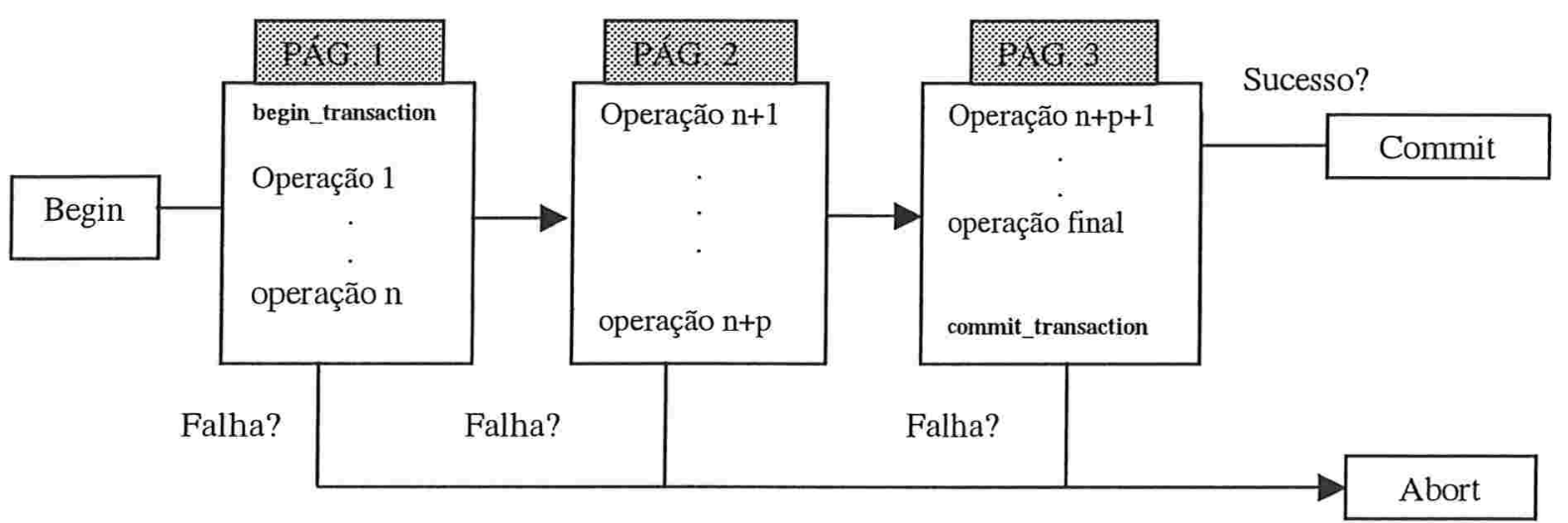

FigURA 4.1.B - ADEQUAÇÃO DO MODELO DE TRANSAÇÕES PLANAS NO CASO DE UMA TRANSAÇÃO ENVOLVENDO VÁRIAS PÁGINAS

Esta solução parece satisfatória, mas pode gerar alguns resultados inconvenientes. Por exemplo, se o usuário executar as operações da primeira e segunda páginas com sucesso e na terceira página alguma operação falhar, então todas as operações da transação serão desfeitas. Esta situação pode parecer normal para usuários de aplicações convencionais de Banco de Dados, mas para usuários de aplicações Web, esta não é uma situação confortável. Para eles, seria esperado que as operações que já havia sido efetuadas nas duas primeiras páginas, como por exemplo, a inclusão de produtos na cesta de compras ou o preenchimento de cadastro pessoal, não fossem desfeitas, para que não fosse necessário 
refazê-las. Portanto, somente as operações da terceira página deveriam ser desfeitas, mas isso não acontece quando se utiliza o modelo tradicional.

Além dos problemas de falha, temos os problemas navegacionais resultantes da utilização dos botões "voltar" e "avançar" presentes nos navegadores Web. Considere, por exemplo, a situação onde o usuário está segunda página e utiliza a opção "voltar" para retornar à página anterior. Neste caso, seria esperado que somente as operações da segunda página fossem desfeitas. Entretanto, isto não é possível, pois no modelo tradicional de transações ou todas as operações ou nenhuma são desfeitas. Assim, para que as operações da segunda página fossem desfeitas, seria necessário que todas as outras operações também o fossem, o que, como já mencionado acima, é um inadequado no ambiente de aplicações Web Banco de Dados. Nas próximas seções serão mostrados outros dois modelos de transações que podem servir de alternativa para a modelagem de transações Web.

\subsection{Transações Aninhadas}

\subsubsection{Definição do Modelo}

O modelo de transações aninhadas consiste na divisão de uma transação em subtransações, estendendo o conceito de atomicidade e permitindo o aborto de uma subtransação sem que, com isso, toda a transação seja abortada.

Uma transação neste modelo pode conter qualquer número de subtransações e cada subtransação, por sua vez, pode subdividir-se em outras subtransações. Assim, uma transação completa forma uma árvore de subtransações, chamada de árvore transacional. A figura 4.2.1 mostra a estrutura de uma transação neste modelo e seus componentes.

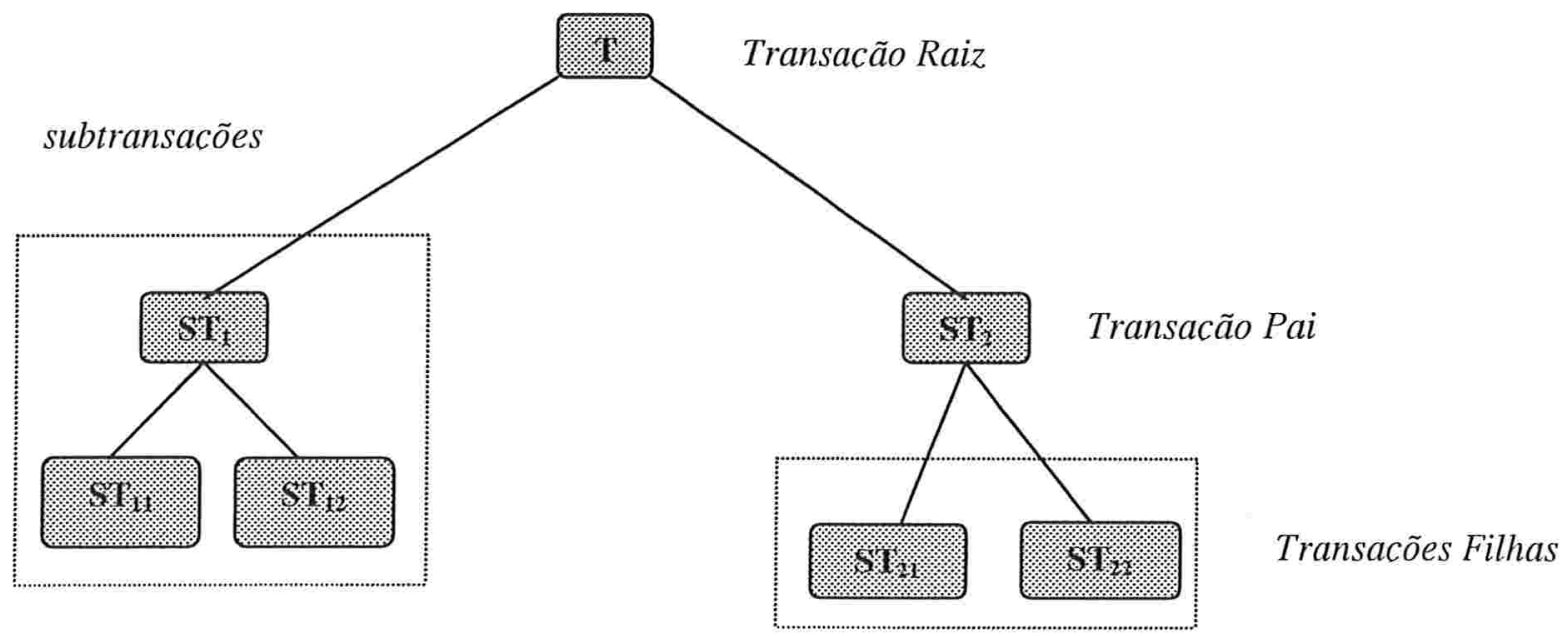

Figura 4.2.1 - Estrutura de uma TransaÇão ANinhada 
A raiz da árvore transacional é chamada root ou nível de topo transacional. Transações que possuem subtransações são chamadas de "pais", e suas subtransações de "filhas". Transações que possuem o mesmo antecedente são denominadas de transações "irmãs". Uma transação filha deve iniciar depois de sua transação pai e terminar antes dela.

A raiz de uma transação satisfaz todas as propriedades ACID (Atomicidade, Consistência, Isolamento e Durabilidade) do modelo tradicional. A propriedade de atomicidade é válida para as subtransações (elas podem confirmar ou abortar independentemente). Uma transação não pode ser confirmada até que todas as suas filhas tenham terminado. A confirmação de uma transação é condicional à confirmação de sua transação pai. Assim, uma transação confirmada ainda pode ser abortada caso sua transação pai venha a ser abortada. O aborto de uma transação filha não implica no aborto da transação pai. Neste caso, a transação pai pode agir de várias formas, tais como:

- Ignorar o erro;

- Desfazer a subtransação;

- Iniciar outra subtransação;

- Abortar a transação.

Se a transação pai abortar, todas as suas subtransações filhas serão desfeitas. As atualizações de uma subtransação serão permanentes somente quando a raiz da transação finalizar corretamente.

O algoritmo de controle de concorrência utilizado neste modelo é baseado no protocolo de bloqueios, no qual não há liberação de bloqueios em uma subtransação ativa. Todas as mudanças de posse de bloqueio se dão ao término (com sucesso ou não) de uma transação. A idéia de bloqueios neste modelo permanece a mesma do modelo tradicional, porém a noção de conflito entre bloqueios foi alterada. Dois bloqueios para transações $T_{i} \mathrm{e}$ $T_{\mathrm{j}}$ se conflitam se pelo menos uma das operações é uma operação de escrita e $T_{i}$ não é ancestral de $T_{j}$, nem $T_{j}$ é ancestral de $T_{i}$. Desta forma não há conflito entre um ancestral e seus descendentes [FF00].

Também segundo [FF00], o protocolo de controle de concorrência por bloqueios em transações aninhadas obedece às seguintes regras:

- Antes de realizar uma operação, uma transação deve obter o bloqueio ao dado. 
- Uma transação só obtém um bloqueio se nenhuma outra transação no sistema possuir um bloqueio conflitante; caso contrário, a transação é posta em espera.

- Ao abortar, todos os bloqueios de uma transação são liberados.

- Uma transação pai só se confirma se todas as suas filhas já terminaram (confirmadas ou abortadas).

- Ao se confirmar, todos os bloqueios de uma transação passam para o seu pai.

As principais vantagens do modelo de transações aninhadas são: modularidade, tolerância a falhas e paralelismo intra-transações.

- A modularidade é obtida pela decomposição da transação hierarquicamente.

- O mecanismo de tolerância a falhas deste modelo permite o usuário definir mais gradualmente a unidade de reabilitação.

- Um maior grau de paralelismo intra-transações é obtido devido ao fato de as subtransações poderem ser executadas concorrentemente.

Como desvantagens das transações aninhadas, pode-se citar [FF00]:

- O custo da recuperação de falhas, haja visto que uma transação confirmada pode ser abortada se algum antecedente seu abortar, levando a um complicado mecanismo de manutenção do log e o desfazer de transações abortadas.

- A sobrecarga do escalonador é bem mais alta do que a do sistema de transações tradicional, uma vez que a verificação de conflitos entre operações é mais complicada, e portanto, mais lenta.

- A decisão sobre o que fazer quando uma transação filha aborta deve ficar a cargo do programador da aplicação.

\subsubsection{Analogia do Modelo de Transações Aninhadas com Transações Web}

Na seção 4.1, as limitações do modelo de transações planas para as transações Web foram discutidas. Agora, vamos mostrar como o modelo de transações aninhadas possui uma estrutura que pode se enquadrar no modelo de transações Web.

Considere a situação onde uma transação compreende várias páginas, como por exemplo, a compra de produtos. No capítulo anterior, a figura 3.2.2 mostrou um esboço dessa transação. Agora vamos mostrá-la modelada como uma transação aninhada. 


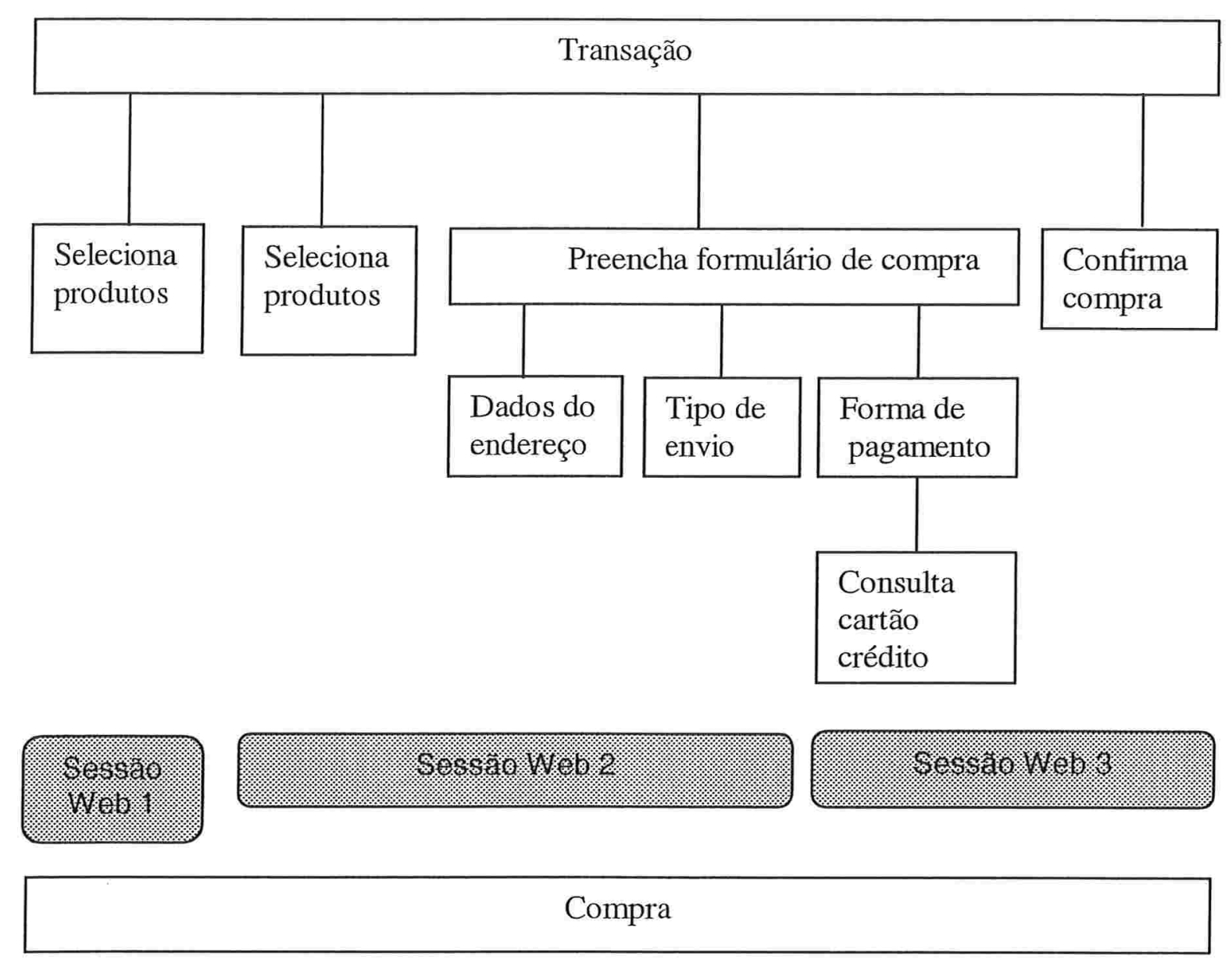

Figura 4.2.2 - TRANSAÇÃo WEB COMO UMA TRANSAÇÃo ANINHADA

Como podemos observar na figura acima, a transação de compra é dividida em subtransações que não são feitas necessariamente numa mesma sessão Web. As subtransações são:

- Selecionar produtos,

- Preencher formulário com dados pessoais; que por sua vez é dividida em outras subtransações:
- Dados sobre endereço
o Tipo de envio e
- Dados do cartão de credito

- Confirmar pedido

Segundo o modelo de transações aninhadas, caso uma das subtransações falhe, como por exemplo, a operadora de cartão de crédito não autorizar a compra, não significa que outras as subtransações serão desfeitas, mesmo que ele decida não proceder com a compra 
neste momento. Quando o usuário retornar ao sistema e desejar efetuar a compra, não será mais necessário escolher os itens novamente, nem fornecer dados de endereço e nem escolher o tipo de envio. Basta passar os dados do cartão de credito, já que foi essa subtransação que falhou.

Em [EB97] é feita um estudo sobre o modelo de transações aninhadas para sistemas de comércio eletrônico, provando-se formalmente a corretude do modelo para transações Web. Segundo [EB97], as transações eletrônicas comerciais podem ser modeladas usando o modelo de transações aninhadas, pois estas oferecem unidades de execução decompostas e um controle maior sobre recuperação e concorrência.

Conclui-se, então, que a estrutura de transações aninhadas é uma opção que pode ser utilizada na modelagem e implementação de transações Web.

A seguir, o modelo de transações encadeadas é apresentado.

\subsection{Transações Encadeadas}

\subsubsection{Definição do Modelo}

Uma transação encadeada é um conjunto de transações planas que executam uma após a outra, sendo que à medida que as transações vão sendo executadas, e se estas são confirmadas, não podem mais ser desfeitas. Assim, as transações são isoladas umas das outras e nenhuma delas afeta qualquer outra [Mar00].

As transações encadeadas são uma variação do modelo de transações planas com savepoints. Savepoints são pontos intermediários que dividem a transação em várias partes, sendo possível recuar até qualquer ponto da transação (savepoint) e continuar a partir daí.

O objetivo do modelo de transações encadeadas [GR93] é ter um desfazer (rollback) mais flexível com menor perda de trabalho quando o sistema falhar, pois restabelece o estado até a confirmação (commit) mais recente.

Entretanto, os objetos bloqueados pelas transações não são liberados quando a transação finaliza. Ao contrário, eles vão sendo passados de uma transação para outra, até que a transação encadeada finalize. Isto faz com que os resultados das transações sejam visíveis somente ao final da execução de todas as transações.

Porém, em alguns casos, como por exemplo, quando uma transação confirma, é possível liberar os objetos bloqueados que não serão compartilhados pelas transações 
subsequientes. Isso é mais eficiente do que manter os recursos bloqueados por toda a cadeia de transações [CY01].

No caso de falha, somente a transação ativa será desfeita e uma nova transação será iniciada para tentar compensar a quebra da sequiência da execução, já que o desfazer (rollback) é limitado à transação correntemente ativa, ou seja, uma vez que uma transação foi confirmada, ela não poderá ser desfeita. As transações usadas para compensar uma transação desfeita chamam-se transações compensatórias. Elas são úteis em situações em que se faz necessário desfazer transações confirmadas ou transações ativas que afetam outras transações, sem que com isso seja preciso recorrer a abortos cascateados [FF00].

A figura 4.3.1 mostra a estrutura do modelo de transações encadeadas.

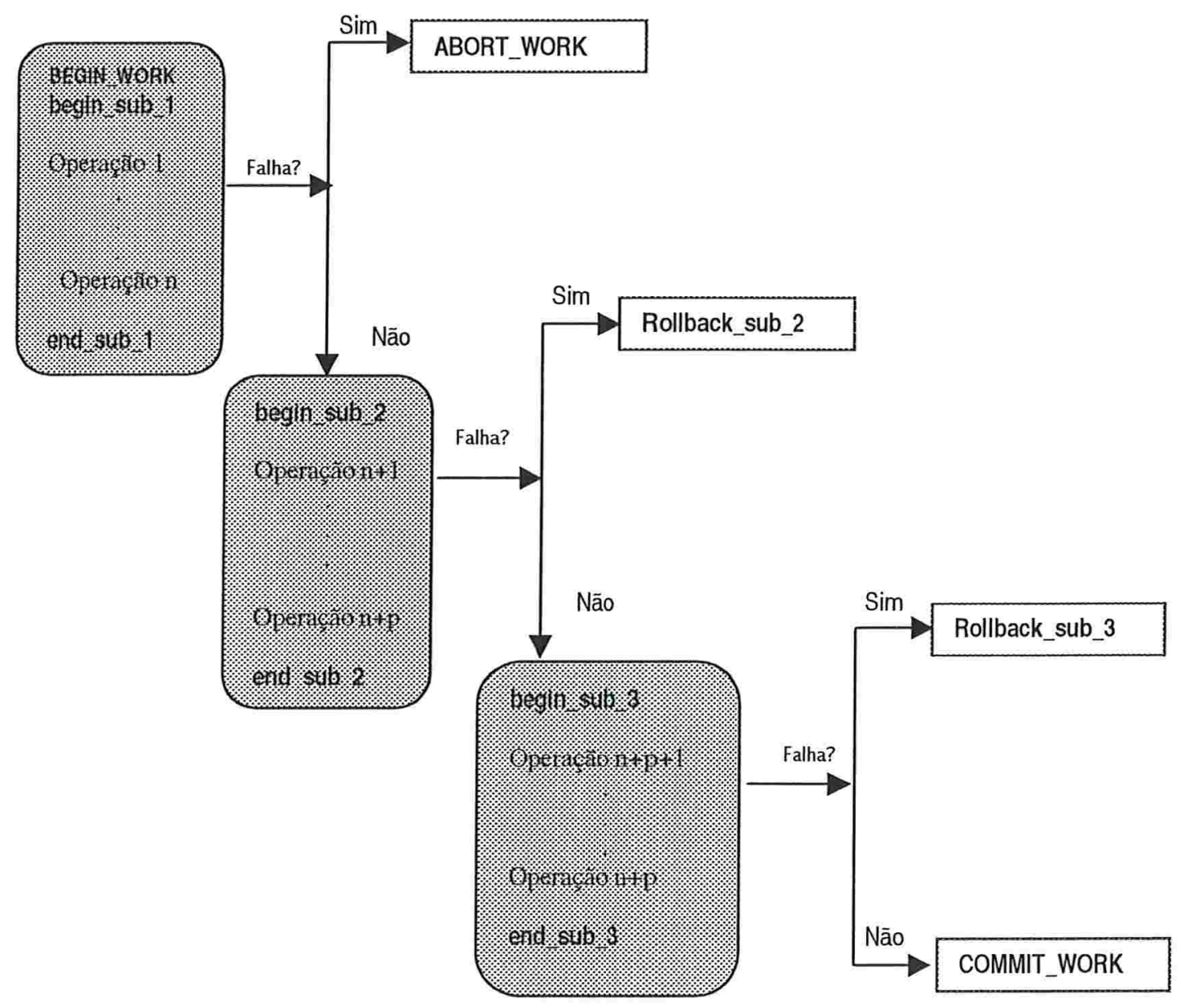

Figura 4.3.1 - ESTRUTURA DE UMA TRANSAÇão ENCADEADA

Na ilustração acima, a transação encadeada é composta por três transações (sub_1, sub_2 e sub_3). Note que as instruções de início e fim (begin_work e commit/abort_work) 
aparecem apenas uma vez durante toda a execução da transação encadeada e são elas que realmente garantem a execução da transação como um todo. Percebe-se também que cada vez que uma transação termina, ela ou é confirmada ou é desfeita, mas apenas a transação que está ativa no momento. Como já mencionado, uma vez que uma transação for confirmada ela não mais poderá ser desfeita. Assim, se houver alguma falha numa transação seguinte a uma que já foi confirmada, apenas a transação que falhou será desfeita e uma nova transação deverá ser iniciada (transação compensatória) para dar continuidade à execução da transação encadeada.

As vantagens deste modelo são a modularidade das transações e o mecanismo de tolerância a falhas permite um menor esforço no caso de recuperação, já que o modelo restabelece o estado até a confirmação (commit) mais recente, sendo necessário desfazer/refazer apenas a transação que estava ativa no momento da falha. 


\subsubsection{Analogia do Modelo de Transações Encadeadas com Transações Web}

Da mesma forma que a seção 4.2.2 apresentou as semelhanças entre modelo de transações aninhadas e o de transações Web, esta faz uma analogia com o modelo de transações encadeadas. A figura abaixo ilustra este caso.

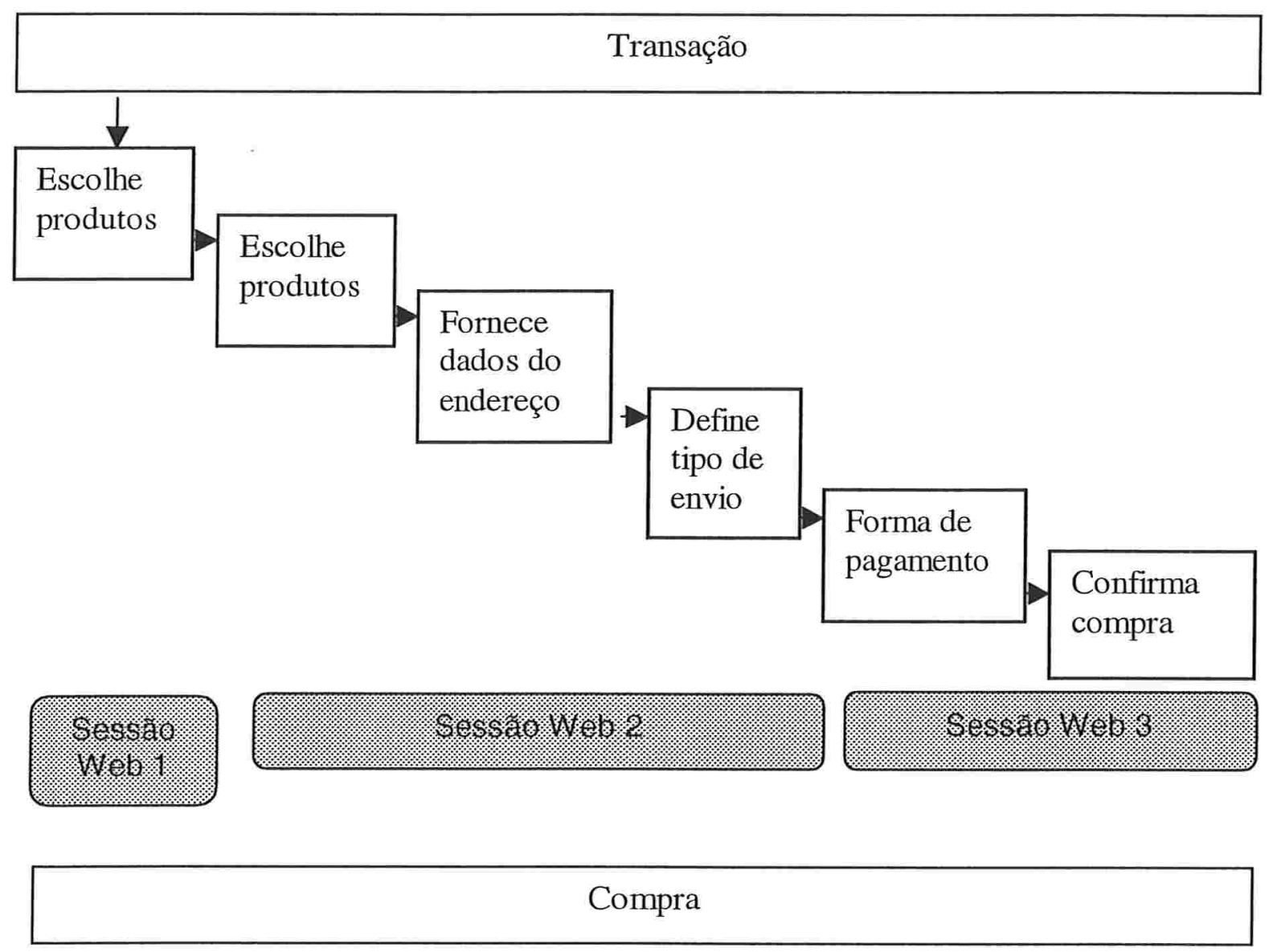

Figura 4.3.2 - TRansaÇão Web Como uma Transação Encadeada

Também aqui a transação de compra na Web é dividida em três transações (ou subtransações) efetuadas em sessões Web diferentes. Assim, quando a uma transação executa e é confirmada, ela não pode mais ser desfeita. Por exemplo, uma vez que os produtos foram selecionados e confirmados, se a transação de preenchimento de dados pessoais falhar, apenas ela será desfeita e uma outra será iniciada para substituí-la, não sendo mais necessário escolher os itens a serem comprados. O mesmo raciocínio se estende por toda a transação Web como uma transação encadeada. 
Portanto, o modelo de transações encadeadas também pode ser utilizado em aplicações que implementem transações Web.

\subsection{Comparação dos Modelos de Transações}

No quadro 4.4 é mostrado um resumo das principais características dos modelos de transações discutidos acima.

\begin{tabular}{|l|c|c|c|}
\hline & Slanas & Aninhadas & Encadeadas \\
\hline Suporte a propriedades ACID & Sim & $\begin{array}{l}\text { Problemas com a } \\
\text { propriedade Durabilidade }\end{array}$ & Sim \\
\hline Divisão do trabalho em subtransações & Não & Sim & Sim \\
\hline $\begin{array}{l}\text { Possibilidade de desfazer/refazer } \\
\text { subtransações }\end{array}$ & Não & Sim & $\begin{array}{l}\text { Somente a } \\
\text { subtransação ativa }\end{array}$ \\
\hline
\end{tabular}

QUADRO 4.4 - QUADRo COMPARATIVO DOS MODELOS DE TRANSAÇÕES

\subsection{Considerações Finais}

Este capítulo apresentou as principais limitações do modelo tradicional de transações quando se tenta aplica-lo às transações Web.

Em seguida, foram abordados dois modelos de transações, entre os vários existentes, que conceitualmente possuem características similares às encontradas no modelo de transações Web.

Mostrou-se também uma pequena analogia dos modelos de transações aninhadas e encadeadas com transações Web.

O objetivo desse capítulo é mostrar a possibilidade de estender o modelo tradicional de transações planas para modelos mais elaborados e que se assemelham mais com transações Web.

No próximo capítulo, serão mostrados os principais modelos de soluções para implementar transações Web. 


\section{Capítulo 5}

\section{Modelos de Soluções Implementáveis para Transações Web}

Este capítulo descreve as principais tecnologias para implementar transações Web. A seção 5.1 mostra as arquiteturas tradicionais de implementação. A 5.2 descreve o ambiente dos servidores de aplicação, que compõem uma arquitetura para aplicações mais complexas e robustas. Nesta mesma seção, serão mostrados os sistemas de componentes utilizados por estes servidores. A seção 5.3 fala sobre as principais tecnologias para o processamento de transações, tendo como objetivo conhecer os recursos existentes que podem ser utilizados para implementar transações Web.

\subsection{Arquiteturas Tradicionais}

A seguir, mostraremos os modelos de arquitetura de integração Web Bancos de Dados, particularmente, no que diz respeito ao gerenciamento de transações.

\subsubsection{Common Gateway Interface}

O início da programação na Internet se deu por meio de CGI (Common Gateway Interface) [NCSA97], que é uma interface padrão para aplicações externas se comunicarem com os servidores Web. A versão corrente é a 1.1.

A figura 5.1.1 mostra a arquitetura CGI.

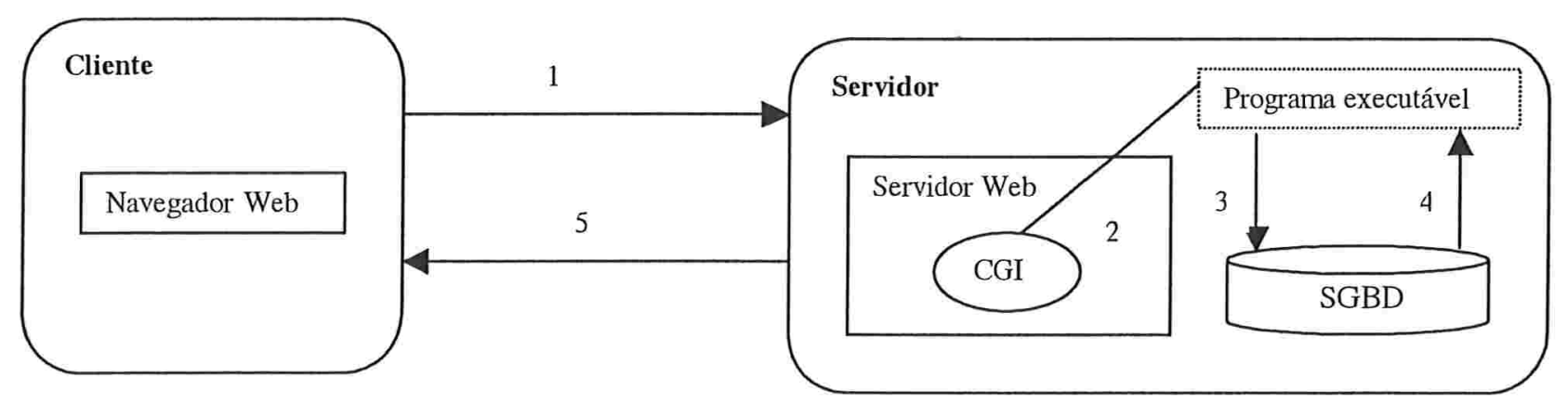

Figura 5.1.1 - ARQUITETURA CGI 
O funcionamento da arquitetura é mostrado a seguir:

1. O cliente Web solicita ao servidor Web a execução de uma aplicação externa, que neste caso é um programa executável na plataforma do servidor Web.

2. O servidor Web dispara um processo para execução do programa através da interface padrão CGI, enviando os dados recebidos do cliente Web de acordo com a implementação do servidor Web para a interface CGI.

3. O programa recebe os dados passados pelo servidor Web via interface CGI, decodifica-os, formula o comando SQL e abre uma conexão com o Banco de Dados para sua execução.

4. O SGBD retorna os dados e a conexão é finalizada. O programa executável trata os dados recebidos e os repassa ao servidor Web via interface CGI, num formato que o cliente Web entenda, como por exemplo, no formato HTML. O processo iniciado pelo servidor Web para execução do programa é finalizado neste momento.

5. O servidor Web retorna os dados repassados pelo programa ao cliente Web.

Uma das principais vantagens do CGI está na liberdade de escolha da linguagem de programação usada para implementar os gateways, assim como no Banco de Dados a ser utilizado. Uma outra facilidade é o uso de linguagens para implementar o acesso ao banco, como por exemplo, SQL, onde os comandos são inseridos em códigos de linguagens como $\mathrm{C}, \mathrm{C}++$ e Perl. Na verdade, usa-se a linguagem de acesso ao Banco de Dados suportada pelo SGBD que faz parte da aplicação.

Existem dois principais problemas essencialmente associados ao uso do CGI [EKR97]:

- O servidor Web pode ficar sobrecarregado, já que a solicitação de um programa CGI inicia um novo processo no servidor, e,

- O gerenciamento de transações é ineficiente, devido à natureza "sem estado" do protocolo HTTP, o que já foi amplamente discutido nos capítulos anteriores.

Na prática, é possível usar programas CGI em aplicações que manipulem recursos atômicos: o usuário seleciona uma URL que chama um executável CGI no servidor Web. Este então executa a ação e retorna a resposta ao pedido do cliente para o navegador depois que a ação foi confirmada. Num ambiente livre de falhas, este mecanismo funciona bem com ações atômicas. Porém, na presença de falhas, é possível que a resposta seja perdida entre o servidor Web e o cliente. Se a transação confirma, a resposta ao cliente será enviada 
depois que a transação termina. Para algumas aplicações isso não é problema, como no caso de a resposta ser apenas a confirmação de que a operação foi executada; ainda assim, não é uma situação desejável, pois é importante que o usuário saiba se a transação terminou com sucesso ou não. Porém, se a resposta é algum tipo de informação necessária para uma transação on-line, como por exemplo, um cookie com dados de identificação para fazer um download de um arquivo onde houve um pagamento para obter tal acesso, a perda desse cookie irá deixar o usuário sem o seu dinheiro e sem o bem que foi comprado. Isso requer que o sistema execute procedimentos para verificar que o cookie realmente foi perdido, invalide-o e então providencie um outro para que o usuário não fique com o prejuízo.

Portanto, conclui-se que para aplicações mais complexas e robustas, o uso de programação CGI não é indicado devido ao fato de ele não possuir um ambiente transacional próprio.

\subsubsection{Hypertext Preprocessor - PHP}

PHP (Hypertext Preprocessor) é uma linguagem de script que é executada pelo servidor Web para criar páginas Web dinâmicas para sistemas de comércio eletrônico ou para qualquer outro tipo de aplicação. A versão atual é PHP4 [BS01].

Os comandos PHP são embutidos em documentos HTML com extensão “.php”. A sintaxe é similar à linguagem $\mathrm{C}$ ou $\mathrm{Perl}$.

A diferença entre um script CGI escrito em outras linguagens, como C ou $\mathrm{Perl}$, e o PHP, é que ao invés de escrever programas com comandos que formatem um documento HTML, escreve-se um arquivo HTML, onde comandos são embutidos para fazer algo, como por exemplo, mostrar o resultado de uma consulta SQL. O código PHP fica entre tags que especificam o início e o fim do código PHP a fim de que o servidor Web possa saber o que deve ser feito.

O módulo PHP4 roda como um módulo nativo dos principais servidores Web. O código PHP é executado no servidor Web, sendo enviado para o cliente apenas HTML puro. Desta maneira, é possível interagir com Bancos de Dados e aplicações existentes no servidor com a vantagem de não expor o código fonte para o cliente. Isso é útil quando o programa está lidando com senhas ou qualquer tipo de informação confidencial.

Quando o servidor Web recebe a solicitação para uma página “php", invoca o mecanismo do PHP que, por sua vez, invoca a linguagem de script para que seja executado o código PHP embutido na página “.php”. 
A arquitetura pode ser observada na figura 5.1.2.

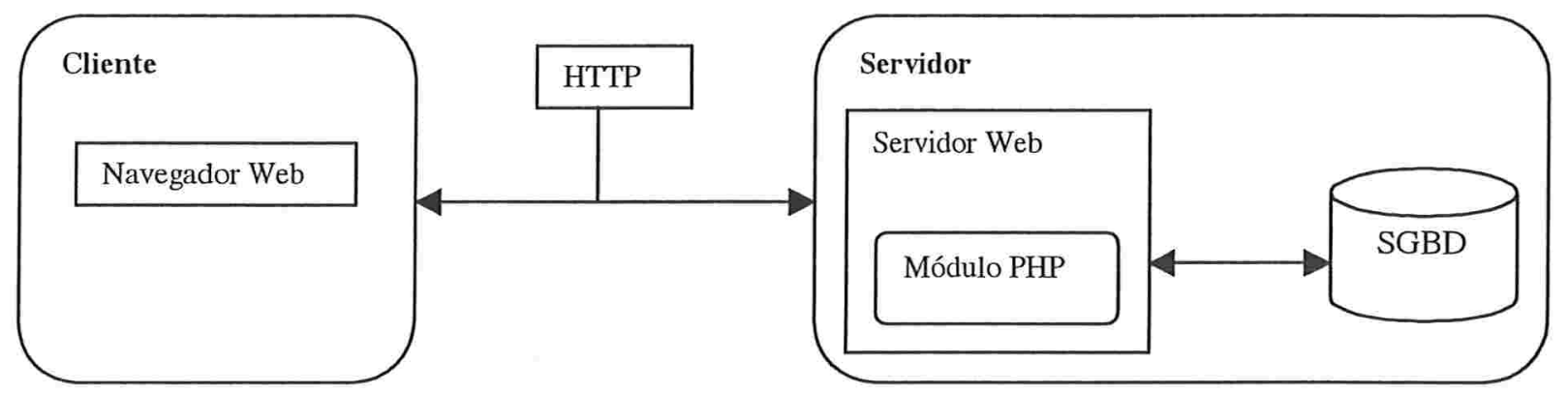

Figura 5.1.2 - ARQUTTETURA PHP

Entre as vantagens do PHP sobre outras linguagens de script, como ASP entre outras, tem-se o fato de ser uma linguagem de código aberto, não-proprietária e que trabalha com qualquer servidor Web disponível na rede.

A versão PHP4 implementa o suporte nativo para sessões, tornando mais fácil o seu gerenciamento. Quando um usuário acessa um site é atribuído a ele um identificador de sessão, chamado session id. Ele pode ser armazenado tanto num cookie quanto passado como parâmetro de uma URL. Esta última opção é mais confiável, pois alguns clientes podem desabilitar seus navegadores a aceitar cookies. Existe um conjunto de funções PHP como session_start(), session_destroy() entre outras, para gerenciar o comportamento de tais sessões.

Como o PHP não possui um ambiente transacional próprio, o suporte ao gerenciamento de sessões já é um avanço dessa nova versão da linguagem. Portanto, para implementar transações usando código PHP é preciso que o SGBD utilizado na aplicação possua o suporte a transações e através desse suporte é que é possível implementar transações em PHP.

\subsubsection{Active Server Pages - ASP}

ASP (Active Server Pages) é um ambiente para programação por scripts que fica localizado no servidor Web, usado para criar páginas dinâmicas, interativas e de alta performance. É o próprio servidor Web que transforma os scripts em HTML padrão, fazendo com que qualquer navegador seja capaz de acessar uma página que utiliza código ASP. A implementação pode ser feita usando VBScript ou JScript. Os arquivos ASP possuem extensão “.asp". 
ASP é mais robusto por não criar um processo no servidor para cada pedido do usuário, como acontece com o CGI. Usando ASP ao invés de CGI, um servidor pode atender a um grande número de pedidos de usuários de forma mais rápida e usando menos memória [Pay01].

ASP surgiu juntamente com o lançamento do servidor Web Internet Information Server (IIS) 3.0. Esta é uma solução Microsoft, que exige que o servidor rode um sistema operacional da Microsoft. Também só funciona com servidores Web da Microsoft (IIS, Personal Web Server, Peer Web Services) o que é uma grande limitação [Mic01b].

A figura 5.1.3 mostra a arquitetura ASP.

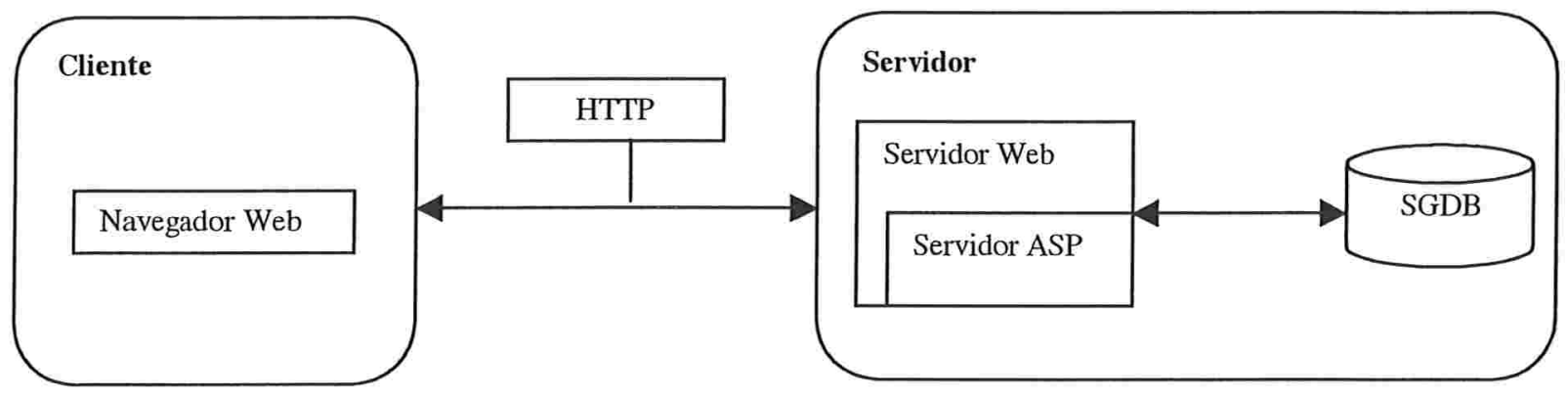

FIgURA 5.1.3 - ARQUTTETURA ASP

Uma grande contribuição de ASP é a possibilidade de implementar sessões, podendo, assim, manter as informações de um usuário no servidor até que ele encerre a sessão.

Quando alguém visita uma página de um site desenvolvido em ASP, uma sessão é criada e imediatamente pode diferenciar aquele usuário de todos os outros que estão no site. Os dados da sessão são armazenados no servidor e não em cookies. Nenhum usuário pode examinar um cookie e determinar o conteúdo de qualquer variável de sessão. Um cookie é usado apenas para coordenar o identificador da sessão do usuário.

É possível implementar transações em ASP. Para isso, ASP trabalha juntamente com MTS (Microsoft Transaction Server), que será discutido na seção 5.3.1. É ele que mantém os estados dos objetos e confirma ou desfaz uma transação.

Para iniciar uma transação usa-se a tag <\%@ TRANSACTION $=$ valor $\frac{\circ}{\circ}$, onde a variável "valor" é um dos seguintes atributos: 


\begin{tabular}{|l|l|}
\hline \multicolumn{1}{|c|}{ ATRIBUTOS } & \multicolumn{1}{c|}{ DESCRIÇÃO } \\
\hline Requires_New & O script inicia uma nova transação. \\
\hline Required & $\begin{array}{l}\text { O script utiliza uma transação e participa de qualquer transação } \\
\text { aberta. Se não existe nenhuma aberta, o script } \text { cria uma. }\end{array}$ \\
\hline Supported & $\begin{array}{l}\text { O script utiliza qualquer transação aberta, mas não inicia uma nova } \\
\text { caso não haja nenhuma correntemente aberta. }\end{array}$ \\
\hline Not_Supported & O script nem participa nem inicia uma transação. \\
\hline
\end{tabular}

TABELA 5.1.3 - ATRIBUTOS DE UMA TRANSAÇÃo EM ASP

Tipicamente, cada página ASP possui sua própria transação, mas é possível continuar transações através de páginas usando os métodos Server.Transfer e Server. Execute. Se a página que está chamando é transacional, e a página corrente usa Transaction=Required ou Transaction=Supported, então a página corrente irá continuar a transação existente, o que torna possível aplicações mais complexas [Pay01].

Para confirmar uma transação, usa-se o método objectContext. SetComplete para dizer ao MTS que este processo está pronto para ser confirmado, como mostra o código abaixo.

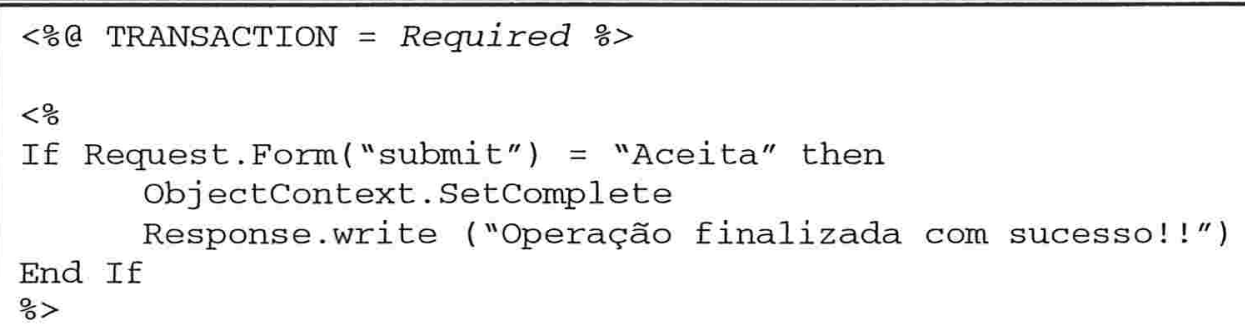

EXEMPLo 5.1.3.A - EXEMPLO do MÉTODO SETCOMPLETE EM ASP

Para desfazer a transação, usa-se o método objectContext. SetAbort, que diz ao MTS que houve um erro e é preciso voltar ao estado anterior. Este método desfaz as mudanças efetuadas sobre quaisquer dados. O código a seguir ilustra este método:

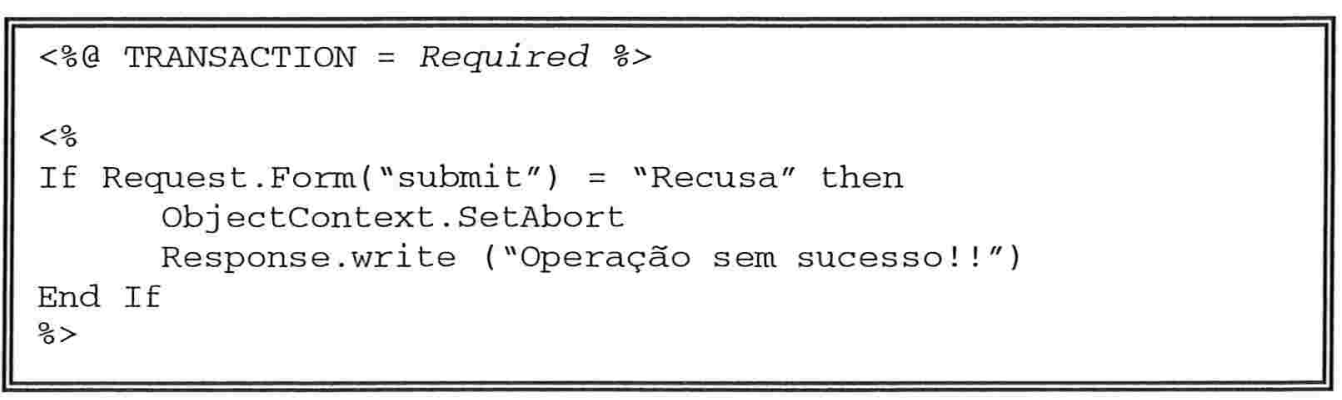

EXEMPLO 5.1.3.B - EXEMPLO DO MÉTODO SETABORT EM ASP 
Um script não pode determinar quando uma transação confirma ou aborta, mas ele pode escrever eventos que são chamados quando uma transação termina com sucesso ou não. Pode-se utilizar os eventos OnTransactionCommit e OnTransactionAbort para retornar diferentes respostas para o usuário, como mostra o código a seguir.

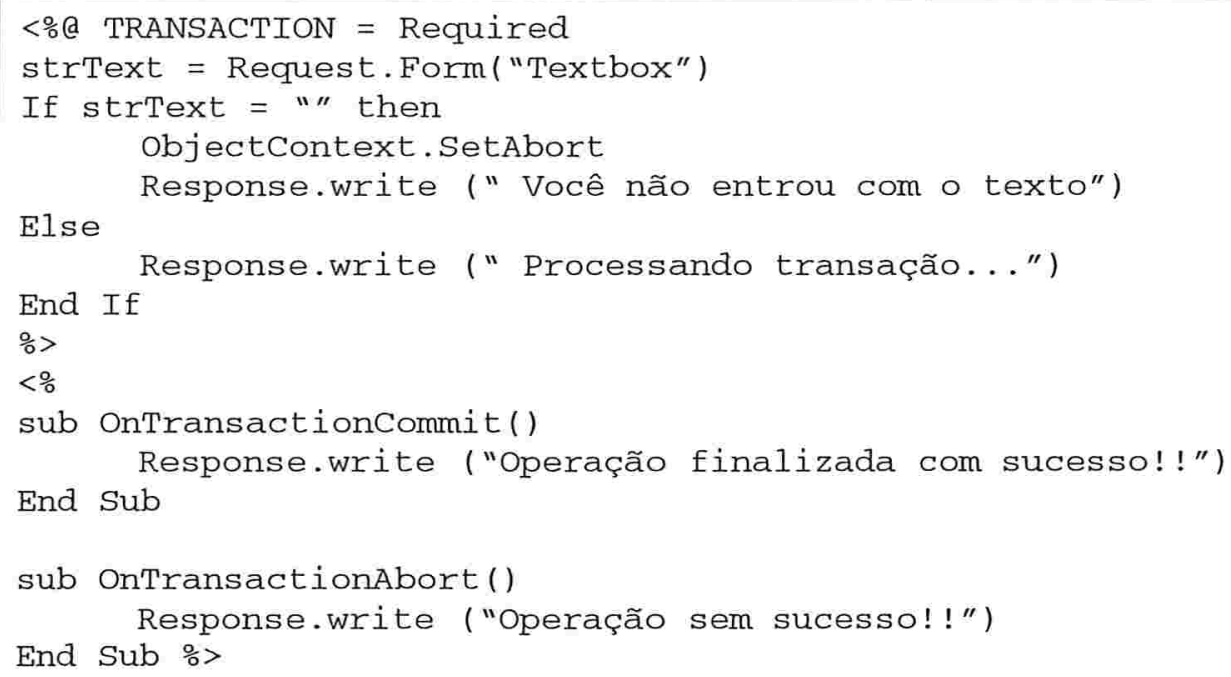

\section{Exemplo 5.1.3.C-EXEMPLO DOS EVENTOS ONTRANSACTIONCOMMIT E ONTRANSACTIONABORT}

Uma transação pode ser abortada se, dado um timeout, este for excedido antes que a transação complete. Além desta forma, a única maneira de a aplicação saber que uma transação deve ser abortada é através do método ObjectContext. SetAbort. Se este método não for invocado explicitamente no código, o MTS irá sempre considerar que a transação terminou com sucesso e portanto, deve ser confirmada. Daí o código OnTransactionCommit é executado. Por outro lado, assim que o método SetAbort é encontrado no código, a execução do script pára, o processo volta e o OnTransctionAbort é executado. Se no código acima o método SetAbort não fosse explicitamente chamado, esta transação nunca iria abortar e o código OnTransactionAbort nunca seria executado.

Conclui-se, então, que a tecnologia ASP possui um bom suporte à transações Web, apesar de utilizar o modelo de transações planas.

\subsubsection{Servlets e Java Server Pages}

A tecnologia servlets é a alternativa Java ao CGI. Servlets [Sun01] são componentes que estendem as funcionalidades de servidores orientados a requisição/resposta, como por 
exemplo, os servidores Web. Entre outras tarefas, são usados para: tratar dados de formulários HTML, reenviar requisiçoes para outros serviłores e servlets, o que é útil para balancear as tarefas distribuídas.

Assim como o CGI, o servidor Web recebe um pedido do cliente que carrega um servlet. Ele então processa o requerimento do usuário e gera uma página HTML que é retornada ao cliente.

A figura abaixo mostra a arquitetura e o ciclo de vida dos servlets. Um servlet é carregado num servidor Web apenas uma única vez, quando o usuário o invoca, através do método init (1). Depois disso, ele pode atender a vários pedidos (2). Cada pedido do cliente gera uma chamada service. Esses pedidos podem ser concorrentes; isso permite que os servlets coordenem atividades entre vários clientes. Os pedidos são processados até que o servlet seja explicitamente fechado pelo servidor Web, através do método destroy (3).

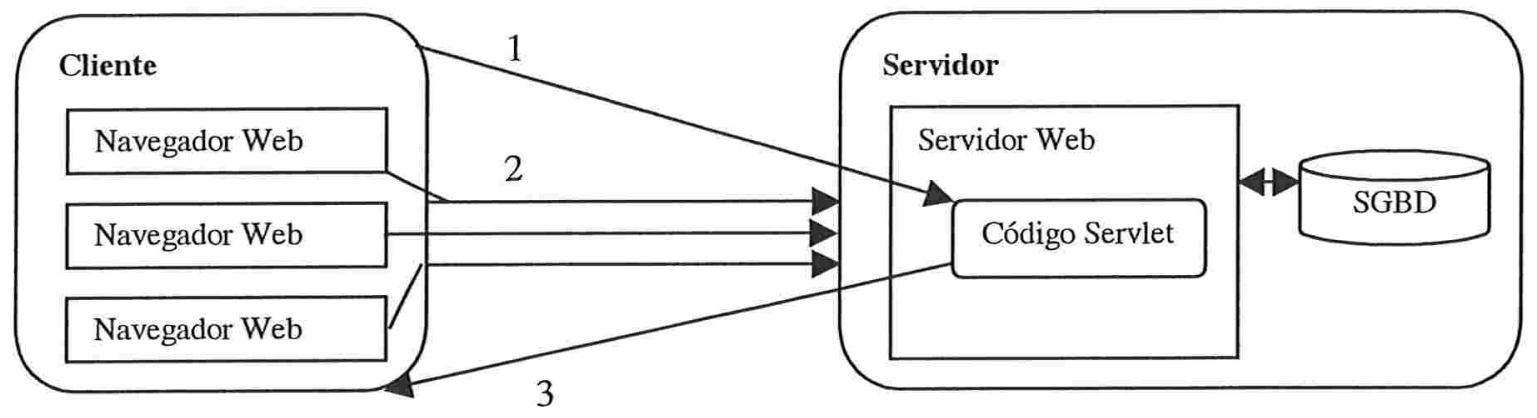

Figura 5.1.4 - ARQUITETURA SERVLETS

Servlets provêem uma solução própria para trabalhar com sessões. É através do uso da API HttpSession, uma interface de alto nível construída sobre cookies. Caso o navegador do cliente esteja desabilitado para manipular cookies, isso é feito através de passagem por parâmetros na URL correspondente. No entanto, isso é transparente ao desenvolvedor de aplicações usando servlets.

As sessões podem ser gerenciadas da seguinte maneira:

- Os objetos HttpSession residem no servidor e representam as sessões. Eles são automaticamente associados à solicitação de um cliente.

- A procura por um objeto HttpSession associado ao pedido de um cliente é feita através do método getSession da classe HttpServletRequest. 
- A procura por informação associada a uma sessão pode ser implementada com o método getValue, que lê informações ligadas a uma sessão.

- Armazenar informações numa sessão é possível com o método putValue.

- Os métodos getId, isNew, getCriationTime, getLastAcessedTime, getMaxInactiveInterval são outros exemplos de métodos para manipular sessões em servlets.

Para implementar transações usando servlets é necessário usar a API JTA (Java Transaction API) implementada pela plataforma J2EE (plataforma Java para o desenvolvimento de aplicações multi-camadas, da qual também fazem parte os servlets). Juntamente, JTA e JTS (Java Transaction Service) formam a base para o suporte transacional da plataforma J2EE. JTS é uma API de baixo nível para gerenciamento de transações que basicamente mapeia Java para o OMG Object Transaction Service (OTS). O JTS será abordado na seção 5.3.3 e o OTS na seção 5.3.4.

Correntemente a plataforma J2EE suporta apenas o modelo de transações planas [Sun01c]. JTA permite que aplicações acessem o gerenciamento de transações de maneira independente de uma implementação específica. JTA especifica as interfaces padrão entre um gerenciador de transação e as partes envolvidas num sistema de transações distribuído: a aplicação transacional, o servidor J2EE e o gerenciador que controla os acessos aos recursos compartilhados pelas transações. É através das interfaces JTA que transações podem ser implementadas usando servlets [Sun01c].

Um componente de aplicação usa a interface JTA UserTransaction para demarcar os limites da transação. O código abaixo mostra como uma transação pode ser implementada usando JTA.

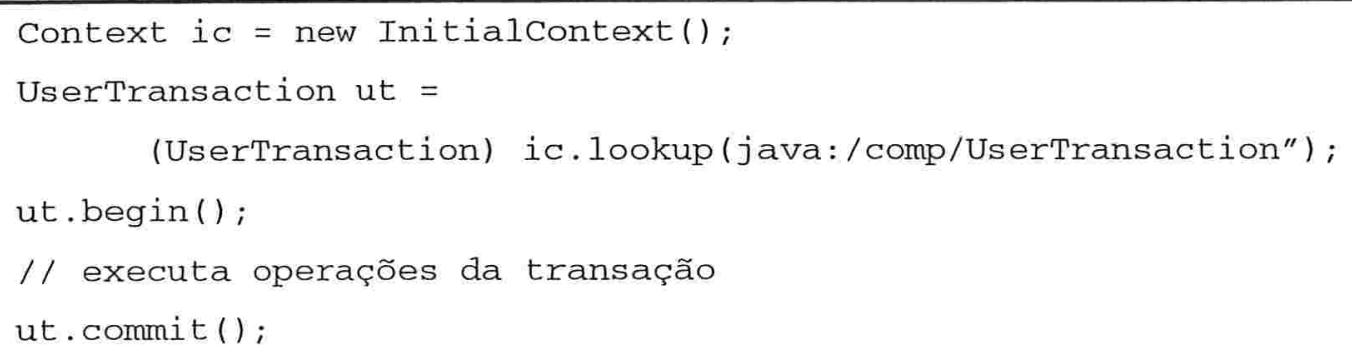


JSP é uma extensão da tecnologia de servlets [Sun01b] desenvolvida para o controle do conteúdo e da apresentação de páginas Web. JSP são pequenos programas especificados numa página Web, com extensão “.jsp”, que rodam no servidor Web. Estas páginas são compiladas dinamicamente dentro de servlets, fazem o processamento e depois devolvem ao cliente uma página HTML com os resultados do seu pedido. Páginas JSP também podem chamar outros componentes Java, como JavaBeans e Enterprise JavaBeans(EJB), que será explicado na seção 5.2.2.

JSP é comparável à tecnologia ASP da Microsoft. Enquanto JSP chama um programa Java que é executado pelo servidor Web, uma página ASP contém um script que é interpretado por um interpretador de scripts (tais como VBScript ou JScript) antes da página ser enviada ao usuário.

Como uma extensão de servlets, a implementação de transações em JSP pode ser feita também através das interfaces JTA.

Portanto, estas são as principais arquiteturas utilizadas no desenvolvimento de aplicações Web Banco de Dados de pequeno ou médio porte. A seguir, veremos um quadro comparativo destas arquiteturas e em seguida, veremos a arquitetura de servidores de aplicação, geralmente utilizada para implementar sistemas de maior complexidade.

\subsubsection{Comparação das Arquiteturas}

Na figura 5.1.5 é mostrado um quadro comparativo resumindo os principais aspectos discutidos nas quatro arquiteturas descritas acima.

\begin{tabular}{|l|l|c|c|c|}
\hline \multicolumn{1}{|c|}{ Arquiteturas } & CGI & PHP & ASP & Servlets \\
\hline $\begin{array}{l}\text { Suppectos } \\
\text { a sessões }\end{array}$ & $\begin{array}{l}\text { Não, deve ser } \\
\text { implementado através } \\
\text { de cookies ou campos } \\
\text { ocultos }\end{array}$ & $\begin{array}{c}\text { Sim, na versão } \\
4.0\end{array}$ & $\begin{array}{c}\text { Sim, através do } \\
\text { objeto Session }\end{array}$ & $\begin{array}{c}\text { Sim através da } \\
\text { interface } \\
\text { Http̧session }\end{array}$ \\
\hline $\begin{array}{l}\text { Suporte nativo } \\
\text { a transações }\end{array}$ & Não & Não & $\begin{array}{l}\text { Sim, juntamente } \\
\text { com MTS }\end{array}$ & $\begin{array}{c}\text { Sim, juntamente } \\
\text { com JTA }\end{array}$ \\
\hline $\begin{array}{l}\text { Linguagem de } \\
\text { programação }\end{array}$ & $\begin{array}{l}\text { Pode ser utilizada } \\
\text { qualquer linguagem }\end{array}$ & PHP & VBScript ou Jscript & Java \\
\hline
\end{tabular}

QUADro 5.1.5 - QuADRo COMPARATIVO DAS ARQUITETURAS TRADICIONAIS 


\subsection{Servidores de Aplicação}

Juntamente com o aumento da demanda por aplicações Internet, principalmente de comércio eletrônico, tem aumentado a complexidade de tais sistemas, pois aspectos como segurança, gerenciamento, escalabilidade, confiabilidade e interoperabilidade são requisitos indispensáveis a tais tipos de aplicação. Porém, é difícil ter sob controle todos estes aspectos sem uma ferramenta que auxilie na tarefa de desenvolver e gerenciar tais aplicações.

A maioria dos servidores Web foi projetada apenas para disponibilizar informações requisitadas pelo cliente, muitas vezes em sistemas de Banco de Dados. Porém, eles não possuem nenhuma funcionalidade que ajude aos desenvolvedores de aplicações Web a gerenciar e controlar os aspectos listados acima.

Em resposta a essas necessidades, os servidores de aplicação têm surgido como um dos principais componentes da infra-estrutura Web que fornecem suporte às aplicações desenvolvidas com a finalidade de disponibilizá-las na Internet.

Servidores de aplicação são softwares que ajudam no desenvolvimento e manutenção de aplicações complexas na Web [Ric98, Ben99b, Cop99, Fei00, Lea00]. Eles compõem uma camada intermediária, tornando o modelo Web cliente/servidor numa arquitetura de 3 camadas, como mostra a figura 5.2. Os servidores de aplicação, Web e Banco de Dados não necessariamente estão localizados na mesma máquina, pelo contrário, normalmente ficam separados. O fato de na figura estarem todos juntos é devido ao fato de estarem todos no lado servidor, já que a arquitetura é dividida no lado cliente e no lado servidor.

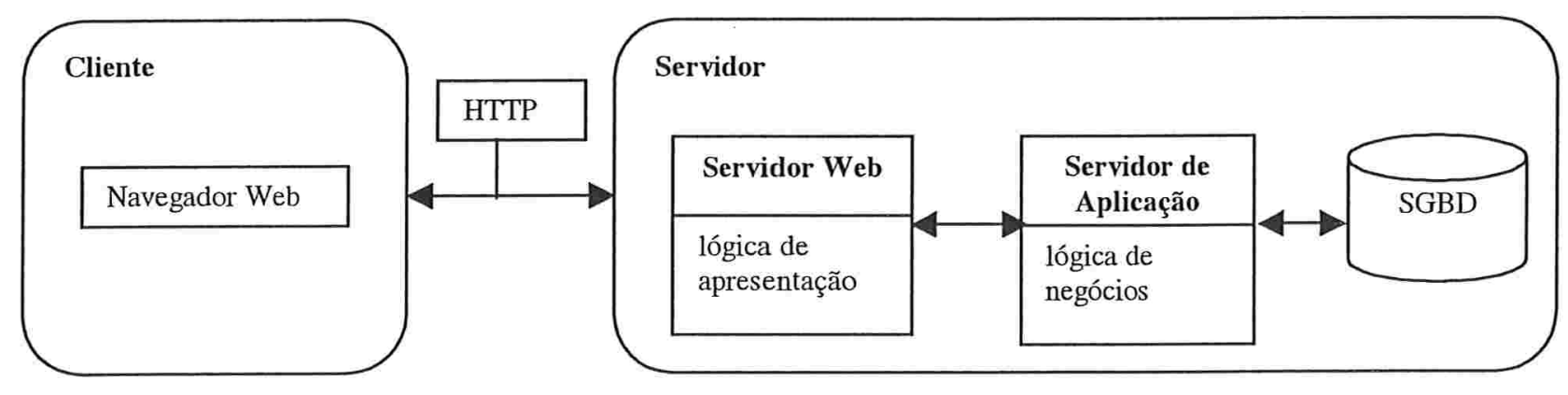

Figura 5.2 - ARQuiteTURA DE SERVIDORES DE APLICAÇ̃̃o

Dessa forma, é possível para os desenvolvedores separar a lógica de apresentação (interface com o usuário) da lógica de negócios (código para acessar, manipular e validar os dados e executar processos) e dos dados propriamente ditos. Esta é a principal contribuição 
dos servidores de aplicação, pois é possível aumentar a produtividade, tornando o desenvolvimento do sistema mais modular e mais fácil de ser gerenciado, já que a lógica de negócios fica armazenada na camada dos servidores de aplicação, portanto, separada da lógica de apresentação.

Os fabricantes de tais produtos têm disponibilizado pacotes contendo ferramentas de ambiente de desenvolvimento integrado com os servidores de aplicação, o que permite a construção de sistemas mais rapidamente.

Os servidores de aplicação interagem com o servidor Web e com o servidor de Banco de Dados. Eles são mais do que ferramentas para conectar Banco de Dados e páginas Web. Entre as suas principais funções, podemos citar:

- Balanceamento da carga de trabalho - um grupo de servidores de aplicação trabalhando em conjunto. À medida que novos pedidos dos clientes vão chegando, são encaminhados para servidores menos ocupados. Isso faz com que a aplicação se torne mais escalável, ou seja, permite que mais clientes acessem o sistema sem que isso signifique queda de desempenho, sendo necessário apenas adicionar máquinas no conjunto já existente de servidores.

- Gerenciamento do estado e da sessão do usuário - esse gerenciamento é feito mantendo uma sessão aberta (persistente) entre o servidor e o cliente até que este saia do sistema, diferente do que acontece normalmente, onde a cada novo pedido do usuário uma sessão é aberta e depois de enviada a resposta, esta conexão é fechada. A persistência dos dados do usuário facilita o desenvolvimento de aplicações mais complexas porque elimina a necessidade de fazer esse tratamento codificando explicitamente o uso de cookies e campos ocultos para passar o estado da sessão pelas páginas visitadas pelo usuário.

- Gerenciamento de transações - no ambiente de servidores de aplicação, os servidores de transações são os responsáveis pelo gerenciamento e execução das transações. Geralmente, isso é implementado via tecnologia de componentes, como por exemplo, componentes EJB (Enterprise JavaBeans), CORBA e COM+. Essas tecnologias serão explicadas na próxima seção.

- Gerenciamento de conexões com o Banco de Dados - os servidores de aplicação não mantêm uma conexão aberta com o Banco de Dados para cada 
usuário individualmente. Ao invés disso, ele mantém um pool de conexões que são compartilhadas entre todos os componentes dos servidores. Se um usuário deseja atualizar um conjunto de dados, o componente solicita ao servidor uma conexão do pool. Se existe alguma disponível, ela é atribuída à solicitação do usuário. Todas as atualizações são feitas e o componente sinaliza quando tudo terminou com sucesso. Quando uma transação termina, a conexão é imediatamente liberada.

- Segurança - os mecanismos de segurança incluem controle de acesso e autenticação de usuários, e suporte para trabalhar com protocolos como SSL e Secure HTTP (HTTPS).

- Tolerância a falhas - no caso de falhas, os pedidos dos clientes podem ser roteados para um outro servidor de forma transparente ao usuário.

- Ambiente de desenvolvimento e execução - ambientes de desenvolvimento e execução fazem parte da plataforma dos servidores de aplicação, visando aumentar a produtividade dos desenvolvedores de aplicações Web ao trabalharem num ambiente integrado e desenvolvido especialmente para este propósito.

- Suporte a componentes de integração - suporte a vários padrões da indústria, tais como JDBC, ODBC, CORBA, COM, EJB, Servlets, o que facilita o desenvolvimento de aplicações Web.

Pode-se observar, portanto, que estes servidores cuidam da maioria dos grandes problemas encontrados durante o desenvolvimento de uma aplicação Web, deixando o desenvolvedor da aplicação livre para ocupar-se apenas da lógica de apresentação e da lógica de negócios. Para que seja possível essa separação, a tecnologia de servidores de aplicação trabalha com componentes e é o que será visto a seguir.

Atualmente, entre os produtos principais podemos citar: WebSphere, da IBM [Ibm01a], ColdFusion, da Macromedia [Mac01], .Net, da Microsoft [Mic01d].

\subsubsection{Sistemas de Componentes}

Uma das principais necessidades no desenvolvimento de sistemas voltados para a Internet é manter a lógica de negócios separada da apresentação das páginas a fim de que as alterações que surgem durante a manutenção de tais sistemas possam ser efetuadas com 
maior rapidez e agilidade. Uma maneira de ter sistemas modularizados que facilite manter a lógica de apresentação separada da lógica de negócios é usando componentes.

Componentes são unidades computacionais com um fim específico e que podem ser usadas para compor várias aplicações. De um modo geral, essas unidades encapsulam suas implementações e oferecem um determinado serviço através de um protocolo (interface) bem definido.

Para servir de infra-estrutura para o desenvolvimento baseado em componentes, existe na indústria de software especificações e implementações de sistemas de componentes. Tais sistemas definem padrões de comunicação e ligação entre seus componentes. A adoção de padrões é a base para oferecer um alto grau de interoperabilidade entre componentes.

Um sistema de componentes define também alguns serviços de apoio tanto ao desenvolvimento de componentes propriamente ditos, quanto das aplicações, tais como serviços de nomes, transações, segurança e persistência.

Entre as tecnologias disponíveis, três sistemas de componentes merecem destaque devido à sua disseminação nas comunidades da indústria (os servidores de aplicação possuem suporte a um ou mais desses sistemas) e da academia. São eles: Enterprise JavaBeans, COM+ (Component Object Model) e CORBA.

Mesmo adotando abordagens diferentes, esses três sistemas apresentam várias características semelhantes. Uma delas é a dissociação entre a interface e a implementação de um componente: para uma mesma interface podem existir diversas implementações (componentes) diferentes, da mesma forma que um componente pode implementar várias interfaces. De acordo com essa separação, componentes só podem ser acessados através das operações definidas em suas interfaces, garantindo o encapsulamento de suas implementações. A separação entre interface e implementação é a base para que esses sistemas possam integrar componentes que estão executando em processos, estações ou plataformas diferentes, ou até mesmo que foram desenvolvidos em linguagens diferentes.

Entretanto, há uma característica que diferencia profundamente Enterprise JavaBeans dos outros dois sistemas. Enquanto COM+ e CORBA procuram integrar componentes desenvolvidos em diferentes linguagens de programação, Enterprise JavaBeans só contempla componentes desenvolvidos em Java. De certa forma, isto simplifica a arquitetura desse sistema. Nas seções a seguir descreveremos estes sistemas, apresentando suas características mais relevantes no contexto deste trabalho. 


\subsubsection{Enterprise JavaBeans}

Enterprise JavaBeans (EJB) é uma arquitetura baseada em componentes voltada para o desenvolvimento de aplicações distribuídas, orientadas a objeto e programadas em Java. A tecnologia EJB faz parte da plataforma da Sun Microsystems chamada J2EE (Java 2 Enterprise Edition), que é um ambiente Java robusto para o suporte a aplicações com rigorosos requisitos de escalabilidade, distribuição e disponibilidade [Pro00, CY01, PA01, Sun01d].

A tecnologia EJB oferece suporte ao desenvolvimento de aplicações baseadas numa arquitetura de objetos distribuídos em várias camadas (multitier). A lógica da aplicação é particionada em um ou mais objetos que são disponibilizados em um servidor de aplicação. Um enterprise bean implementa a lógica do negócio da qual uma aplicação depende. Instâncias de enterprise bean são chamadas objetos bean.

Combinando tecnologias tradicionais de processamento de transações on-line com tecnologias de objetos distribuídos, EJB rodando sobre servidores de aplicação oferecem um ambiente de execução robusto com graus elevados de escalabilidade e desempenho, especialmente adequado para aplicações Internet.

A infra-estrutura de EJB define uma série de interfaces padronizadas para que uma aplicação possa ter acesso a serviços de chamadas remotas de métodos (RMI), de nomes e diretórios (JNDI), de criação dinâmica de páginas HTML (servlets e JSP), de mensagens (JMS), de transações (JTS) e de acesso a Banco de Dados (JDBC).

A arquitetura EJB é mostrada na figura abaixo:

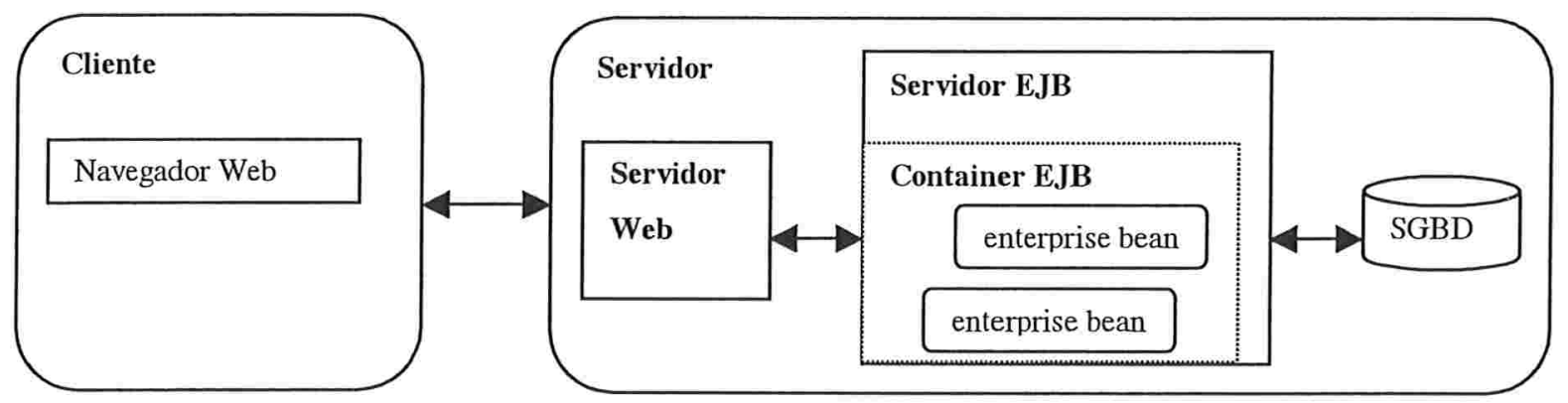

Figura 5.2.1.1 - ARQUitetura de ENTERPRISE JAVABEANS

Os enterprise beans residem num Container EJB, que roda num servidor EJB. Essas três partes - os beans, o Container, e o servidor EJB - compõem a camada do meio numa arquitetura 3-camadas [HG00]. 
A especificação EJB permite qualquer tipo de cliente, podendo portanto ser utilizado diversos tipos de protocolos na comunicação dos servidores EJB com os clientes além de permitir que estes sejam escritos em qualquer linguagem de programação que não seja Java.

O servidor EJB é uma coleção de serviços com o objetivo de prover um ambiente para uma instalação EJB. Esses serviços incluem gerenciamento de transações e objetos distribuídos, invocação destes objetos e serviços de sistemas de baixo nível. É também o servidor EJB que gerencia a população de beans residentes na memória principal.

O Container EJB é onde ficam "guardados" os componentes EJB, isto é, onde "moram" os beans. Ele fornece um ambiente transacional, escalável e seguro no qual os beans podem operar. É ele também que controla todo o ciclo de vida dos objetos EJB, incluindo a criação e a remoção, além de fazer o gerenciamento do seu estado. O Container é transparente para o cliente. É responsável pela implementação da interface EJB home e pela interface EJB remote.

Um cliente acessa um objeto bean através da interface home e interface remote. A interface home fornece métodos para a criação e remoção de objetos bean, além de métodos de consulta sobre os beans existentes, chamados "métodos localizadores". A interface remote reflete a funcionalidade de um bean, também chamada de "métodos de negócios", ou seja, as operações específicas da aplicação [Pro00].

Existem três tipos de componentes enterprise beans:

- Session beans - são objetos de curta duração que existem em nome de um único cliente e não representam qualquer dado compartilhado e/ou persistente num Banco de Dados. Um session bean pode ser:

- stateless - neste modelo o bean não mantém o estado entre as chamadas de métodos. Como consequiência, qualquer instância de um session bean pode ser usada por qualquer cliente. Como exemplo pode-se mencionar um catálogo de produtos de uma loja virtual que pode ser acessado por vários clientes.

o stateful - o bean mantém o estado entre as chamadas de métodos e as transações. Uma vez que um cliente obteve um específico session bean, ele deve usar esta instância por todo o tempo de duração da sessão. Por exemplo, uma cesta de compras pode ser implementada como um session bean stateful, já que cada cliente tem a permissão de acessar apenas sua própria cesta. 
- Entity beans - representam dados persistentes, usualmente armazenados num Banco de Dados. Um entity bean é transacional, permite acesso compartilhado de múltiplos clientes e pode ter longa duração. Por exemplo, as tabelas de um Banco de Dados relacional.

- Message-driven beans - são consumidores de mensagens assíncronas. Estes beans são chamados pelo Container como resultado da chegada de uma mensagem JMS (Java Message Service). Para um cliente, um message-driven bean é um consumidor de mensagem que implementa alguma lógica de negócios rodando no servidor.

O modelo de transações suportado no ambiente EJB é o modelo tradicional de transações planas. Portanto, este ambiente não suporta nenhum outro modelo de transações. Segundo [CY01], o motivo pelo qual essa limitação foi estabelecida é fazer com que a tecnologia EJB seja compatível com a grande maioria de sistemas de Banco de Dados, que utilizam o modelo de transações planas.

Existem trabalhos como [Pro00], que propõe uma extensão no modelo de transações EJB a fim de permitir que modelos mais complexos de transações sejam suportados.

Várias transações concorrentes podem ser executadas e cada uma delas é completamente isolada uma das outras. Transações não podem cooperar no nível de Banco de Dados ou no nível de objetos bean. Isso é causado pelo fato de que os SGBDs não possuem compartilhamento de recursos e no caso específico de objetos beans, a especificação do EJB diz que tais objetos não podem ser compartilhados entre transações, exceto os stateless session beans que não possuem identidade e portanto, não tomam conhecimento da transação em andamento.

As transações em EJB são completamente isoladas em termos de seus ciclos de vida e controle de fluxo. Uma transação não é capaz de mudar seu comportamento baseada no estado de uma outra transação. Por exemplo, não é possível abortar uma transação caso uma outra transação também aborte, como acontece no modelo de transações aninhadas.

O escopo de uma transação é definido pelo seu contexto, que é compartilhado pelos objetos beans que participam da transação. Basicamente, um cliente obtém o contexto de uma transação que é implicitamente transferido com pedido do cliente. O cliente pode iniciar uma transação usando o método begin ou terminar usando os métodos abort ou commit. Todos os métodos chamados entre o início e o fim de uma transação são 
associados ao seu contexto [Pro00]. A arquitetura EJB requer que o Container suporte a interface java.transaction. UserTransaction definida em Java Transactions API (JTA).

Transações em EJB podem ser divididas em duas categorias:

- gerenciadas pelo Bean - o enterprise bean é responsável pelo gerenciamento de todos os aspectos da transação. Isso inclui operações como criar o objeto transação, iniciar explicitamente uma transação, finalizar a transação, quer seja por confirmação ou por aborto.

- gerenciadas pelo Container - o Container EJB mantém o gerenciamento das transações. Ele executa a delimitação da transação baseado nos atributos listados na tabela 5.2.1.1, no deployment desciptor correspondente [PA01]. Estes atributos definem a responsabilidade do Container para gerenciar um pedido de um objeto bean quando um método é invocado via interfaces home ou remote. A responsabilidade do Container depende do valor do atributo da transação, como mostra a tabela a seguir.

\begin{tabular}{|l|l|}
\hline \multicolumn{1}{|c|}{ ATRIBUTOS } & \multicolumn{1}{c|}{ DESCRIÇão } \\
\hline Not_Supported & $\begin{array}{l}\text { Quando um cliente chama um método, a transação a qual este objeto } \\
\text { pertence, se existe alguma, é suspensa e reinicia depois da execução } \\
\text { do método. }\end{array}$ \\
\hline Required & $\begin{array}{l}\text { Se o cliente está num contexto transacional, o bean chamado torna-se } \\
\text { parte deste contexto. Se o cliente não possui nenhuma associação com } \\
\text { a transação, o Container inicia uma nova transação e executa o } \\
\text { pedido com esta transação. }\end{array}$ \\
\hline Supports & $\begin{array}{l}\text { Se o cliente está num contexto transacional, o bean chamado torna-se } \\
\text { parte deste contexto. Se o cliente não possui nenhuma associação com } \\
\text { a transação, o Container não inicia uma nova transação, executando o } \\
\text { pedido sem transação. }\end{array}$ \\
\hline Requires_New & $\begin{array}{l}\text { Se o cliente está num contexto transacional, a transação do cliente é } \\
\text { suspensa e uma nova transação é criada durante a execução desse } \\
\text { método. Se o cliente não possui nenhuma associação com a transação, } \\
\text { o Container cria uma nova transação durante a execução desse } \\
\text { método. }\end{array}$ \\
\hline Mandatory & $\begin{array}{l}\text { Se o cliente está num contexto transacional, o Container executa os } \\
\text { mesmos passos descritos no atributo Required. Se o cliente não está } \\
\text { num contexto transacional, o Container dispara a exceção } \\
\text { javax.transaction. TransactionRequiredException. }\end{array}$ \\
\hline Never & $\begin{array}{l}\text { Se o cliente está num contexto transacional, o Container dispara a } \\
\text { exceção javax.rmi RemoteException. Se o cliente não está } \\
\text { num contexto transacional, o Container executa os mesmos passos } \\
\text { descritos no atributo Not_Supported. }\end{array}$ \\
\hline
\end{tabular}

TABELA 5.2.1.1 - ATRIBUTOS DE UMA TRANSAÇÃo EJB 
Apesar de ser uma tecnologia relativamente nova, a arquitetura EJB tem sido bastante adotada pela maioria dos servidores de aplicação por ser uma tecnologia Java e, como tal, bastante difundida para o desenvolvimento de aplicações Web.

\subsubsection{Component Object Model - COM+}

COM+ é uma extensão do modelo de desenvolvimento de componentes COM (Component Object Model) fornecido pela Microsoft [Kir97, Cha98, Raj00]. Além deste modelo, COM+ incorpora o gerenciamento de transações através do MTS (Microsoft Transaction Server) e o controle de filas de mensagens através do MSMQ (Microsoft Message Queue). Os serviços oferecidos pelo COM+ incluem ente outros [Cha98]:

- Um registro de eventos que permite que componentes publiquem um evento e outros subscrevam para ser notificados quando o evento acontece. Por exemplo, quando uma transação de vendas é efetivada, ela pode disparar um evento que permitirá que outros programas sejam notificados deste evento para processamento futuro.

- Componentes enfileirados - um serviço através do qual os componentes do COM podem fazer chamadas para outro componente, quer esse componente esteja ou não disponível para recebê-lo. As solicitações serão registradas, enfileiradas e reproduzidas automaticamente mais tarde quando o componente ficar disponível.

- Balanceamento de carga dinâmico - difunde automaticamente os pedidos dos clientes através de múltiplos componentes COM equivalentes.

- Caching - COM+ possui um componente chamado IMDB (In-Memory Database), que é uma fonte de dados OLE DB, que age como cache para tabelas usadas frequientemente. Com ele é possível que tabelas de um Banco de Dados inteiro possam ser carregadas na memória sem a necessidade de acesso ao disco. Isto pode ser útil em aplicações de comércio eletrônico, por exemplo, para armazenar no cache o catálogo de produtos, que são informações que não mudam freqüentemente.

- Integração total MTS/COM - oferece melhorias nos serviços tais como gerenciamento de transações, segurança e interoperabilidade com outros ambientes transacionais. 
COM é uma arquitetura de software que permite que aplicações e sistemas sejam construídos a partir de componentes que podem ser fornecidos por diferentes desenvolvedores.

COM define um padrão binário para a interoperabilidade de componentes. Toda a comunicação entre componentes deve ocorrer por meio de interfaces. Uma interface COM é um "contrato" entre componentes de softwares que fornece um conjunto de operações relacionadas semanticamente (métodos), sendo assim uma maneira dos componentes disponibilizarem seus serviços.

Implementações de COM provêem os serviços básicos necessários para localizar, ativar e acessar componentes, independente da sua localização. Serviços adicionais podem ser construídos definindo interfaces e implementando componentes que exponham essas interfaces. Na verdade, um ponteiro para um componente é um ponteiro para uma das interfaces que o implementam.

COM define uma interface especial conhecida com IUnknown, que permite que seus componentes saibam quais as outras interfaces estão disponíveis. IUnknown possui três métodos:

- QueryInterface - permite aos clientes descobrir em tempo de execução quando uma interface é suportada por um componente; ao mesmo tempo é o mecanismo que o cliente usa para pegar um ponteiro para uma dada interface.

- AddRef e Release - são métodos para fazer a contagem de referências a objetos. O método AddRef é chamado quando outro componente está usando a interface; o método Release é chamado quando outro componente não precisa mais usar aquela interface.

COM+ traz algumas facilidades de implementação em relação ao COM. Em [Kir97] essas facilidades são mostradas em detalhes. Está fora do escopo desse trabalho descrever com detalhes essas tecnologias.

O servidor de transações empregado pelo COM+ é o Microsoft Transaction Server (MTS) e será descrito na seção 5.3.1.

\subsubsection{CORBA}

O Object Management Group (OMG) é um consórcio, criado em 1989, composto por mais de 800 empresas, dentre elas Netscape, IBM, Sun, Motorola, Nokia e Boeing. Seu objetivo inicial é a definição de padrões abertos que permitam a interoperabilidade entre 
componentes de software de forma independente de localização, plataforma, sistema operacional, linguagem de programação e protocolos de comunicação, em um ambiente distribuído.

A padronização do OMG é desenvolvida sobre um modelo de objetos e uma arquitetura geral de referência denominada OMA (Object Management Architecture). Nesta arquitetura cada componente de software é representado por um objeto que encapsula dados e processos (métodos) [MST97].

A arquitetura OMA, mostrada na figura a seguir, padroniza as interfaces de vários componentes, de maneira a facilitar o desenvolvimento de aplicações distribuídas que utilizam a tecnologia de objetos distribuídos. A OMA é composta por quatro tipos de componentes: um componente básico denominado Object Request Broker (ORB), serviços adicionais utilizados pelos desenvolvedores para gerência de objetos distribuídos (serviços CORBA), serviços que são compartilhados por diferentes aplicações (Facilidades CORBA) e as próprias aplicações distribuídas (objetos de aplicação).

Objetos de aplicação

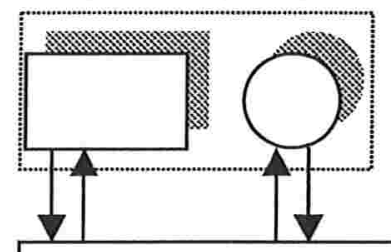

Object Request Broker

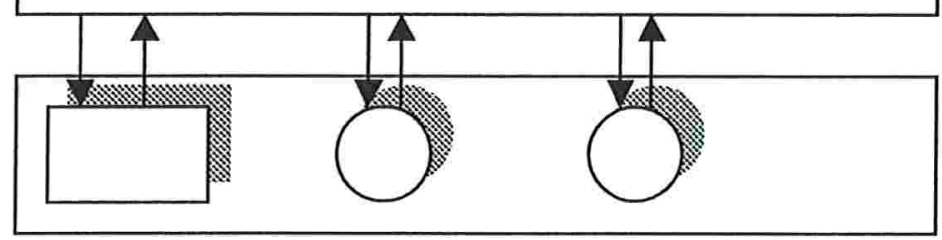

Serviços CORBA
Facilidades CORBA

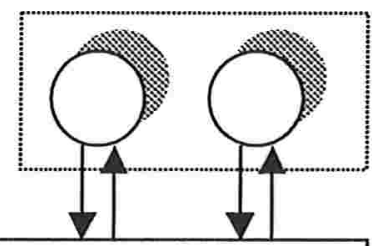

FigURA 5.2.1.3 - ARQUTTETURA OMA

O ORB provê uma infra-estrutura que possibilita aos objetos a comunicação independentemente da plataforma e técnicas específicas usadas para implementar os objetos [MST97]. O ORB fornece serviços de comunicação e localização de objetos distribuídos. A arquitetura resultante é conhecida como Common ORB Architecture - CORBA.

Os serviços utilizados para o desenvolvimento de objetos distribuídos são conhecidos como "serviços CORBA". Esses serviços - como serviços para criação de objetos, para o 
controle de acesso aos objetos e para a manutenção de dados sobre objetos movidos de um lugar para outro - dão consistência às aplicações e contribuem para aumentar a produtividade dos implementadores da aplicação. São alguns exemplos desses objetos: serviço de nomes, de ciclo de vida, de persistência, de transações, de eventos, de notificação dentre outros.

Um outro grupo de serviços - conhecidos como facilidades CORBA - definem um conjunto de serviços que podem ser utilizados por várias aplicações, mas que não são considerados fundamentais, como é o caso do serviço de objetos. Exemplos destes serviços são: a facilidade de Bancos de Dados, de impressão, de correio eletrônico.

Os objetos de aplicação, nada mais são que as aplicações criadas pelos usuários da arquitetura OMA. Estes objetos não estão sujeitos a padronização pelo OMG. Geralmente utilizam as funcionalidades do serviço de objetos e das facilidades comuns. Conceitualmente, uma aplicação aderente ao padrão OMA pode ser vista como um conjunto de classes de objetos e instâncias de objetos interligadas por uma rede de comunicação de dados que segue o padrão através de interfaces definidas em um modelo de objetos e na arquitetura CORBA.

A arquitetura CORBA pode ser vista como um modelo de comunicação baseado na tecnologia de orientação a objetos para ambientes de computação distribuída. Além da estrutura, o padrão CORBA define a interface que permite que aplicações façam pedidos aos objetos, de uma forma transparente e independente, indiferente à linguagem, sistema operacional ou considerações de localização.

As interfaces aos objetos são definidas usando a Linguagem de Definição de Interfaces (Interface Definition Language - IDL), chamada OMG IDL. A linguagem IDL é puramente declarativa, não providenciando deste modo, nenhum detalhe relativo à implementação dos objetos. As operações sobre um objeto são feitas através de uma referência ao mesmo. O uso da linguagem IDL está associado ao seu mapeamento específico para cada linguagem de programação. Este mapeamento está descrito no Modelo de Objetos CORBA que, atualmente, padroniza o mapeamento de IDL para as linguagens C, Java, C++, SmallTalk, ADA e COBOL.

A arquitetura CORBA utiliza um modelo orientado a objetos e define um módulo intermediário entre clientes e servidores, o ORB - Object Request Broker. Neste modelo, os clientes enviam requisições para o ORB solicitando a execução de serviços sem especificar o servidor (objeto) que deve responder às suas requisições. O ORB é quem provê todos os 
mecanismos necessários para localizar a implementação específica do objeto que atende à solicitação, responsável por preparar a implementação do objeto para receber o pedido e por comunicar o pedido ao objeto. Dessa forma, somente o ORB necessita conhecer a localização dos clientes e servidores na rede, tornando assim a localização do servidor transparente para o cliente.

O CORBA Component Model (CCM) é parte da especificação de CORBA 3.0. O CCM é um modelo de componente localizado no lado do servidor para o desenvolvimento de aplicações CORBA. A especificação do CCM foi modelada em muitos pontos baseada na do EJB. Entretanto, CCM utiliza CORBA como arquitetura para interoperabilidade, não estando associada a uma linguagem em particular [Nar01].

O CCM estende o modelo de objetos do CORBA definindo funcionalidades e serviços em um ambiente padronizado, que permitem que o desenvolvedor implemente, gerencie, configure e implante os componentes que integram os serviços CORBA geralmente utilizados. Estes serviços incluem transações, segurança, persistência e eventos.

A descrição detalhada dos objetos descritos acima está fora do escopo deste trabalho, mas pode ser encontrada em [Nar01].

Uma implementação dos serviços CORBA é o Object Transaction Service (OTS), que define interfaces para serviços de objetos que fornecem serviços transacionais. Ele será descrito na seção 5.3.3.

\subsection{Tecnologias de Processamento de Transação}

A seguir, será feito um relato das principais tecnologias e padrões de processamento de transações para fornecer uma visão geral de quais tecnologias podem ser usadas para implementar transações Web.

Os servidores de transações, que são softwares responsáveis pelo gerenciamento de transações Web, utilizam uma ou mais das tecnologias que serão abordadas. Assim, esperase contribuir mais com o estudo dessas tecnologias do que com o estudo de algum produto específico, pois tendo conhecimento dessas tecnologias, qualquer produto que precise vir a ser estudado será mais facilmente compreendido, pois ele estará baseado em uma dessas tecnologias. 


\subsubsection{X/Open}

O modelo de processamento de transação distribuída X/Open DTP (Distributed Transaction Processing) [VR99] é um modelo proposto pelo consórcio de vendedores Open Group para promover o paradigma de sistemas abertos e portabilidade das aplicações. Este modelo é um padrão entre quase todos os vendedores comerciais de Banco de Dados e de monitores de processamento de transação.

O X/Open DTP consiste de quatro componentes:

- Programas de Aplicação - é um programa cliente que implementa as operações das transações através das bibliotecas fornecidas por GR e GT.

- Gerenciadores de Recursos (GR) - responsáveis por gerenciar o acesso aos recursos compartilhados como Banco de Dados, arquivos, filas de mensagens, etc.

- Gerenciadores de Transação (GT) - responsáveis pelo controle e coordenação da execução das transações.

- Gerenciador de Recursos de Comunicação - responsável por facilitar a interoperabilidade entre diferentes GTs em diferentes domínios de processamento de transações.

Este modelo também especifica as seguintes interfaces:

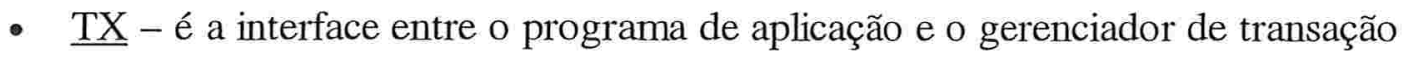
e é implementada pelo gerenciador de transação. Esta interface provê serviços de delimitação de transações, agrupamento de transações, status e operações de controle.

- $\underline{X A}$ - define a interação entre os gerenciadores de recursos e os de transações. Esta interface define dois conjuntos de funções: $x a_{-}$e $a x_{-}$. A funções do conjunto $x a_{\text {_ }}$ são implementadas pelos gerenciadores de recursos para ser usadas pelos gerenciadores de transação. Já as funções ax_ são implementadas pelos gerenciadores de transação para ser usadas pelos gerenciadores de recursos.

- $\underline{X A}+$ - esta interface define a interação entre uma gerenciador de transação e um gerenciador de recursos de comunicação. A informação de uma transação é comunicada ente diferentes domínios de GTs usando esta interface. 
- $\underline{\text { TxRPC }}$ - esta interface provê portabilidade para comunicação entre os programas de aplicação dentro de uma transação.

O modelo X/Open está bem estabelecido na indústria. Vários servidores de transação tais como TXSeries/Encina, da IBM [Ibm01b], Tuxedo, da BEASystems [Bea01], suportam a interface TX. Embora o MTS não suporte TX, ele pode interoperar com Banco de Dados compatíveis com XA.

\subsubsection{Java Transaction Service e Java Transaction API}

O Java Transaction Service (JTS) e Java Transaction API (JTA) formam a base da tecnologia Java para o processamento de transações, dentro da plataforma J2EE [Sun01c].

O JTS especifica a implementação de um gerenciador de transação que suporta a especificação JTA e implementa o mapeamento Java do OMG Object Transaction Service (OTS), que será visto na seção 5.3.4. JTS usa as interfaces CORBA ORB/TS e IIOP para a propagação do contexto das transações entre gerenciadores de transação JTS [Al199].

JTA permite que aplicações acessem gerenciadores de transações de forma independente da implementação, pois define um conjunto de interfaces Java entre o gerenciador de transação e as partes envolvidas num sistema de transações distribuídas. Essas partes são a aplicação transacional, o servidor J2EE e o gerenciador que controla o acesso aos recursos compartilhados afetados pela transação.

A arquitetura JTS pode ser vista na figura abaixo.

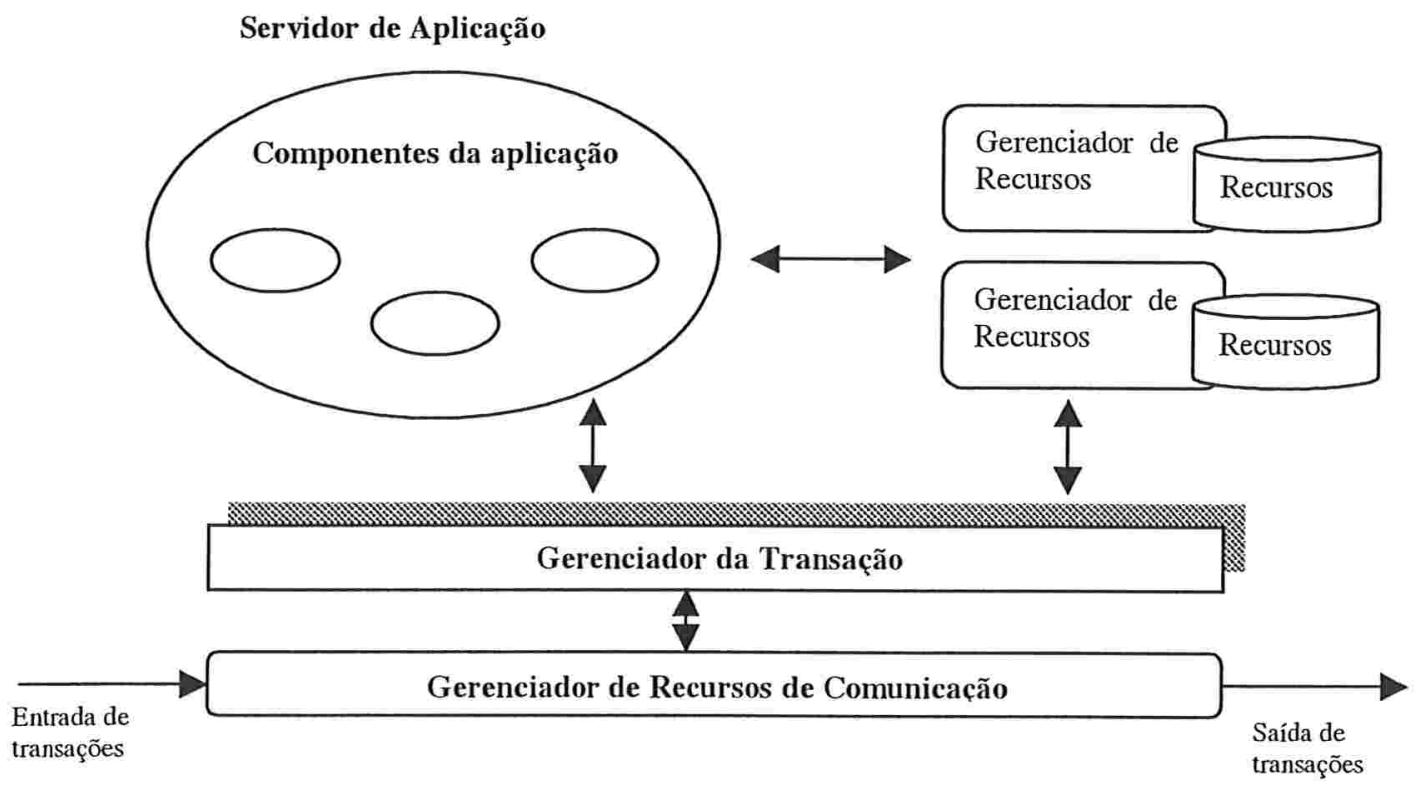

Figura 5.3.2 - ARQUitetura JTS 
A arquitetura JTS consiste dos seguintes componentes:

- Gerenciador de Transação - é o componente central desta arquitetura e é provido por uma implementação do JTS. Ele provê interfaces para criar transações, permite obter e devolver recursos, implementa o protocolo de sincronização, inicia e comanda o protocolo de recuperação e o protocolo de confirmação bifásica (2PC) com os gerenciadores de recursos.

- Servidor de Aplicação - um dos aspectos chave do JTS é que ele permite que um servidor de aplicação seja implantado em cima do serviço de transação. Os desenvolvedores da aplicação podem desenvolver e implantar componentes da aplicação nos servidores de aplicação para iniciar e gerenciar transações. Dessa forma, os servidores de aplicação não precisam se preocupar com a semântica transacional de suas aplicações.

- Componentes da aplicação - esses são os clientes para os recursos transacionais e implementam a lógica de negócios das transações. Eles são implantados nos servidores de transação. Dependendo da arquitetura do servidor de aplicação, esses componentes podem direta ou indiretamente criar transações e operar sobre os recursos transacionais. Por exemplo, um servidor EJB permite a delimitação declarativa de uma transação, o que significa que os componentes EJBs não precisam implementar transações explicitamente. No entanto, uma implementação Java de um CORBA OTS, requer que um objeto CORBA seja explicitamente declarado.

- Gerenciador de Recurso - um gerenciador de recurso é um componente compatível com o padrão X/Open XA que gerencia um sistema de armazenamento estável e persistente, e participa dos protocolos de recuperação e de confirmação bifásica (2PC) juntamente com o gerenciador de transação. Ele também define interfaces para o servidor de aplicação e para os componentes da aplicação operarem sobre os dados gerenciados por ele.

- Gerenciador de Recursos de Comunicação - permite que o gerenciador de transação participe de transações iniciadas por outros gerenciadores de transação.

Como vimos na seção 5.1.4, usa-se JTS e JTA juntamente com servlets e páginas JSP para implementar transações. 


\subsubsection{Microsoft Transaction Server}

O Microsoft Transaction Server (MTS) é um servidor de transação baseado no modelo de componentes da Microsoft, o Component Object Model (COM). O modelo de programação do MTS provê interfaces para construir componentes COM transacionais, enquanto o ambiente de execução provê recursos para implantar e gerenciar esses componentes e transações. Usando o MTS, o trabalho realizado por múltiplos componentes COM podem ser compostos numa única transação [All99].

Diferente de outras tecnologias, como CORBA, MTS é um produto e não está baseado em especificações abertas. Entre as suas principais características pode-se destacar:

- Transações automáticas

- Segurança configurável

- Pooling de conexões com Banco de Dados

- Suporte a múltiplos Banco de Dados e gerenciadores de recursos

- Gerenciamento do estado dos componentes

- Integração com transações mainframe

A figura 5.3.3 mostra a arquitetura do MTS.

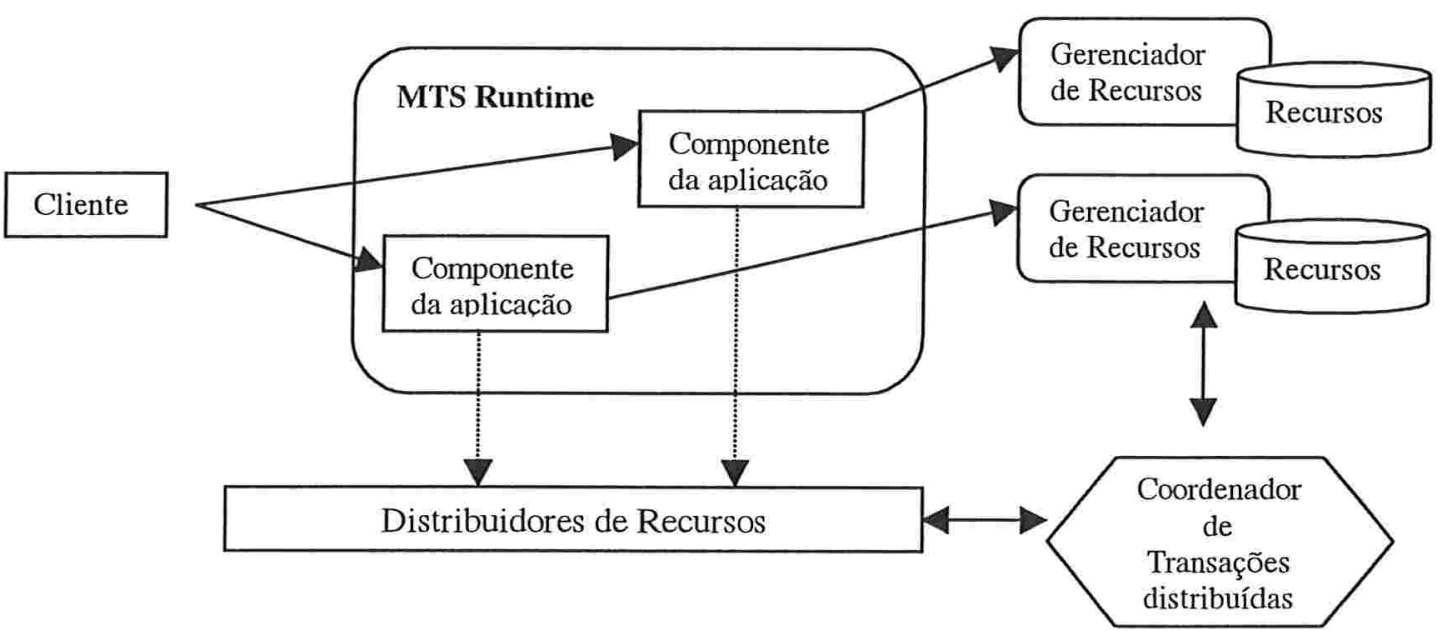

FigURA 5.3.3 - ARQUITETURA MTS

O ambiente MTS consiste dos seguintes módulos:

- MTS Run-time - é o ambiente onde as instâncias dos componentes MTS executam e são gerenciadas. O MTS run-time dispõe de recursos para a implantação e o gerenciamento dos componentes MTS. Ele possui as seguintes características: 
○ Gerenciamento de transações distribuídas

- Gerenciamento automático de processos e threads

- Gerenciamento de objetos (criação, pooling, reciclagem)

- Serviço de segurança distribuído para controlar a criação e o uso de objetos

- MTS Explorer - é uma interface gráfica dirigida para implantar e gerenciar componentes MTS no MTS Run-time. Também pode ser usado para monitorar transações com o Coordenador de Transações Distribuídas.

- Coordenador de Transações Distribuídas (DTC) - é o gerenciador de transações do MTS. Coordena transações que envolvem múltiplos Banco de Dados. O trabalho pode ser confirmado como uma transação atômica mesmo que envolva múltiplos gerenciadores de recursos em máquinas separadas.

- $\quad$ MTS API - fornece interfaces e classes para a construção de componentes transacionais. Está presente nas linguagens de programação da Microsoft como Visual Basic e Visual C++.

- Distribuidores de Recursos - gerencia dados compartilhados não-duráveis em benefício das aplicações MTS. Existem dois distribuidores de recursos:

- Distribuidor de Recursos ODBC - é essencialmente um administrador de driver ODBC com as seguintes funcionalidades adicionais:

- Gerencia pools de conexões para banco de dados com suporte a ODBC, incluindo correção e reutilização de conexões.

- Insere e retira conexões com o Banco de Dados no contexto de objetos MTS.

o Gerenciador de Propriedade Compartilhada - gerencia propriedades específicas de processos de grandes aplicações (pares nome/valor) e provê acesso sincronizado a estes dados.

- Gerenciadores de Recursos - é um Banco de Dados, um sistema de arquivos ou qualquer outro sistema que provê acesso a recursos compartilhados. Para um gerenciador de recursos participar de transações MTS, ele deve suportar um dos seguintes protocolos: 
- Transações $O L E$ - este é o protocolo de confirmação bifásica (2PC) baseado em componentes COM usado pelos administradores de recursos para participar de transações coordenadas pelo DTC.

- Protocolo X/Open DTP XA - com este protocolo o MTS solicita um mapeamento entre Transações $O L E$ para XA.

Um objeto MTS é uma instância de um componente MTS. Para cada objeto MTS, o MTS cria e mantém um objeto contexto (ObjectContext) que provê a execução do contexto para um objeto MTS. O objeto contexto também mantém informação sobre o contexto da transação. Distribuidores de recursos e o DTC podem acessar as informações de contexto das transações para delimita-las, para solicitar ou liberar recursos, etc.

MTS permite que a delimitação das transações seja feita tanto de forma programática quanto declarativa. A demarcação declarativa é obrigatória para todos os componentes implantados no MTS. Além disso, clientes MTS podem iniciar e terminar transações através da programação.

$\mathrm{Na}$ demarcação declarativa, dependendo das propriedades de transações dos componentes, o MTS automaticamente inicia uma transação. As possíveis propriedades de transações são:

\begin{tabular}{|l|l|}
\hline \multicolumn{1}{|c|}{ PROPRIEDADES } & \multicolumn{1}{|c|}{ DESCRIÇÃO } \\
\hline Requires New & $\begin{array}{l}\text { instâncias dos componentes devem executar dentro de suas próprias } \\
\text { transações, independente de que o objeto chamador tenha iniciado a } \\
\text { transação. }\end{array}$ \\
\hline Requires & $\begin{array}{l}\text { instâncias dos componentes sempre executam dentro do contexto da } \\
\text { transação. É esperado que o objeto invocado esteja sendo executado no } \\
\text { contexto da transação. }\end{array}$ \\
\hline Supports & $\begin{array}{l}\text { instâncias dos componentes podem executar dentro do escopo da } \\
\text { transação do objeto chamador, se existir alguma. }\end{array}$ \\
\hline $\begin{array}{l}\text { Does Not } \\
\text { Support }\end{array}$ & $\begin{array}{l}\text { instâncias dos componentes não executam dentro do escopo de nenhuma } \\
\text { transação. O MTS não associa o trabalho feito por tais objetos a nenhuma } \\
\text { transação. }\end{array}$ \\
\hline
\end{tabular}

TABELA 5.3.3 - PROPRIEDADES DE UMA TRANSAÇÃO EM MTS

Na demarcação programática, os clientes MTS podem delimitar transações explicitamente através de programação usando o objeto TransactionContext. Um cliente pode iniciar uma transação criando uma instância do objeto Transactioncontext e finaliza-la chamando os métodos Commit ou Abort desse objeto. Todos os objetos MTS criados dentro desses limites irão executar sobre o mesmo contexto transacional, exceto quando o componente é configurado para solicitar uma nova 
transação ou não suporta transações. MTS implicitamente mantém a associação entre o objeto Transactioncontext e a transação.

O MTS implementa apenas o modelo de transações planas. Segundo [Mic01c], para qualquer modelo de transação ser implementado é preciso que, além do servidor de transação, o SGBD também possua suporte a este modelo. Como a maioria dos SGBDs implementa apenas o modelo de transações planas, o MTS possui suporte apenas para este modelo.

O MTS trabalha apenas com o servidor Web da Microsoft Internet Information Server (IIS). A integração do MTS com o IIS permite que os desenvolvedores configurem páginas Web para executar dentro de uma transação MTS [Mic01b]. O código ASP a seguir mostra como isso pode ser feito:

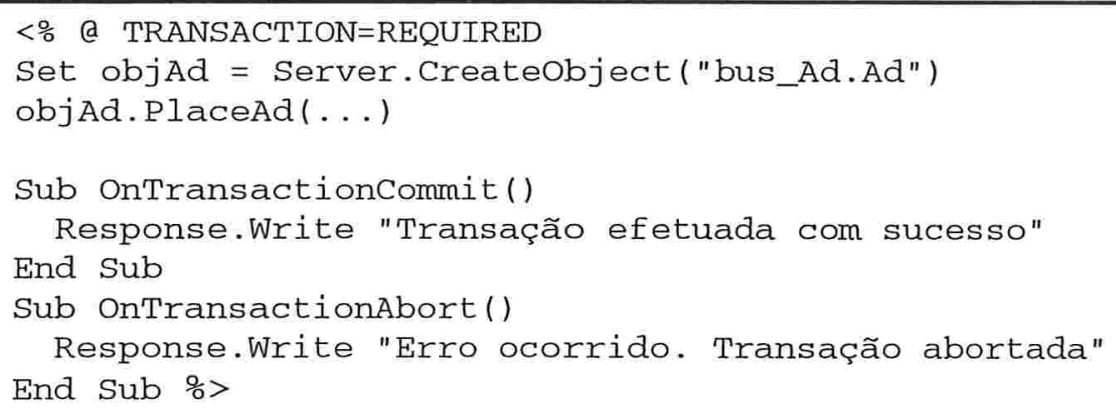

EXEMPLO 5.3.3 - EXEMPLO DE UMA TRANSAÇÃO MTS NUM ARQUIVO ASP

A tag <\%@TRANSACTION=REQUIRED $\%>$ num arquivo ASP permite que o MTS crie uma transação para a página. Todos os componentes invocados dentro desta página podem executar dentro de uma única transação MTS, com ações de recuperação e desfazimento (rollback).

O servidor IIS inclui eventos transacionais onde os desenvolvedores podem usar resultados de transações. O exemplo mostrado acima exibe diferentes textos baseados no resultado da transação.

Como vimos anteriormente na seção que fala de ASP, essa solução possui um bom suporte a transações.

\subsubsection{OMG Object Transaction Service - OTS}

O Object Transaction Service (OTS) é um serviço de processamento de transações distribuídas especificado pelo OMG. Esta especificação estende o modelo CORBA e define 
um conjunto de interfaces para executar o processamento de transações entre múltiplos objetos CORBA.

O modelo OTS é baseado no padrão X/Open Distributed Transaction Processing (DTP). O OTS substitui as interfaces funcionais XA e TX do X/Open DTP pelas interfaces CORBA IDL. Ele pode ser visto como uma implementação orientada a objetos, usando tecnologia CORBA e o modelo de referência X/Open [VR99].

Além dos aspectos gerais de processamento de transações, o OTS também suporta transações aninhadas, suspensão e reinício de transações e propagação da transação controlada pelo programador [Gor00].

A figura 5.3.4 ilustra onde o OTS se ajusta na arquitetura CORBA.

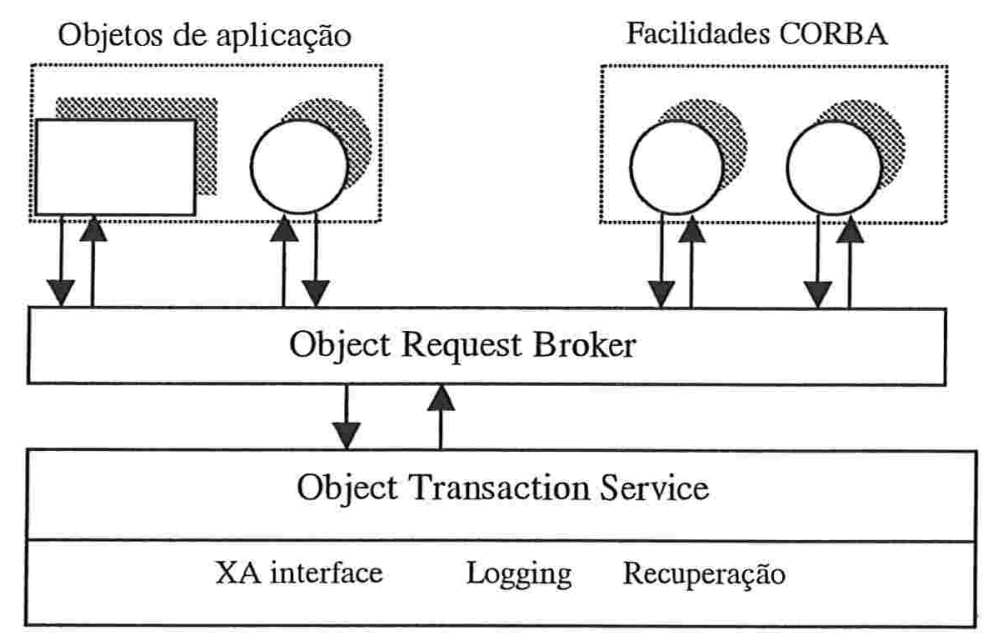

FigURA 5.3.4 - ARQUITETURA CORBA OTS

Como um serviço CORBA, ele aumenta a funcionalidade do ORB provendo gerenciamento de transação para objetos distribuídos. Objetos podem iniciar uma transação e então executar uma ou mais operações em objetos remotos dentro do contexto daquela transação. Quando o trabalho termina, o objeto pode tentar confirmar a transação. O OTS então usa o protocolo de confirmação bifásica (2PC) para terminar a transação.

A arquitetura OTS consiste dos seguintes componentes [Al199]:

- Transação cliente - é um programa ou um objeto que executa operações em objetos transacionais.

- Objeto Transacional - é um objeto CORBA que encapsula ou se refere a dados persistentes e cujo comportamento depende de quais operações são executadas durante uma transação. 
- Objeto Recuperável - é um objeto transacional que mantém diretamente dados persistentes e participa em protocolos de transações.

- Servidor Transacional - é uma coleção de um ou mais objetos transacionais.

- Servidor Recuperável - é uma coleção de objetos, dos quais pelo menos um é recuperável.

- Objeto Recurso - é um objeto no serviço transacional que é registrado para participação no protocolo de recuperação e no protocolo de confirmação bifásica (2PC).

Os seguintes produtos oferecem implementações de OTS entre outros: OrbixOTS [Ion01], OTSARjuna [LS01] e TPBroker [Hit01].

\subsection{Considerações Finais}

Como foi visto durante todo esse capítulo, existem soluções desenvolvidas para aplicações Web (CGI, ASP, etc) e soluções que são padrões comerciais para todos os tipos de aplicações (X/Open, OTS). Pode-se concluir, portanto, que para implementar transações Web há uma grande variedade de tecnologias disponíveis, cabendo à equipe de desenvolvimento escolher a que melhor se enquadre no seu domínio de aplicação, pois há soluções para sistemas desde os mais simples até os mais complexos.

No próximo capítulo, tem-se as conclusões deste estudo e propostas de trabalhos futuros. 


\section{Capítullo 6}

\section{Conclusão e Trabalhos Futuros}

O ambiente de integração Web Banco de Dados é uma área de pesquisa que está em pleno desenvolvimento, onde a cada dia surgem novas tecnologias visando simplificar esta integração.

Apesar deste amplo dinamismo, observou-se que durante anos as pesquisas nesta área restrigiram-se basicamente ao problema de como mapear operações "sem estado" da Web para as operações contínuas dos SGBDs. Entretanto, a medida que foram surgindo soluções cada vez mais eficientes, observou-se que o simples mapeamento não garantiria por completo a integração. Era necessário que fossem solucionados outros problemas, como por exemplo, os relacionados com os aspectos transacionais.

Os problemas transacionais consistem, basicamente, em como suportar as propriedades ACID das transações tradicionais sobre os SGBDs, num ambiente hipertexto Web, baseado em operações de longa duração.

É justamente neste contexto que se apresenta a contribuição desta dissertação, através da análise destes problemas, mostrando um estudo sobre possíveis modelos de transações para o ambiente de integração, em substituição ao modelo convencional de transações planas que se mostrou inadequado por não suportar transações de longa duração e a capacidade de desfazer parte da transação.

Além disso, este estudo apresenta um compêndio das soluções existentes para resolver estes problemas e implementar transações de Banco de Dados no ambiente Web. Além de soluções mais simples como CGI, ASP e Servlets, mostrou-se também um estudo sobre os servidores de aplicação, que tem se tornado de suma importância devido à crescente complexidade dos sistemas desenvolvidos para o ambiente Web.

Como a tecnologia principal utilizada pelos servidores de transações são os modelos de componentes, então foi feita uma descrição dos três modelos principais: CORBA, COM+ e Enterprise JavaBeans, enfocando como tais tecnologias suportam e implementam as transações sobre Banco de Dados. 
Por fim, além dos modelos de componentes, foi feito um estudo sobre as principais tecnologias de processamento de transações, já que as soluções existentes para implementação de transações Web passam necessariamente por uma das tecnologias abordadas.

Uma informação em especial foi investigada: qual o modelo de transações utilizado por cada tecnologia estudada. Conclui-se que a grande maioria utiliza apenas o modelo de transações planas, à exceção de CORBA/OTS, que suporta opcionalmente o modelo de transações aninhadas. Constatou-se que isso acontece devido ao fato que a grande maioria dos SGBDs também não suporta modelos estendidos de transações. Isso inviabiliza o desenvolvimento de aplicações utilizando modelos de transações diferentes do modelo convencional de transações planas.

Enfim, seria desejável que o modelo de transações planas fosse estendido a modelos mais complexos de transações, como vimos durante o decorrer do trabalho. Esta extensão facilitaria muito o desenvolvimento de novos paradigmas de aplicações, como por exemplo, os sistemas voltados para a Internet que possuem um grande potencial de crescimento.

Como extensões deste trabalho, propõe-se:

- Definição formal de um modelo de transações para o ambiente de integração tendo como base um dos modelos apresentados neste estudo (transações aninhadas e transações encadeadas) para suportar transações de longa duração.

- Fazer um estudo detalhado de como cada uma das tecnologias descritas implementam realmente transações no ambiente Web Banco de Dados, já que quase todas elas só trabalham com o modelo de transações planas.

- Fazer um estudo analisando o grau de dificuldade em se implementar transações Web usando diferentes modelos conceituais de transação.

- Fazer um estudo sobre transações Web mais complexas, como por exemplo, as que envolvem negócios em empresas, o business-to-business. Como são transações mais elaboradas, devem ter soluções mais específicas para sua implementação.

- Fazer um estudo sobre transações Web distribuídas, unindo as soluções clássicas de processamento de transações distribuídas, como por exemplo o 
protocolo X/Open, com as soluções desenvolvidas para a Web, como o protocolo TIP, avaliando as vantagens e desvantagens.

Por fim, espera-se ter atingido os objetivos deste trabalho de reunir os principais problemas e soluções sobre transações Web. 


\section{Referências Bibliográficas}

[Al199] S. Allamaraju. "Nuts and Bolts of Transaction Processing”, 1999.

http://www.subrahmanyam.com/articles/transactions/NutsAndBoltsOfTP.html

[AMJ95] A. Silberschatz, M. Stonebraker, J.Ullman. "Database Research: Achievements and Opportunities Into the $21^{\text {st }}$ Century". Report of NFS Workshop on the Future of Database System Research, 1995.

http://citeseer.nj.nec.com/silberschatz96database.html

[Bea01] BEA Systems. "BEA Tuxedo", 2001.

http://www.beasys.com/products/tuxedo/index.shtml

[Ben99a] S. Benfield. "The Application Server Marketplace". Web Techniques, 1999. http://webreview.com/wr/pub/1999/02/26/appservers/index.html

[Ben99b] S. Benfield. "What Do Application Servers Really Do?". Web Techniques, 1999. http://webreview.com/wr/pub/1999/02/26/appservers/index2.html

[Ber96] P. A. Bernstein. "Middleware: A model for distributed system services". Communications of the ACM, Vol. 39(2), pp. 86-98, 1996.

http://www.cs.colorado.edu/ carzanig/edu/csci7818/repository/p86-bernstein.pdf

[BHLMRR00] B.Bennett, B. Hahm, A. Leff, T. Mikalsen, K. Rasmus, J. Rayfield, I. Rouvellou. "A Distributed Object Oriented Framework to Offer Transactional Support for Long Running Business Process”. Proceedings Middleware 2000, 2000.

http://www.research.ibm.com/AEM/documents/lruow_mw2000.pdf

[Bi198] D. Billard. "Transactional Services for the Internet". Proceedings of WebDb'98, University of Geneva, 1998.

http://www.dia.uniroma3.it/webdb98/papers/23.ps

[BHG87] P. A. Bernstein, V. Hadzilacos, N. Goodman. "Concurrency Control and Recovery in Database Systems". Addison-Wesley Publishing Company, 1987.

[Bro00] A. Brown. "Large-Scale, Component-Based Development". First Edition. PrenticeHall PTR, 2000.

[BS01] S.S. Bakken, E. Schmid. "PHP Manual Online", 2001.

http://www.php.net/manual

[Cha98] D. Chappell. "COM+ Redux", 1998.

http://www.chappellassoc.com/artcom.htm 
[Cop99] R. Copeland. "Web App Servers- This New Class Of Middleware Is Sppending Application Development And Becoming A Strategic Platform for Web-To-Legacy Integration". InformationWeek, 1999.

http://webreview.com/wr/pub/1999/02/26/appservers/index.html

[CP85] S. Ceri, G. Pelagatti. "Distributed Databases Principles and Systems". International Edition. McGraw-Hill Book Company, 1985.

[CY01] D. Connor, D. Young. "Professional EJB”. Capítulo 9, páginas 363-416. Wrox Press, 2001. http://developer.java. sun.com/developer/Books/ProEJB/ch9.pdf

[DIMG95] A. Díaz, T.Isakowitz, V.Maiorana, G. Gilabert. "RMC: a tool to design www applications". Proceedings Fourth International World Wide Web Conference, 1995.

http://www.w3.org/Conferences/WWW4/Papers/187/

[Dua96] N. N. Duan. "Distributed Database Access in a Corporate Environment Using Java". Proceedings 5th International World Wide Web Conference, 1996.

http://www5conf.inria.fr/fich_html/papers/P23/Overview.html

[EB97] S. Ehikioya, K. Barker. "A Formal Specification Strategy for Electronic Commerce". Proceedings International Database Engineering and Application Symposium (IDEAS97). IEEE Computer Society, 1997.

http://computer.org/proceedings/ideas/8114/8114toc.htm

[EKR97] G. Ehmayer, G. Kappel, S.Reich. "Connecting Databases to the Web: a Taxonomy of Gateways". Proceedings 8th International Conference on Database and Expert Systems Applications, 1997.

ftp://ftp.ifs.uni-linz.ac.at/pub/publications/1997/0597.ps.gz

[EN94] R. Elmasri, S. B. Navathe. "Fundamentals of Database Systems". Second Edition. The Benjamin/Cummings Publishing Company, Inc, 1994.

[EN00] R. Elmasri, S. B. Navathe. "Fundamentals of Database Systems". Third Edition. The Benjamin/Cummings Publishing Company, Inc, 2000.

[Fei99] J. Feiler. "Database-Driven Web Sites". First Edition. Morgan Kaufmann Publishers. Inc, 1999.

[Fei00] J. Feiler. "Application Servers - Powering the Web-Based Enterprise". First Edition. Morgan Kaufmann Publishers. Inc, 2000.

[FF00] J. E. Ferreira, M. Finger. "Controle de Concorrência e Distribuição de Dados: a teoria clássica, suas limitações e extensões modernas". 12a Escola de Computação, IMEUSP, 2000.

[FLM98] D. Florescu, A. Levy, A. Mendelzon. "Database Techniques for the World Wide Web: A Survey". ACM SIGMOD, 1998.

ftp://ftp.db.toronto.edu/pub/papers/sigrec.ps.gz 
[Fra95] M. Frank. "Databases and the Internet". DBMS OnLine Magazine, 1995. http://www.dbmsmag.com/f19512.html

[Fra98] P. Fraternali. "Web Development Tools: A Survey". Proceedings 7th International World Wide Web Conference, 1998.

http://www7.scu.edu.au/programme/posters/1835/com1835.htm

[Gor00] I. Gorton. "Enterprise Transaction Processing Systems". First Edition. AddisonWesley, 2000.

[GR93] J. Gray, A. Reuter. "Transaction Processing: Concepts and Techniques". Morgan Kaufmann Publishers, Inc, 1993

[Hall00] M . Hall. "Core Servlets and JavaServer Pages (JSP)". Enterprise Edition Series, 2000.

http://www.coreservlets.com

[HG00] M. Hapner, D. Green. "An Overview of Java ${ }^{\mathrm{TM}}$ Componentes for Middle-Tier Servers". Java ${ }^{\mathrm{TM}}$ Platform Enterprise Edition, 2000.

http://java.sun.com/j2ee/articles/midtier.html

[Hit01] Hitachi Software. "Hitachi TPBroker”. 2001.

http://www.hitachisoftware.com/products/Brochures/tpb_broch.htm

[HLRSW01] I. Houston, M.C. Little, I. Robinson, S.K. Shrivastava, S.M. Wheater. "The CORBA Activity Service Framework for Supporting Extended Transactions". Proceedings IFIP/ACM International Conference on Distributed Systems Platforms (Middleware 2001), 2001.

http://www.arjuna.com/Publications/papers/03.pdf

[HM96] S. P. Hadjefthymiades e D. I. Martakos. "A Generic Framework for the Deployment of Structured Databases on the World Wide Web". Proceedings 5th International World Wide Web Conference, 1996.

http://www5conf.inria.fr/fich_html/papers/P22/Overview.html

[HMV96] M. Hasan, A. Mendelzon, D. Vista. "Applying Database Visualization to the World Wide Web". ACM SIGMOD, 1996.

ftp://ftp.db.toronto.edu/pub/papers/sigmodrecord.ps.gz

[HM97] S. P. Hadjefthymiades e D. I. Martakos. "Improving the performance of CGI compliant database gateways". Proceedings 6th International WWW Conference, 1997. http://www.scope.gmd.de/info/www6/technical/paper044/paper44.html

[Ibm01a] IBM. "IBM WebSphere Application Server", 2001.

http://www.ibm.com/software/appserv/

[Ibm01b] IBM. "IBM TXSeries", 2001.

http://www-4.ibm.com/software/ts/txseries/ 
[Ion01] Iona Systems. "OrbixOTS". 2001.

http://www.iona.com/docs/manuals/orbix/33/html/orbixots33_pguide/intro.html

[Kim96] Pyung-Chul Kim. "A Taxonomy on the Architecture of Database Gateways for the Web". Technical Report, Database Laboratory Dept. of Information Communications Engineering, Chungnam National University, 1996.

http://grigg.chungnam.ac.kr/projects/UniWeb/documents/taxonomy/text.html

[Kir97] M. Kirtland. "Object-Oriented Software Development Made Simple with COM+ Runtime Services". Microsoft Systems Journal, 1997.

http://www.microsoft.com/msj/1197/complustop.htm

[Lea00] R. Leander. "Building Application Servers". First Edition. Cambridge University Press, 2000.

[LEK98] J. Lyon, K. Evans e J. Klein. "Transaction Internet Protocol Version 3.0". The Internet Engineering Task Force, 1998.

http://www.ietf.org/rfc/rfc2371.txt

[Lim97] I. N. Lima. "O Ambiente Web Banco de Dados: Funcionalidades e Arquiteturas de Integração". Dissertação de Mestrado, Departamento de Informática da PUC-Rio, 1997.

[LS98] M.C. Little, S.K. Shrivastava. "Java Transactions for the Internet". $4^{\text {th }}$ Conference on Object-Oriented Technologies and Systems, 1998.

http://arjuna.ncl.ac.uk/group/papers/p073.pdf

[LS01] M. Little, S.K. Shrivastava. "OTSArjuna”, 2001.

http://arjuna.ncl.ac.uk/OTSArjuna/index.html

[LSCI97] M. C. Little, S. K. Shivastava, S. J. Caughey, e D. B. Ingham. "Constructing Reliable Web Applications Using Atomic Actions". Sixth Intl. World Wide Web Conference, 1997.

http://www.scope.gmd.de/info/www6/technical/paper012/paper12.html

[Mac01] Macromedia. "ColdFusion 5.0", 2001.

http://www.macromedia.com/software/coldfusion

[Mar00] D. Marsh. "Global Transactions - X/Open XA - Resource Managers". 2000.

http://www. aurorainfo.com/wp3/index.htm

[MGN97] M. Mock, M. Gergeleit, E. Nett. "Cooperative Concurrency Control on the Web". Proceedings FTDCS, 1997.

http://citeseer.nj.nec.com/mock97cooperative.html

[Mic01a] Microsoft Library. "An Introduction to Microsoft Transaction Server", 2001.

http://msdn.microsoft.com/library/en-us/dnmts/html/msdn_mtsintro.asp 
[Mic01b] Microsoft Library. "Microsoft Transaction Server and Internet Information Server: Technology for the Web", 2001.

http://msdn.microsoft.com/library/en-us/dnmts/html/msdn_mtsiis.asp

[Mic01c] Microsoft Library. "Microsoft Transaction Server FAQ: Databases and Transactions", 2001.

http://msdn.microsoft.com/library/en-us/dnmts/html/msdn_transfaq.asp

[Mic01d] Microsoft. "Microsoft .Net Enterprise Servers", 2001.

http://www.microsoft.com/servers/evaluation/overview/net.asp

[MMR00] W. Meira Jr, C. D. Murta, R. S. F. Resende. "Comércio Eletrônico na WWW". $12^{\mathrm{a}}$ Escola de Computação, IME-USP, 2000.

[MRSTCGV00] T.Mikalsen, I. Rouvellou, S. Sutton, S. Tai, M. Chessell, C. Griffin, D. Vines. "Transactional Business Process Servers: Definition and Requirements". Proceedings ACM Conference on Object-Oriented Programming, Systems, Languages, and Applications 2000.

http://www.research.ibm.com/AEM/documents/tbps_oopsla2000.pdf

[MST97] R. Melo, S. Silva, A. Tanaka. "Banco de Dados em Aplicações Cliente Servidor". Editora Infobook, 1997.

[Nar01] A. R. Nardi. "Visão Geral do CORBA Component Model". Seminário do Projeto SIDAM, 2001.

http://www.ime.usp.br/ kon/Sidam/ResumoSeminarios/NardiCCM.ppt

[Ne195] M. Nelson. "Accessing Databases Through the World Wide Web: Issues and Current Practice”, 1995.

[Net99] Introduction to NetDynamics, 1999.

http://www.netdynamics.com

[NCSA97] The National Center for Supercomputing Applications. "The CGI Specification - version 1.1", 1997.

http://hoohoo.ncsa.uiuc.edu/cgi/interface.html

[NS96] T. Nguyen, V. Srinivasan. "Acessing Relational Databases from the World Wide Web". ACM SIGMOD, 1996.

http://www.informatik.uni-trier.de/ ley/db/conf/sigmod/NguyenS96.html

[Ora00] Oracle Internet Application Server 8i (Oracle iAS) Technical White Paper, 2000.

[PA01] A. Pharoach, F.Arni. "Creating Commercial Components (EJB ${ }^{\mathrm{TM}} 2.0$ )". Technical White Paper, 2001.

http://www.componentsource.com

[Pay01] C. Payne. "ASP Transactions", 2001.

http://www.asp101.com/articles/chris/asptransactions/default.asp 
[Per95] L. Perrochon. "W3 'Middleware': Notions and Concepts". Proceedings 4th International Conference on the World Wide Web, 1995.

http://www.perrochon.com/archiv/pubs/95www4/95www4.html

[Pro00] M. Prochazka. "Extending Transactions in Enterprise JavaBeans". Technical Report 3/2000, Department of Software Engineering, Charles University, 2000. http://nenya.ms.mff.cuni.cz/ prochazk/papers/trejb032000.pdf

[Raj00] G. S. Raj. "COM+ Complete Tutorial”, 2000.

http://gsraj.tripod.com/com/basic_com/index.html

[Ric98] M. Ricciuti. "Application Server Eludes Definition". CNET News.com, 1998. http://news.cnet.com/news/0-1003-200-332521.html

[Ser01] Sun Microsystems. "Java ${ }^{\mathrm{TM}}$ Servlet Technology", 2001.

http://java.sun.com/products/servlet/whitepaper.html.

[Sil00] SilverStream Application Server 3.5, Deliver Web Application for Your Enterprise, 2000 .

http://www.silverstream.com/appserver

[Str96] R. E. Streit. "Acesso a Banco de Dados Relacionais via WWW: Estudo de alternativas e proposta de ferramenta". Dissertação de Mestrado, Instituto de Informática da Universidade Federal do Rio Grande do Sul, 1996.

[Sun01] Sun Microsystem. "Java ${ }^{\mathrm{TM}}$ Servlet Tecnology. The Power Behind the Server", 2001.

http://java.sun.com/produtcs/servlet

[Sun01b] Sun Microsystem. "Java Server Pages ${ }^{\mathrm{TM}}$. Dynamically Generated Web Content.", 2001.

http://java.sun.com/produtcs/jsp

[Sun01c] Sun Microsystem. "J2EE Blue Print", 2001.

http://java.sun.com/j2ee/blueprints

[Sun01d] Sun Microsystem. "Enterprise JavaBeans ${ }^{\mathrm{TM}}$ Specification Version 2.0", 2001. http://java.sun.com/products/ejb

[VR99] A. Vogel, M. Rangarao. "Programming with Enterprise JavaBeansTM, JTS and OTS". First Edition. John Wiley \& Sons, Inc, 1999.

[WK94] S. Williams, C. Kindel. "The Component Object Model: A Technical Overview", 1994.

http://msdn.microsoft.com/library/default.asp

[W3C01] W3C Consortium. "W3C - Home Page", 2001.

http://www.w3.org/WWW 
[YKD96] J. J. Yang, G. E. Kaiser, S.E. Dossik. "An External Transaction Service for WWW". Proceedings 5th International. World Wide Web Conference, 1996.

http://www5conf.inria.fr/fich_html/papers/P31/Overview.html 